\title{
Mechanisms of posttetanic potentiation and its possible role in maturation of the calyx of Held synapse
}

\author{
PhD Thesis \\ in partial fulfilment of the requirements \\ for the degree "Doctor of Philosophy (PhD)" \\ in the Neuroscience Program \\ at the Georg-August University Göttingen, \\ Faculty of Biology
}

\author{
submitted by \\ Natalya Korogod \\ born in Dniepropetrovsk, Ukraine
}



Herein I declare

that my $\mathrm{PhD}$ thesis "Mechanisms of posttetanic potentiation and its possible role in maturation of the calyx of Held synapse" has been written independently and with no other sources and aids than quoted

Göttingen, 21.03.2006

Signature 



\section{List of Contents}

LIST OF CONTENTS

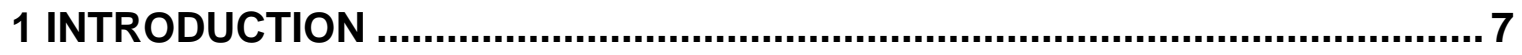

1.1 Synaptic transmission in chemical synapses ..........................................................................................

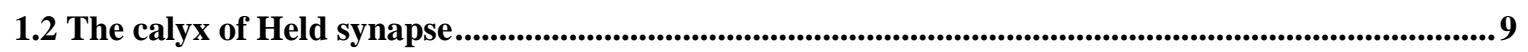

1.3 The development of the auditory brainstem network .................................................................................10

1.4 The role of synaptic plasticity in development of neuronal connections..............................................12

1.5 Synaptic plasticity at the calyx of Held synapse........................................................................................13

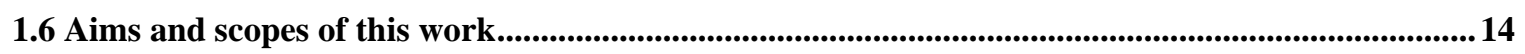

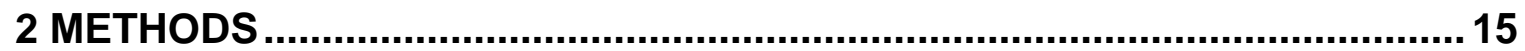

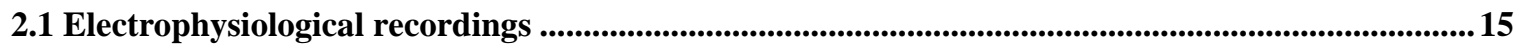

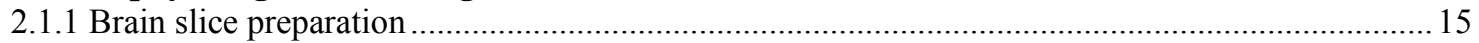

2.1.2 Solutions and drugs used for electrophysiological recordings ................................................ 17

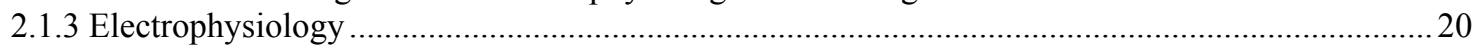

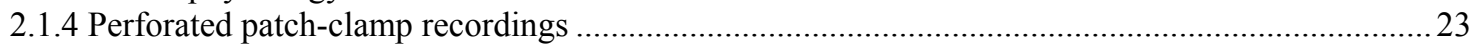

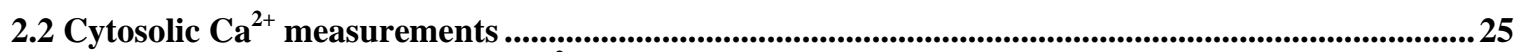

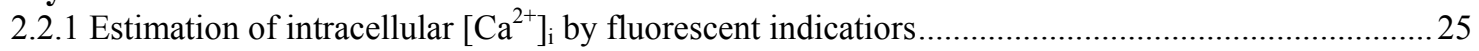

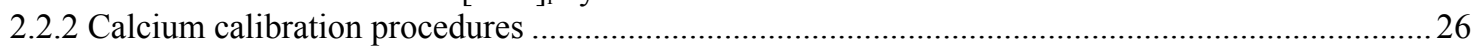

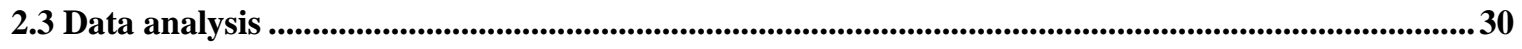

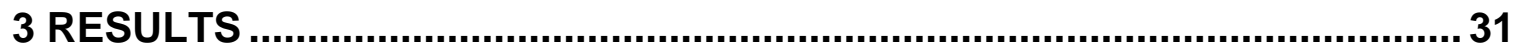

3.1 Identification of posttetanic potentiation at the calyx of Held........................................................31

3.2 Developmental regulation of posttetanic potentiation .....................................................................33

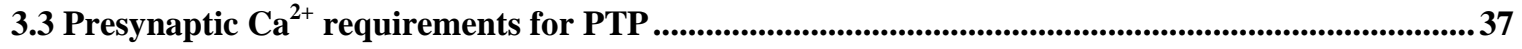

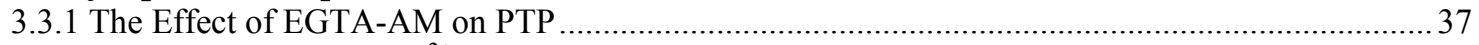

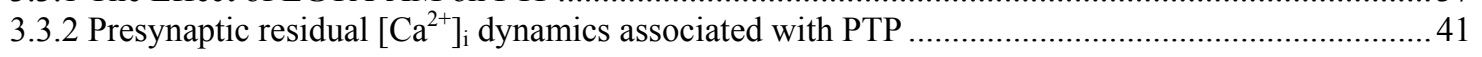

3.4 Glutamate spillover and PTP ......................................................................................................................4

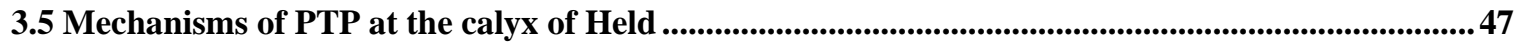

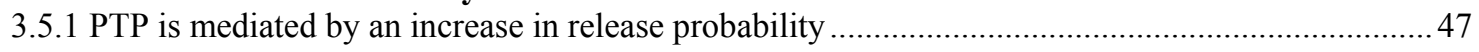

3.5.2 Whole-cell recordings of the presynaptic terminal suppress PTP..............................................49

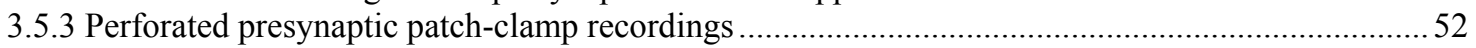

3.5.4 Involvement of phospholipase-C/protein kinase-C in PTP ................................................5

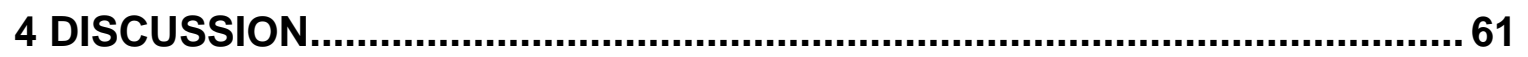

4.1 Identification and developmental regulation of PTP at the calyx of Held.....................................62 


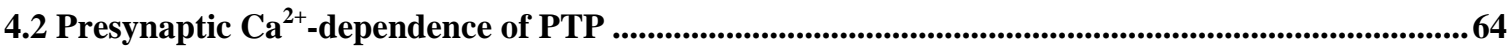

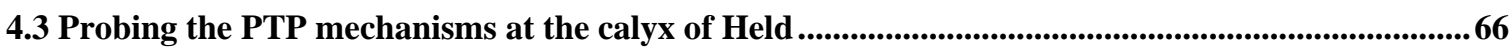

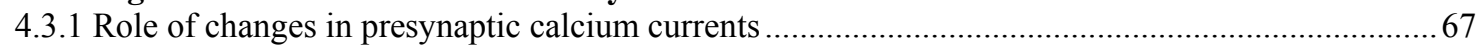

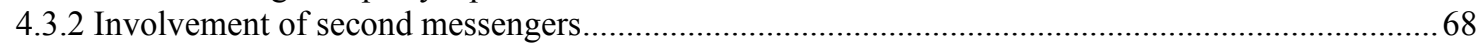

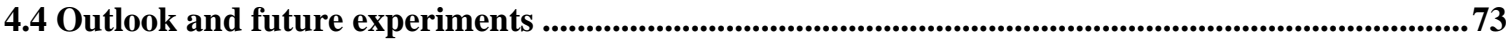

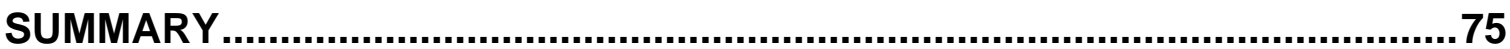

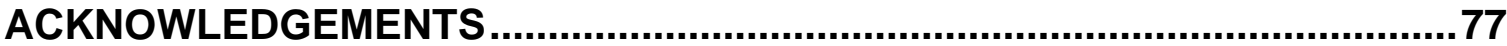

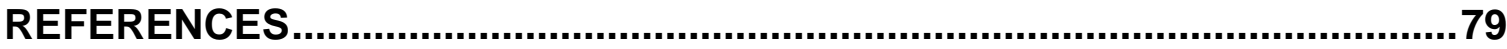

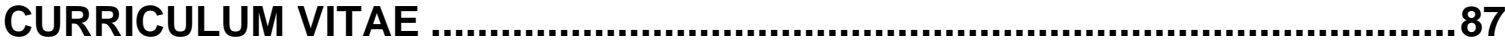

PUBLICATION LIST ................................................................................. 89 


\section{Introduction}

\subsection{Synaptic transmission in chemical synapses}

The communication between neurons takes place at synapses, which are among complex structures of the central nervous system. According to the mechanisms of the signal transmission, synapses are classified into two types: chemical and electrical. The majority of the synapses in mammalian nervous system are chemical. Thus, transmission is mediated by fusion of small synaptic vesicles with the presynaptic plasma membrane (Fig.1-1A).
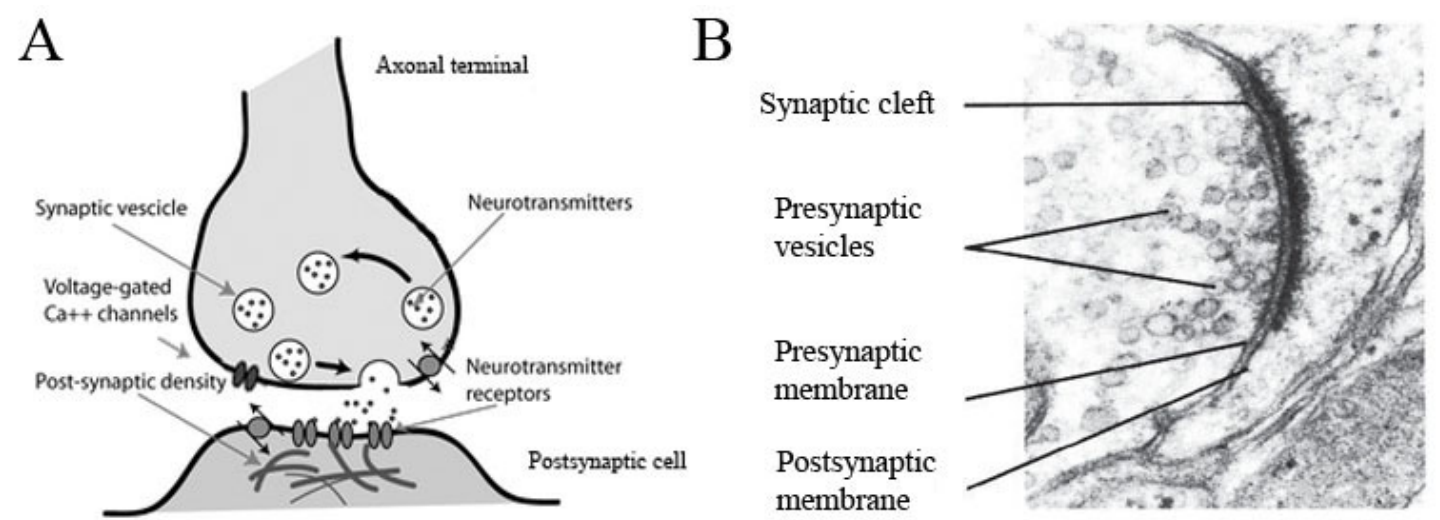

Figure 1-1. The chemical synapse. $A$, Scheme visualizing fundamental steps in synaptic transmission (refer to the text for details). $B$; Electron micrograph of synaptic contact, showing active zone, with small synaptic vesicles that are docked to and clustered around active zone, which faces postsynaptic density of the postsynaptic neuron.

This process of transmitter release occurs at specialized contact sites between preand postsynaptic plasma membranes. Membrane bound organelles, the neurotransmitter containing synaptic vesicles, are found to be docked to and clustered around the presynaptic density, called active zone (Fig.1-1B). The active zone contains $\mathrm{Ca}^{2+}$ channels and molecular machinery controlling fusion of the vesicles with the plasma membrane. The postsynaptic density on the other hand contains neurotransmitter receptors and ligand-gated ion channels. Transmission is initiated upon arrival of an action potential (AP) at the presynaptic terminal, where it opens voltage-gated $\mathrm{Ca}^{2+}$ channels. The influx of $\mathrm{Ca}^{2+}$ ions leads to a rapid increase in the intracellular $\mathrm{Ca}^{2+}$ concentration that activates certain molecular machinery, which causes vesicles to fuse with the plasma membrane. By fusing with the plasma membrane, synaptic vesicles release their neurotransmitter 
content into the synaptic cleft and thereby activate ligand-gated ion channels on the postsynaptic membrane (Fig.1-1A,B).

Based on the postsynaptic effect, the synapses in the central nervous system (CNS) can be either excitatory or inhibitory. The primary type of excitatory synapse in the CNS operates by the release of glutamate to act on glutamate receptors which are pharmacologically classified based on specific ligand binding as AMPA ( $\alpha$-amino-3hydroxy-5-methyl-4-isoxazoleproprionic acid) and N-methyl-D-aspartate receptors (NMDA). Activation of these receptors will generate excitatory postsynaptic currents (EPSCs), which depolarizes postsynaptic neuron. Rapid inhibition in the central nervous system is mediated by GABAergic or glycinergic inhibitory synapses, the activation of which leads to inhibitory postsynaptic currents (IPSCs) that either hyperpolarize, or stabilize the postsynaptic membrane potential.

Acute changes in synapse activation patterns may induce alterations in its transmitter release characteristics, which are reflected in different forms of synaptic plasticity. If the strength of the synapse increases after bursts of presynaptic activity, this process is referred to as synaptic enhancement, whereas a decrease in synaptic strength is called synaptic depression. Depending on the duration of a particular form of synaptic plasticity, it could be further classified into short or long-term plasticity. Long-term potentiation (LTP) can last from a few hours to a lifetime. On the other hand, short-term enhancement (STE), which was originally thought to reflect a single process, was shown to have at least four unique components (Fisher et al., 1997; Zucker and Regehr, 2002): fast-decaying facilitation (lasting tens of milliseconds); slow-decaying facilitation (lasting hundreds of milliseconds); augmentation (with a decay time constant of $\sim 5-10 \mathrm{~s}$ ) and post-tetanic potentiation (PTP, which lasts for $30 \mathrm{~s}$ to several minutes).

There are multiple cellular mechanisms, most likely acting simultaneously, which could be responsible for different forms of synaptic plasticity (Goda and Stevens, 1996; Zucker, 1999; Cohen-Cory, 2002; Zucker and Regehr, 2002). To understand in which ways the synaptic strength can be modified, the quantal theory was developed, which was originally introduced by Del Castillo and Katz in 1954. This quantal analysis is based on binomial statistics, with three parameters determining the size of a stimulus-evoked response: the average size of quantal unit, the number of sites that can release a quantum, and the probability of release in response to stimulation at each release site (Johnson and Wernig, 1971). This set of parameters correlates with the morphology and the function of synapses and can be modulated by different pre- and postsynaptic mechanisms. 


\subsection{The calyx of Held synapse}

The calyx of Held synapse is one of two giant synapses in the auditory brainstem neuronal circuitry (Fig.1-2A), which is formed between globular bushy cells (GBCs) in the anterior ventral cochlear nucleus $(\mathrm{aVCN})$ and the principal neurons in the contralateral medial nucleus of the trapezoid body (MNTB).

A

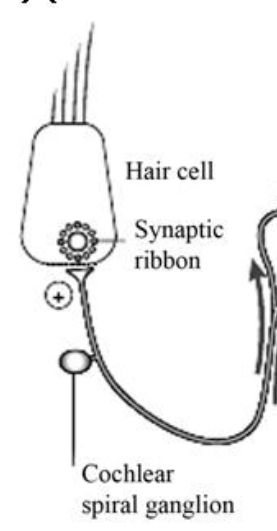

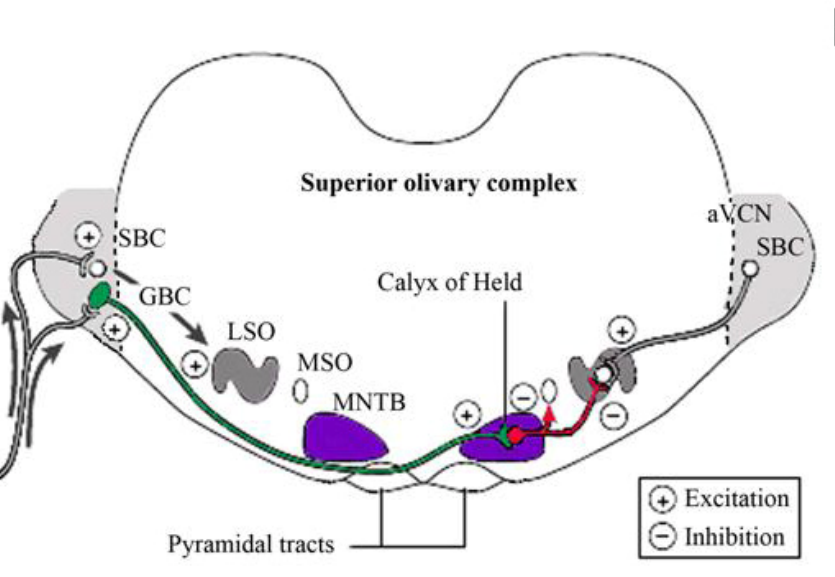

B

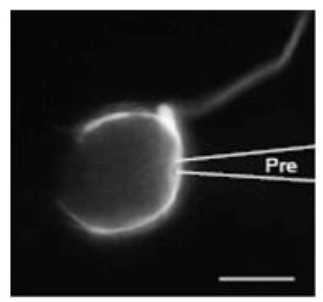

Figure 1-2. Schematic representation of auditory neuronal circuitry. $A$, The cells responsible for the perception of sound (inner and outer hair cells) of the organ of Corti in the cochlea send information via axons of the spiral ganglion to the cochlea nucleus $(\mathrm{CN})$. There axons branch to make synaptic contacts in the anterior $(\mathrm{aVCN})$ and posterior ventral and in the dorsal $\mathrm{CN}$. The $\mathrm{CN}$ of both sides project to the SOC, which is composed of three principal nuclei: LSO, MSO and MNTB. The 'calyx of Held' synapses arise from a projection of globular bushy cells onto inhibitory principal cells of the contralateral MNTB. The balance of synaptic excitation (from the $\mathrm{VCN}$ ) and inhibition (from the MNTB) in the LSO is thought to play a role in sound source localization (circuitry scheme is modified from (von Gersdorff and Borst, 2002)). $B$, Image of a calyx of Held nerve terminal filled with a fluorescent $\mathrm{Ca}^{2+}$ indicator dye via a wholecell patch-clamp pipette (Pre). Scale bar, $10 \mu \mathrm{m}$. Reproduced, with permission, from (Schneggenburger and Neher, 2000).

Each MNTB neuron receives only one giant synapse (von Gersdorff and Borst, 2002). The calyx of Held consists of multiple, thick "fingers" that clasp the postsynaptic cell. In addition, these terminals contain multiple conventional active zones $(\sim 600$ in P9 rats, (Satzler et al., 2002)), where synaptic vesicles cluster, facing the postsynaptic density. The individual active zones are found to be similar to those in other synapses in the central nervous system. This unusual morphology and the multiple sites of synaptic vesicle fusion ensure fast, reliable synaptic transmission, such that incoming presynaptic action potentials (APs) trigger postsynaptic EPSPs, which reliably exceed the threshold 
for postsynaptic AP generation, even at high input frequencies. The glutamate, released from the presynaptic cell, generates dual component postsynaptic currents. The fast component results from activation of AMPA-type glutamate receptor, while the slow component is generated by activation of NMDA-type. The calyx of Held synapse represents a very useful model system to study synaptic transmission and its modulation, because both the presynaptic terminal and the postsynaptic neuron are electrophysiologically accessible (Fig.1-2B).

\subsection{The development of the auditory brainstem network}

The auditory brainstem neuronal circuitry shows a highly ordered organization. One of the interesting questions that arises is how such precise connections are established?

Synapse formation and stabilization in the central nervous system (CNS) is a dynamic process. Numerous mechanisms coordinate where and when synapses are made in the developing brain. These mechanisms were classified into two major groups, i.e., genetically determined (or activity-independent) and activity-dependent that can be further subdivided into those associated with spontaneous activity and those depending on sensory-evoked responses (Friauf and Lohmann, 1999; Cohen-Cory, 2002).

Within the scope of this study, we were interested in evaluating the activitydependent plasticity, which could play a role during the early postnatal (P0-P4) development of the neuronal auditory brainstem circuit and particularly of the calyx of Held.

In rats, afferent fibers, which later give rise to the future calyces, start to grow out of aVCN at embryonic day 15 (E15, 7 days before birth) and the most advanced already cross the midline at E15 (Fig.1-3, upper panel). It was shown in the study of Kandler and Friauf (1993) that the first contacts onto the principal cells of the MNTB are already established between P0 (postnatal day 0, the day of birth) and P3 (Kandler and Friauf, 1993). To trace the synapse development, authors used carbocyanine dye DiI and biocytin labelling of axonal fibers in an in vitro fixed-slice preparations. They found that within the next week further axonal growth and synaptic maturation occur. By P10, almost all calyces had achieved a morphology that resembled a mature calyx and by P14 they were almost indistinguishable from those of adults (Fig.1-3, lower panel).

Along with the morphological modifications, different functional changes take place at the calyx of Held synapse. In the Figure 1-3 (lower panel, left) a postsynaptic response 
is shown that was obtained from P0 rat by the local axon stimulation (see Methods). Usually, evoked EPSCs at this age were only in the order of a few hundred pA, fluctuated extensively in amplitude and occurred in marked asynchrony. With development of the animals, EPSCs increase in amplitude, become synchronous and phased-locked (Fig.1-3, lower panel). This synchronization of neurotransmitter release was shown to be dependent on the intracellular $\mathrm{Ca}^{2+}$ dynamics and $\mathrm{Ca}^{2+}$ clearance mechanism during maturation (Chuhma and Ohmori, 1998, , 2001, , 2002). At the same time maturation of the synapse is accompanied by several other fine-tuning processes both pre- and postsynaptically: (i) an increase in the expression level of Ca-binding proteins (Felmy and Schneggenburger, 2004); a developmental switch in $\mathrm{Ca}^{2+}$ channel subtypes from a mixture of R, N and P/Q to solely P/Q subtype(Iwasaki et al., 2000); a change from AMPA/NMDA to mainly AMPA-receptor -mediated EPSCs (Takahashi, 2005); an increase in the size of a readily-released pool (RRP) of vesicles with parallel reduction in release probability (Taschenberger and von Gersdorff, 2000; Ishikawa et al., 2002; Joshi and Wang, 2002; Fedchyshyn and Wang, 2005).
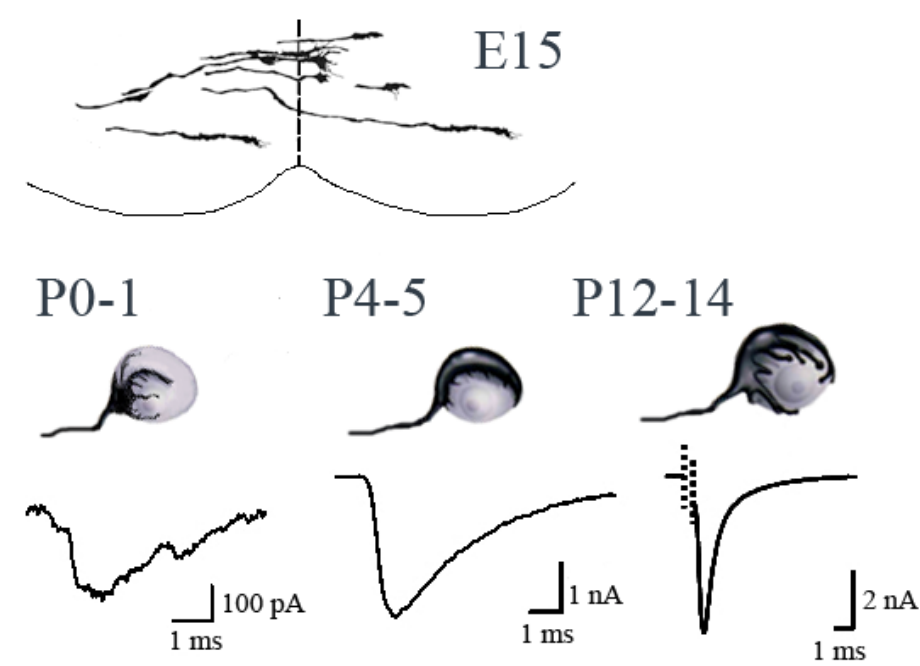

Figure 1-3. A schematic representation of the calyx of Held maturation. At embryonic day E15 axon growth cones travel to the contralateral side, where they will form first contacts with principal neurons before birth. Once the synapse is established, further maturation occurs, during which the calyx changes its shape from cup-like to a highly branched structure. At the same time synaptic responses increase in amplitude, become synchronized and fast to provide the phase-locked highfidelity transmission.

One can see that the main maturation changes occur before the onset of hearing, which is around P12 in rats. Thus, the assembly of the calyx of Held occurs in the absence of acoustically evoked activity. At the same time, it was shown by Lohmann and coworkers (1998), that activity plays a vital role during the first 1-2 postnatal weeks. These authors made organotypic slice cultures from auditory brainstem and found that the circuitry could be maintained correctly only when voltage-gated $\mathrm{Ca}^{2+}$ channels of the L- 
type (which are expressed at the cell body of the globular bushy cells (GBCs)) were activated, for instance by application of high $(25 \mathrm{mM}) \mathrm{KCl}$ to the keeping medium.

Thus, several lines of evidence point towards a participation of activity-dependent forms of synaptic plasticity in the development of the calyx of Held synapse. However, what can be the source of activity for the calyces before the onset of hearing? It was proposed that spontaneous activity of inner hear cells (Beutner and Moser, 2001) and subsequent activation of the auditory nerve fibers, may play an important role in this process (Friauf and Lohmann, 1999). Indeed, spontaneous firing rates of the auditory nerve and fibers in the trapezoid body vary from several $\mathrm{Hz}$ to nearly $200 \mathrm{~Hz}$ and can approach $500 \mathrm{~Hz}$, when driven by intense acoustic stimuli (Warchol and Dallos, 1990; Chen et al., 1996; Trussell, 1999).

\subsection{The role of synaptic plasticity in development of neuronal connections}

As was already discussed above, activity-dependent forms of synaptic plasticity, and especially synaptic potentiation, were shown to be important for the synapse establishment and maturation. Among them, long-term potentiation (LTP) has received special attention, because of its probable role both in memory and learning and because of its putative role in integration of AMPA receptors into the postsynaptic membrane during development of synapses. The experimental paradigm used for its study, which represents repetitive high-frequency stimulation (HFS), gave rise to synaptic potentiation that is accompanied by structural and molecular changes at the single synapse level (Goda and Stevens, 1996; Atwood and Wojtowicz, 1999). It was proposed that some synaptic connections between neurons could be ineffective or "silent", especially at the immature age. This could be due to presynaptic and/or postsynaptic factors (for review see (Voronin and Cherubini, 2003)). "Presynaptically silent" synapses produce no response, because either there are no quanta to be released or these quanta have low probability of release. "Postsynaptically silent" ones are unable to detect release due to a lack of postsynaptic receptors. Interestingly, repetitive stimulation of "silent" synapses can convert them into functional ones (Goda and Stevens, 1996; Atwood and Wojtowicz, 1999). For example, during early postnatal development (P2-P5) a significant proportion of thalamocortical synapses in rat somatosensory (barrel) cortex are functionally silent and these are converted to active synapses during LTP. These silent synapses disappear by postnatal 
day 8-9, the exact time at which the susceptibility of these synapses to LTP is lost (Isaac et al., 1997).

\subsection{Synaptic plasticity at the calyx of Held synapse}

It was shown that in young rats or mice synaptic depression dominates during HFS at the calyx of Held synapse (Borst et al., 1995; von Gersdorff et al., 1997), which is mediated both by presynaptic and postsynaptic mechanisms (Schneggenburger et al., 1999; Wu and Borst, 1999; Neher and Sakaba, 2001; Scheuss et al., 2002). Briefly, presynaptic mechanisms include $\mathrm{Ca}^{2+}$ current inactivation (Forsythe et al., 1998; $\mathrm{Xu}$ and $\mathrm{Wu}, 2005)$, feedback activation of mGluRs known to down regulate presynaptic $\mathrm{Ca}^{2+}$ currents (Takahashi et al., 1996) or a transient decrease in the number of readilyreleasable vesicles (Schneggenburger et al., 2002). Postsynaptic mechanisms include AMPA receptor desensitization (Scheuss et al., 2002). Facilitation of transmitter release can also be observed when release probability is decreased (Felmy et al., 2003); for example, by reducing the extracellular $\mathrm{Ca}^{2+}$ concentration. The finding that depression is the prevalent form of short-term plasticity has initially led to the view that the release probability at this synapse must be quite high (Chuhma and Ohmori, 1998; Weis et al., 1999).

Evidence has accumulated, however, that a presynaptic AP releases a surprisingly small fraction of the pool of readily releasable vesicles (RRP), which was shown to be quite large at the calyx of Held synapse by using voltage clamp or $\mathrm{Ca}^{2+}$ uncaging methods (Schneggenburger and Neher, 2000; Sakaba and Neher, 2001; Sun and Wu, 2001). This small release fraction is a property shared with other CNS synapses (Reim et al., 2001; Hallermann et al., 2003) and indicates that potentiation of transmitter release might occur under certain physiological conditions.

Based on the above described studies, we have hypothesized that during the early postnatal development, the calyx of Held might also show activity-dependent forms of synaptic potentiation like LTP, that contribute to driving the profound morphological and functional changes of this synapse during the early postnatal development (Kandler and Friauf, 1993; Taschenberger and von Gersdorff, 2000; Iwasaki and Takahashi, 2001; Joshi and Wang, 2002). 


\subsection{Aims and scopes of this work}

The aim of this work was to study the properties and approach the mechanisms of activity-dependent synaptic plasticity in early postnatal development of the calyx of Held synapse.

For this, we performed recordings in auditory brainstem slices from young rats (postnatal day, P4-P7) and probed synaptic responses by applying prolonged HFS. Repetitive stimulation of the synapse induced a robust form of short-term potentiation at the calyx of Held, which shared many properties with posttetanic potentiation (PTP) studied previously at CNS synapses and at neuromuscular junctions, but which was unknown at the calyx of Held.

Developmental regulation of PTP was investigated by performing experiments in different age groups. PTP was also found later postnatally, but synapses had a decreased sensitivity to the induction of PTP compared with early developmental stages.

To investigate the mechanisms underlying posttetanic potentiation at the calyx of Held, we made intracellular presynaptic $\left[\mathrm{Ca}^{2+}\right]_{\mathrm{i}}$ measurements, combined with paired preand postsynaptic electrophysiological recordings. These experiments indicated an important role of residual $\left[\mathrm{Ca}^{2+}\right]_{\mathrm{i}}$ in the induction of PTP. Different pharmacological manipulations identified protein kinase $\mathrm{C}(\mathrm{PKC})$ to play an additional role in this process besides residual $\mathrm{Ca}^{2+}$ as a key mechanism of PTP. 


\section{Methods}

\subsection{Electrophysiological recordings}

\subsubsection{Brain slice preparation}

The preparation of transverse auditory brainstem slices followed the general procedure of making thin slices from the tissue of mammalian central nervous system described in (Edwards et al., 1989). Postnatal day 0 (P0) to P14 Wistar rats were decapitated. The whole brain was carefully removed from the cut-open skull with forceps and kept cold throughout sectioning. For this purpose, the tissue was submerged into icecold standard extracellular solution (composition described in section 2.1.2). Dissection and slicing was done in low $\left[\mathrm{Ca}^{2+}\right](0.1 \mathrm{mM})$ extracellular solution to down-regulate metabolic processes and to avoid hypoxic damage of the nerve cells. The brainstem containing the region of interest (MNTB), together with the caudal part of the cerebrum and the cerebellum, were separated from the rostral parts of the brain by a slightly inclined transverse cut with a scalpel (Fig. 2-1A). After that, the pia mater and arachnoidea were carefully removed from the ventral surface of the brainstem using small forceps to facilitate cutting of the slices. The tissue block was glued onto a Teflon block of a slice chamber with the rostral plane oriented towards the block using cyan acrylic glue (UHU Sekundenkleber, UHU GmbH \& Co. KG, Baden, Germany). The Teflon block could be turned around one axis. If necessary, it was turned slightly such that the fibers projecting from the ventral cochlear nucleus (VCN) to the medial nucleus of the trapezoid body (MNTB, labeled "Tz" in Fig. 2-1) ran parallel to the slicing plane. Transverse $200-\mu \mathrm{m}$-thick slices were made with a vibratome slicer (Integraslice 7550 MM; Campden Instruments, Leicester, UK). The $7^{\text {th }}$ nerve (Nervus facialis) was used as a marker for the start of the region of interest (containing MNTB and VCN, Fig. 2-1B). Depending on the age of the animal, one could obtain three to six slices containing the MNTB region. A schematic drawing of a slice used for recordings is shown in Fig. 2-1B.

After sectioning, each slice was immediately placed into an incubation chamber containing oxygenated $\left(95 \% \mathrm{O}_{2}, 5 \% \mathrm{CO}_{2}\right)$ extracellular solution containing $2 \mathrm{mM} \mathrm{Ca}^{2+}$. Slices were maintained at $37{ }^{\circ} \mathrm{C}$ for up to four hours. 


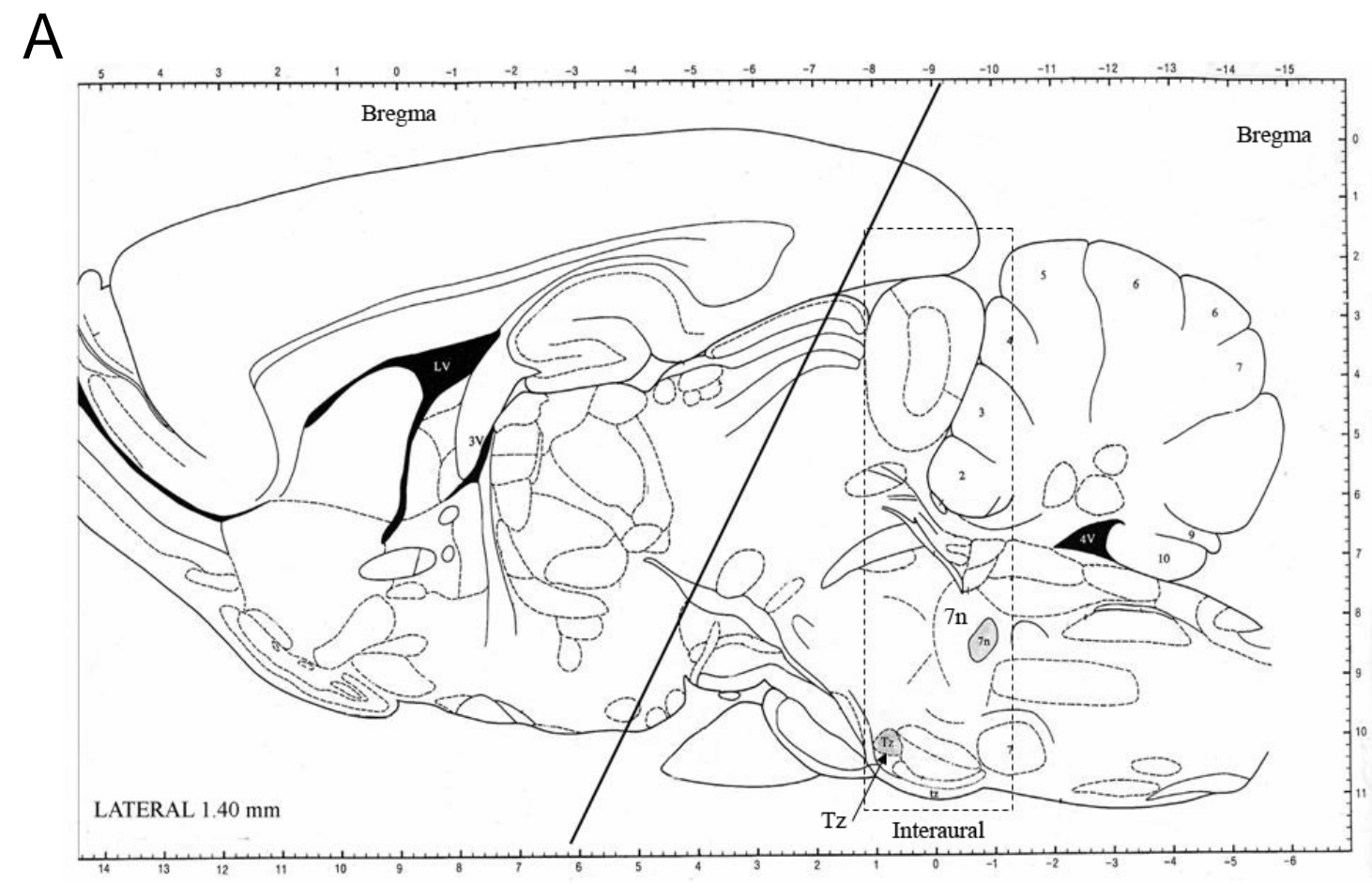

$\mathrm{B}$

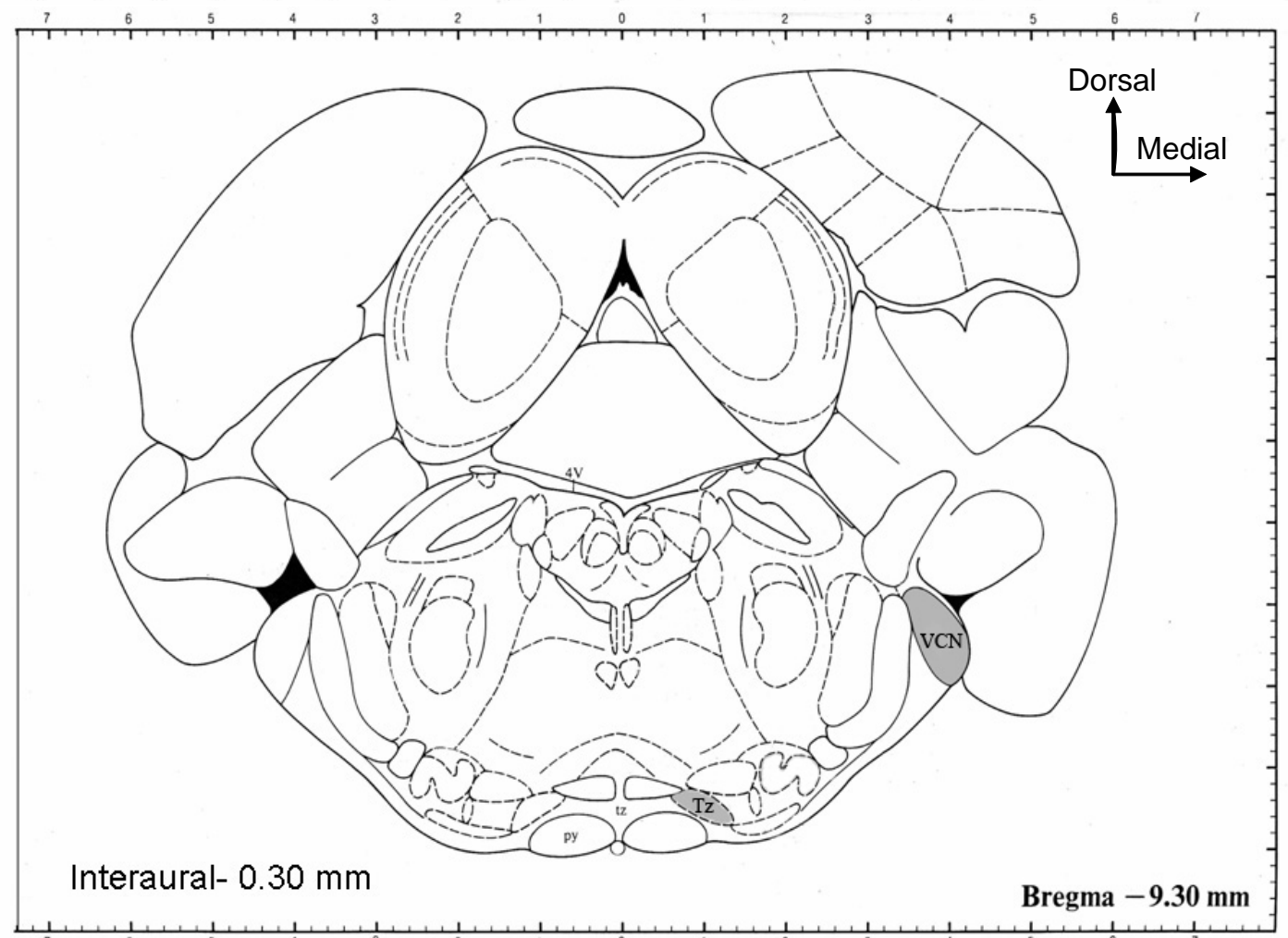

Figure 2-1. Slice preparation procedure. $A$, Lateral view of the adult rat brain (rostral to caudal from left to right; picture is modified from "The rat brain atlas", (Paxinos G, 1986)). The inclined black line shows the position of the transverse cut. Dashed rectangle outlines the region of interest: medial nucleus of the trapezoid body (MNTB), marked "Tz" (black arrow), and VCN (ventral cochlear nucleus, which anterior part contains globular bushy cells, giving rise to the calyx of Held synapses). $B$, Schematic map of a transverse slice, containing the region of interest. The important nuclei are labelled in gray. 


\subsubsection{Solutions and drugs used for electrophysiological recordings}

This section includes the compositions of extra- and intracellular solutions that were used for experiments. The composition of two basic extracellular solutions is listed in Table 2-1. The standard (Ringer) extracellular solution (middle column) was used during slice incubation and electrophysiological recordings. The Ringer solution with low $\mathrm{Ca}^{2+}$ (right column) was used for the slice preparation.

Table 2-1. Extracellular solutions

\begin{tabular}{|c|c|c|}
\hline Substance & $\begin{array}{c}\text { Standard Ringer } \\
{[\mathbf{m M}]}\end{array}$ & $\begin{array}{c}\text { Ringer used for the slice } \\
\text { preparation [mM] }\end{array}$ \\
\hline $\mathrm{NaCl}$ & 125 & 125 \\
\hline $\mathrm{NaHCO}_{3}$ & 25 & 1.25 \\
\hline $\mathrm{NaH}_{2} \mathrm{PO}_{4}$ & 1.25 & 2.5 \\
\hline $\mathrm{KCl}$ & 2.5 & 0.1 \\
\hline $\mathrm{CaCl}_{2}$ & 2 & 3 \\
\hline $\mathrm{MgCl}_{2}$ & 1 & 25 \\
\hline Glucose & 25 & 0.4 \\
\hline Ascorbic acid & 0.4 & 2 \\
\hline Na-pyruvate & 2 & 3 \\
\hline Myo-inositol & 3 & \\
\hline
\end{tabular}

Extracellular solutions had a $\mathrm{pH}$ of 7.4 when bubbled with $95 \% \mathrm{O}_{2}$ and $5 \% \mathrm{CO}_{2}$ with an osmolarity of $\sim 310$ mOsm. The salts $\mathrm{NaCl}, \mathrm{NaHCO}_{3}, \mathrm{NaH}_{2} \mathrm{PO}_{4}, \mathrm{KCl}, \mathrm{CaCl}_{2}$, $\mathrm{MgCl}_{2}$ were obtained from Merck (Darmstadt, Germany). D (+)-Glucose, myo-inositol, Na-pyruvate and L- ascorbic acid were purchased from Sigma (Steinheim, Germany).

Table 2-2 summarizes the pharmacological compounds and their particular concentrations that were used in different subsets of experiments. These substances were added from 100-1000 fold higher concentrated stock solutions of each substance (in $\mathrm{H}_{2} \mathrm{O}$ ). The Ro-31-8220, Gö-6976, BIS, Calphostin C, Calmidozolium stock solutions were made in DMSO. In these cases, the final DMSO concentration did not exceed $0.1 \%$ volume. The particular application mode and incubation times for each substance will be outlined in the Results section. 
Table 2-2. Drugs and concentrations used

\begin{tabular}{|c|c|c|}
\hline Substance & Final concentration & Purchased from \\
\hline Strychnine & $1 \mu \mathrm{M}$ & Tocris (Bristol, UK) \\
\hline Bicuculine & $10 \mu \mathrm{M}$ & Tocris (Bristol, UK) \\
\hline TTX (tetrodotoxin) & $1 \mu \mathrm{M}$ & $\begin{array}{c}\text { Alamone labs } \\
\text { (Jerusalem, Israel) }\end{array}$ \\
\hline $\begin{array}{l}\text { Tetraethylammonium } \\
\text { chloride (TEA-Cl) }\end{array}$ & $10 \mathrm{mM}$ & Sigma (Germany) \\
\hline $\begin{array}{l}\text { D-AP5 (D-(-)-2 amino-5- } \\
\text { phosphonopentanoic acid) }\end{array}$ & $50 \mu \mathrm{M}$ & Tocris(Bristol, UK) \\
\hline CTZ (cyclothiazide) & $0.1 \mathrm{mM}$ & Tocris(Bristol, UK) \\
\hline Kynurenic acid & $1 \mathrm{mM}$ & Tocris(Bristol, UK) \\
\hline Ro-318220 & $3 \mu \mathrm{M}$ & Merck, Calbiochem \\
\hline $\begin{array}{c}\text { CPPG } \\
\text { ((RS)- } \alpha \text {-cyclopropyl-4- } \\
\text { phosphonophenylglycine) }\end{array}$ & $300 \mu \mathrm{M}$ & Tocris \\
\hline Gö - 6976 & $10 \mu \mathrm{M}$ & Merck, Calbiochem \\
\hline BIS & $10 \mu \mathrm{M}$ & Merck, Calbiochem \\
\hline Calphostin C & $20 \mu \mathrm{M}$ & Merck, Calbiochem \\
\hline Calmidozolium & $20 \mu \mathrm{M}$ & Merck, Calbiochem \\
\hline $\begin{array}{l}\text { EGTA-AM (tetra- } \\
\text { acetoxymethyl ester) }\end{array}$ & $200 \mu \mathrm{M}$ & Molecular Probes \\
\hline
\end{tabular}

Some of the above-mentioned substances, for example like Ro-31-8220, could not reach the intracellular space of the cells when applied acutely to the slices. Therefore, we used "preincubation" technique, in which slices were incubated with these particular drugs for $\sim 30 \mathrm{~min}$ to 2 hours that significantly improved the output of experiments. To do so, we designed a small slice-keeping chamber (of $\sim 40 \mathrm{~mL}$ volume). The stock solution of a particular substance was mixed with $30 \mathrm{~mL}$ of extracellular solution to have final desirable drug concentration. After the brain dissection procedure, some of the slices, containing the region of interest, were placed in this chamber and incubated for the above-mentioned time. During experiments, slices were continuously perfused with 
recording solution containing the same drug concentration as during preincubation. For the control experiments, we placed some of the slices, which were obtained by brain dissection from the same animal, in extracellular recording solution without corresponding drug.

The following tables describe the constituents of the intracellular (patch-pipette) solutions. In most of the experiments cesium-gluconate based intracellular solution was used both for pre- and postsynaptic recordings (Table 2-3).

Table 2-3. Cs-gluconate pre- and postsynaptic intracellular solution

\begin{tabular}{|c|c|c|c|}
\hline Substance & $\begin{array}{c}\text { Final concentration } \\
\text { [mM] }\end{array}$ & MW [g/mol] & Purchased from \\
\hline Cs-gluconate & 140 & 328 & $\begin{array}{c}\text { Self-made } \\
\text { according to } \\
\text { (Meyer, 1999) }\end{array}$ \\
\hline HEPES & 10 & 238 & Sigma, Germany \\
\hline TEA-Cl & 20 & 1 M stock & Sigma, Germany \\
\hline $\mathrm{Mg}-\mathrm{ATP}$ & 4 & 507.2 & Sigma, Germany \\
\hline $\mathrm{Na}_{2} \mathrm{Pcreatine}$ & 5 & 255.1 & Sigma, Germany \\
\hline $\mathrm{Na}_{2} \mathrm{GTP}$ & 0.3 & 567 & Sigma, Germany \\
\hline
\end{tabular}

A potassium-based intracellular solution was used for the presynaptic current-clamp recordings (Table 2-4).

Table 2-4. K-Gluconate presynaptic intracellular solution

\begin{tabular}{|c|c|c|c|}
\hline Substance & $\begin{array}{c}\text { Final concentration } \\
{[\mathbf{m M}]}\end{array}$ & MW [g/mol] & Purchased from \\
\hline $\begin{array}{c}\text { K-gluconate } \\
\text { (D-gluconic } \\
\text { acid) }\end{array}$ & 140 & 234.2 & Sigma, Germany \\
\hline $\mathrm{HEPES}$ & 10 & 238 & Sigma, Germany \\
\hline $\mathrm{KCl}$ & 20 & 74.55 & Sigma, Germany \\
\hline $\mathrm{Mg}$-ATP & 2 & 507.2 & Sigma, Germany \\
\hline $\mathrm{Na}_{2}$ Pcreatine & 5 & 255.1 & Sigma, Germany \\
\hline
\end{tabular}




\begin{tabular}{|c|c|c|c|}
\hline $\mathrm{Na}_{2} \mathrm{GTP}$ & 0.3 & 567 & Sigma, Germany \\
\hline
\end{tabular}

All intracellular solutions were adjusted to $\mathrm{pH} 7.2$ and had an osmolarity of about 300310 mOsm.

\subsubsection{Electrophysiology}

For recordings, a slice at a time was placed into the glass bottomed recording chamber and covered with a platinum U-shaped flattened wire with a grid of parallel nylon threads. This grid prevented the slices from any dislocation during the recordings. During experiments, the slice was continuously perfused with extracellular recording solutions from a gravity-fed system of syringes and Teflon tubing with a flow rate of about $1 \mathrm{~mL} / \mathrm{min}$. The solution level in the chamber was controlled by overflow suction tubing connected to a vacuum pump. The slices were positioned and visualized under an upright microscope BX50WI (Olympus, Tokyo, Japan) using a five× objective. Desirable calyces of Held or somata of the postsynaptic principal neurons were identified under infrared gradient contrast illumination (Luigs and Neumann, Ratingen, Germany) with a $60 \times$ water immersion objective (NA $=0.9$, LUMPPlanFI, Olympus, Japan). The recordings were made at room temperature $\left(22-25^{\circ} \mathrm{C}\right)$ with an EPC-9/2 patch-clamp amplifier (HEKA, Lambrecht, Germany). Electrical currents and/or potentials were sampled with the computer running Pulse software (Version 8.63, HEKA, Germany).

If not otherwise stated, patch pipettes were pulled from a borosilicate glass $(2 \mathrm{~mm}$ diameter, $0.3 \mathrm{~mm}$ wall thickness) using a vertical two-step temperature controlled pipette puller (PIP-5, HEKA, Lambrecht, Germany). To minimize the capacitance resulting from the immersion into the bath, the outer tip-proximal wall of the pipette was coated with Sylgard (Sinus Electronics GmbH, Untereisesheim, Germany). The voltage- and/or current-clamp configuration of the "whole-cell patch-clamp technique" was used in experiments (Fig.2-2). The first step in this technique is to obtain a high resistance contact between the pipette and the cell membrane (formation of a "gigaseal") by touching the cell surface with the pipette tip and applying gentle suction. A patch of membrane under the pipette is then ruptured by application of a short pulse of negative pressure, reaching the whole-cell configuration. Following patch disruption, the solution inside the patch pipette will enter into and equilibrate with the cell interior. In whole-cell experiments, both the electrical and chemical components of the driving force may be regulated; the electrical component by means of the patch-clamp amplifier and the concentration 
gradient by adjusting the composition of the intra- and/or extracellular bathing solutions (Fig.2-2). In whole-cell voltage-clamp configuration, the membrane potential is held constant (i.e., "clamped") while the current flowing through the membrane is measured. In the case of current-clamp recordings, a constant current is injected into the cell, while the membrane potential is measured.

Postsynaptic recordings were performed in the voltage-clamp mode at a holding potential of $-70 \mathrm{mV}$. Compensation of the pipette capacitance and of the cell membrane capacitance was done by using internal, software controlled compensation circuits of the EPC-9/2 amplifier. Series resistance $\left(R_{\mathrm{s}}\right.$; range, 4-15 M $\Omega$ ) was compensated up to $80 \%$, so that the uncompensated $R_{\mathrm{S}}$ never exceeded $3 \mathrm{M} \Omega$. EPSC traces were corrected off-line for the remaining $R_{\mathrm{s}}$ error (Meyer et al., 2001).

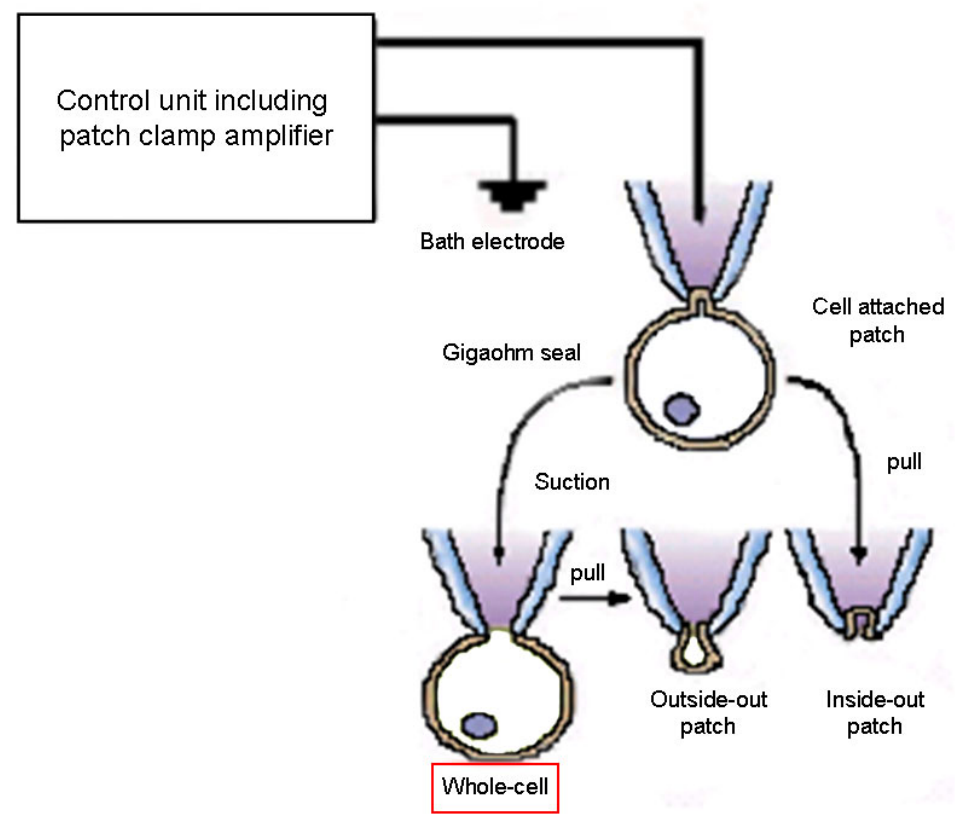

Figure 2-2. Schematic representation of different configurations of the patch-clamp technique. By seal formation, one obtains the "cell-attached" configuration (upper panel, right), which is the precursor to all other configurations of the patch-clamp technique. Breaking the patch by application of a suction pulse through the patch pipette will create the "whole-cell" configuration (lower panel, left). From the whole-cell configuration, one may proceed further by withdrawing the pipette from the cell, which results in the "outside-out" patch (because the outside of the membrane will face towards the bath solution; lower panel, middle). Withdrawing the pipette directly from the cell-attached mode will isolate a patch of membrane and lead to the excised patch configuration, which is called "inside-out" patch. We mostly used the "whole-cell" configuration of the patch-clamp technique. 
The presynaptic recordings were mainly done under current clamp, and the membrane potential was kept close to $-70 \mathrm{mV}$ by injecting a small (range -60 to $-30 \mathrm{pA}$ ) holding current. EPSCs were evoked by stimulating presynaptic axons with a concentric, bipolar stimulating electrode (MCE-100; Rhodes Medical Instruments, Woodland Hills, USA), which was placed between the medial border of the MNTB and the midline of the brainstem. Stimulation pulses were generated with an isolated pulse stimulator (A-M Systems, Model 2100, Kirkland, Washington, USA). Voltage pulses were $100 \mu$ s long with amplitudes varied between 5 and $35 \mathrm{~V}$. Prior to recordings, the cells in the MNTB region had to be identified, whose input was activated by fiber stimulation. Cells were screened using a patch pipette filled with extracellular solution. Suitable postsynaptic cells ( $\sim 10-20 \%$ of superficial cells) were selected by measuring the presynaptic and postsynaptic action currents after afferent fiber stimulation (Borst et al., 1995; Meyer et al., 2001). In some experiments, the afferent fibers were stimulated by a monopolar stimulation electrode mounted inside a wide-opening $(5-10 \mu \mathrm{m})$ patch pipette, which was placed in the vicinity $(\sim 20-50 \mu \mathrm{m})$ of a recorded MNTB principal cell. In this case, the whole-cell recording of an MNTB cell was first established, and the stimulation pipette was then lowered onto a neighboring region in the slice until a large EPSC could be reliably stimulated. With both methods, we found robust PTP after $100 \mathrm{~Hz}$ stimulation trains. Postsynaptic patch pipettes contained the intracellular Cs-gluconate solution (selfmade according to (Meyer, 1999)). The pipette solution for presynaptic whole-cell recordings contained either K-gluconate (in case of current-clamp) or Cs-Gluconate (in case of voltage clamp) intracellular solution. The compositions of these intracellular solutions are described in section 2.1.2.

Baseline synaptic strength was assessed by applying pairs of afferent fiber stimuli at an intersimulus interval of $10 \mathrm{~ms}$, which were repeated every $10 \mathrm{~s}$. During the intervening intervals, $9.6 \mathrm{~s}$ stretches of postsynaptic current were recorded (sampling frequency 20 $\mathrm{kHz}$, low-pass filter $6 \mathrm{kHz}$ ) to evaluate the amplitude and the frequency of spontaneous miniature postsynaptic currents (mEPSCs). The mEPSCs were detected off-line with a template-matching routine with a function kindly provided by Dr. Holger Taschenbereger and Dr. Volker Scheuss. Amplitude histograms of mEPSCs were constructed for control conditions and for short time periods $(\sim 30 \mathrm{~s})$ after the induction of PTP. For the plot shown in Figure 3-6E, the average mEPSC frequency was calculated for each $9.6 \mathrm{~s}$ sampling interval. 


\subsubsection{Perforated patch-clamp recordings}

During our investigation of PTP at the calyx of Held, we found that PTP was absent under conditions of the presynaptic whole-cell recordings (Fig. 3-10, Results). Therefore, we decided to employ the perforated patch-clamp configuration (Fig. 2-3) in a subset of experiments. The term "perforated" means that an electrical access to the cell is provided through the channels, which are formed in the membrane by antibiotics that are included into the pipette solution. We used Amphotericin B (Calbiochem, Germany). The channels formed by this perforating compound are permeable to monovalent cations and $\mathrm{Cl}^{-}$, but impermeable to divalent ions such as $\mathrm{Ca}^{2+}$ or $\mathrm{Mg}^{2+}$ (Holz and Finkelstein, 1970; Rae et al., 1991). Therefore this technique has several advantages over conventional whole-cell patch-clamp (AxonGuide, 1993): (i) recordings of whole-cell currents can be done without dialyzing metabolites or second messengers, which are impermeable through the pores; (ii) intracellular multivalent ions, for example, such as $\mathrm{Ca}^{2+}$, are not affected; (iii) moreover, the perforated-patch technique is less damaging to the cells, and can be therefore used in case long lasting recordings are needed.
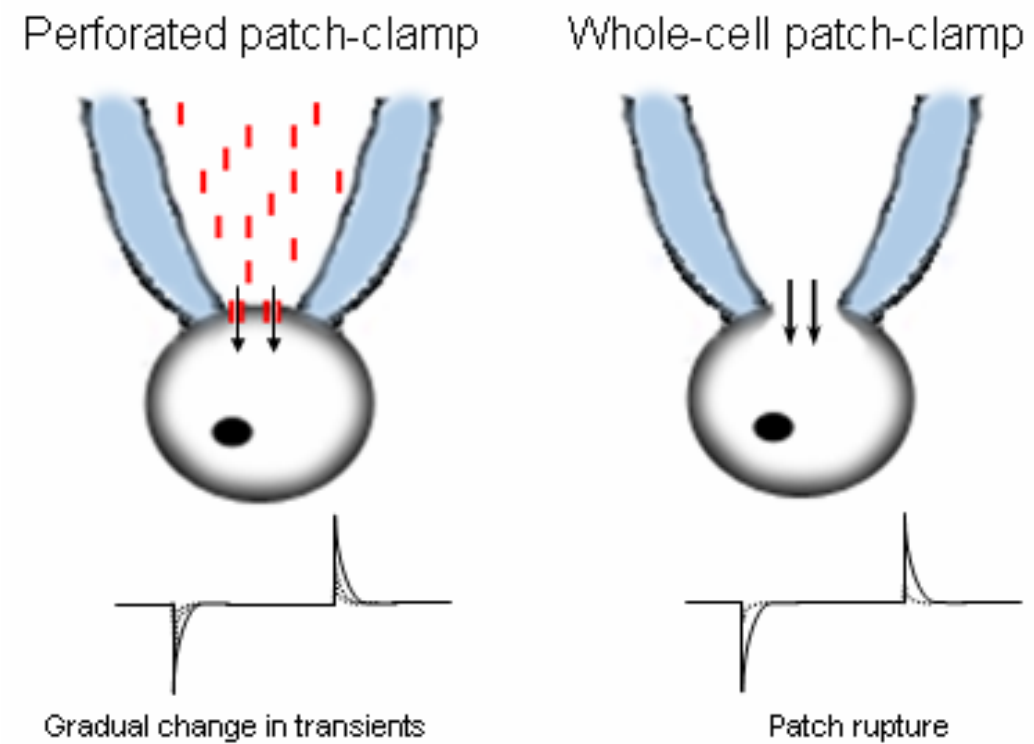

Figure 2-3. Schematic representation of access formation into the cell interior in perforated patch-clamp (left panel) and in whole-cell configuration (right panel). The electrical connection between cell and pipette is established not by suction as in "whole-cell" configuration (right panel), but by incorporation of a channel-forming antibiotic in the cell-attached mode ("perforated patch"). We used Amphotericin B, which diffuses (red small lines, left panel) to the pipette tip and gradually increases the pipette-cell conductance. This process can be monitored by observing current response to repetitive voltage steps (lower panel, left). 
The perforated-patch technique has some disadvantages when compared to the conventional whole-cell approach. For example, the perforation process requires longer time for achieving good electrical access as measured by the series resistance $\left(R_{s}\right)$. This resistance represents a combination of the resistances of the patch pipette tip and of the perforated patch membrane itself. Therefore, some considerations have to be taken into account to minimize series resistance. First, it is better to use pipettes with larger tips of $3 \mathrm{M} \Omega$ (but small enough in order to form a "gigaseal"). Second, optimal pipette geometry is important for fast antibiotic diffusion to the pipette tip and for a bigger surface area available for the insertion of pore-forming channel. We used patch pipettes, pulled from soft thin-walled glass (WPI, Sarasota, USA), which allowed to fulfill both requirements mentioned above.

An Amphotericin B stock solution was prepared every day at a concentration of $3 \mathrm{mg} / 60 \mu \mathrm{L}(54 \mathrm{mM})$ according to the protocol developed in the laboratory of Prof. Dr. Tobias Moser for cochlear inner hair cells, see also (Albillos et al., 2000). Because of limited solubility in water this compound was dissolved in dimethylsulphoxide (DMSO, Sigma) by ultrasonication ( $5-10 \mathrm{~min}$ ), preceded by gentle shaking and warming-up to $\sim 30$ ${ }^{\circ} \mathrm{C}$ for $\sim 10 \mathrm{~min}$. Ampotericin B in stock solution loses activity upon prolonged storage and freezing. Therefore, it is best to prepare it freshly before experiments and use within 1 hour. Amphotericin B was added (final concentration of $325 \mu \mathrm{M}$ ) to the Cs-Gluconate intracellular solution and dissolved through further sonication for $15 \mathrm{~min}$ in darkness. Because DMSO perturbs seal formation, the patch pipette tip was first dipped for $1 \mathrm{~min}$ in an antibiotic free solution and then the pipette was back-filled with Amphotericin B containing pipette solution. After the formation of a "gigaseal", the cell was kept in the cell-attached configuration (Fig.2-3) and the membrane potential was held at $-70 \mathrm{mV}$ until permeabilization reached a steady state. The progress of perforation was monitored by the slow increase in the amplitude of the transient capacitance current in response to $10 \mathrm{mV}$ hyperpolarizing voltage steps (Fig.2-3, lower panel). Usually, a final series resistance $\left(R_{\mathrm{s}}\right)$ of $15-26 \mathrm{M} \Omega$ was obtained after $\sim 20-40 \mathrm{~min}$. A sudden change in the size of the capacity transients normally indicated the rupture of the patch membrane (switching into whole-cell configuration). In this case, the respective cells were discarded from analysis. In order to ensure that the perforated patch mode was maintained during the whole recording, we included into the presynaptic pipette solution low concentration $(25 \mu \mathrm{M})$ of the fluorescent dye fura-2 (pentapotassium salt, Molecular Probes, Oregon, USA), which due to its structure can not permeate the pores formed by Amphotericin B. 
The fluorescence was periodically checked by exciting the dye at $380 \mathrm{~nm}$. Under perforated patch-clamp one could see only fluorescence in the patch pipette, whereas a staining of the calyx of Held could be observed if the patch was ruptured into whole-cell.

\subsection{Cytosolic $\mathrm{Ca}^{2+}$ measurements}

\subsubsection{Estimation of intracellular $\left[\mathrm{Ca}^{2+}\right]_{i}$ by fluorescent indicators}

One of the common methods to estimate intracellular $\left[\mathrm{Ca}^{2+}\right]_{i}$ is to use fluorescent $\mathrm{Ca}^{2+}$ indicators, which shift their excitation spectra upon binding $\mathrm{Ca}^{2+}$. A number of factors should be considered when choosing a fluorescent $\mathrm{Ca}^{2+}$ indicator. Some of the important criteria are excitation/emission spectra and $\mathrm{Ca}^{2+}$ - binding affinity, which is reflected by the dissociation constant $\left(\mathrm{K}_{\mathrm{D}}\right)$. Calcium indicators shift their absorption or emission spectra according to $\left[\mathrm{Ca}^{2+}\right]_{\mathrm{i}}$ in the concentration range of detectable responses $\left(0.1 \times \mathrm{K}_{\mathrm{D}}\right.$ to $\left.10 \times \mathrm{K}_{\mathrm{D}}\right)$. However, the $\mathrm{Ca}^{2+}$ sensitivity of a dye is generally most reliable in a $\left[\mathrm{Ca}^{2+}\right]$ range near the $\mathrm{K}_{\mathrm{D}}$ value. Depending on the $\mathrm{Ca}^{2+}$ concentration range to be measured, one can select between low-affinity (high $\mathrm{K}_{\mathrm{D}}$ ) or high-affinity (low $\mathrm{K}_{\mathrm{D}}$ ) $\mathrm{Ca}^{2+}$ indicators. High-affinity dyes are used to detect small changes in $\mathrm{Ca}^{2+}$ concentrations. They may emit bright fluorescence, but rapidly buffer calcium and become saturated at relatively low $\left[\mathrm{Ca}^{2+}\right]_{\mathrm{i}}$. Therefore, if changes in $\left[\mathrm{Ca}^{2+}\right]_{\mathrm{i}}$ are in the order of several tens of micromoles or if one needs to assess the kinetics of $\left[\mathrm{Ca}^{2+}\right]_{i}$, one should use high $\mathrm{K}_{\mathrm{D}^{-}}$ fluorescence indicators.

In our study, the changes in $\left[\mathrm{Ca}^{2+}\right]_{\mathrm{i}}$ during posttetanic potentiation (PTP) were monitored by using fura-4F (pentapotassium salt, Molecular Probes, Oregon, USA), which has a $\mathrm{K}_{\mathrm{D}}$ for $\mathrm{Ca}^{2+}$ of $1.4 \mu \mathrm{M}$ (the average value, obtained from the calibration procedure, see below). Because PTP could not be studied in whole-cell presynaptic recordings (see Results, Fig.3-10), we introduced fura-4F into the terminal via brief (1-2 min) presynaptic recordings with an intracellular $\mathrm{K}^{+}$-gluconate solution (see above) containing $200 \mu \mathrm{M}$ fura-4F. After 1-2 min of whole-cell recording, the pipette was carefully withdrawn. We estimated that this procedure resulted in the loading of calyces with $80-120 \mu \mathrm{M}$ fura-4F, based on the fluorescence intensity of calyces measured during longer-lasting presynaptic whole-cell recordings with $100 \mu \mathrm{M}$ fura-4F. Quantitative estimation of calcium concentration can be done by ratiometric measurements of fluorescent intensity at different wavelength of excitation light (Grynkiewicz, 1985): 


$$
\left[\mathrm{Ca}^{2+}\right]_{i}=K_{\text {eff }} \frac{R-R_{\min }}{R_{\max }-R}
$$

where $\mathrm{R}$ is an experimentally measured ratio of fluorescence intensities at two different excitation wavelength of 350 and $380 \mathrm{~nm}(2) ; R_{\min }$ is ratio in the absence of $\mathrm{Ca}^{2+} ; \mathrm{R}_{\max }$ is ratio of $\mathrm{Ca}^{2+}$ - saturated dye; $\mathrm{K}_{\mathrm{eff}}$ is the effective dissociation constant of the indicator.

$$
R=F_{350} / F_{380}
$$

The calibration constants $\mathrm{K}_{\mathrm{eff}}, \mathrm{R}_{\min }, \mathrm{R}_{\max }$, mentioned above, were determined in a calibration procedure (Schneggenburger 2004, see also 2.2.2) that combines in vitro measurements in thin quartz-glass capillaries and in vivo measurements of the limiting ratios at low and at a suitable intermediate $\left[\mathrm{Ca}^{2+}\right](1.04 \mu \mathrm{M}$ for fura- $4 \mathrm{~F}) .\left[\mathrm{Ca}^{2+}\right]_{\mathrm{i}}$ imaging was performed using a Polychrome IV monochromator (TILL Photonics, Grafelfing, Germany) to excite fura-4F at 350 and $380 \mathrm{~nm}$. A slow-scan water-cooled CCD camera IMAGO (TILL Photonics, VGA chip with $480 \times 640$ pixels) with on-chip binning $(8 \times 15$ pixels) and $10 \mathrm{~ms}$ exposure time captured the resulting fura-4F fluorescence signals. Pairs of images at each wavelength were taken at $0.5 \mathrm{~Hz}$ before and after the induction of PTP and at $20 \mathrm{~Hz}$ during $100 \mathrm{~Hz}$ trains. $\left[\mathrm{Ca}^{2+}\right]_{\mathrm{i}}$ was calculated from background-corrected fluorescence values collected from the six to eight brightest superpixels located in the calyx area, using the equation given in (Grynkiewicz, 1985) and (Schneggenburger et al., 2002).

\subsubsection{Calcium calibration procedures}

\section{In vitro calcium calibration}

The calibration constants $K_{\text {eff, }}, R_{\min }, R_{\max }$, which are necessary for estimating the absolute $\left[\mathrm{Ca}^{2+}\right]_{\mathrm{i}}$ in the cell, can be drastically affected by probe-environmental conditions. Thus, it is very important to do calibration in the same conditions as in corresponding experiment. In our calibration procedure, we first performed a five-point calibration to estimate the equilibrium binding constant $\left(\mathrm{K}_{\mathrm{D}}\right)$ of fura-4F for $\mathrm{Ca}^{2+}$.

$\mathrm{R}_{\min }$ and the ratio at $\left[\mathrm{Ca}^{2+}\right]_{i}$ closest to the $\mathrm{K}_{\mathrm{D}}$ of the dye were measured during whole-cell recordings of calyces of Held, using the same solutions as in the in vitro calibration. The series of five calibration solutions, containing various free $\left[\mathrm{Ca}^{2+}\right]_{\mathrm{i}}$, were prepared by mixing intracellular solution, different $\mathrm{CaCl}_{2}$ and $\mathrm{Ca}^{2+}$ buffer concentration $\left(\mathrm{K}_{2}\right.$-EGTA and $\mathrm{K}_{2}$ - HEDTA) to "clamp" $\left[\mathrm{Ca}^{2+}\right]_{i}$ to the desired level: (i) one solution 
without $\mathrm{Ca}^{2+}$ to calculate $\mathrm{R}_{\text {min }}$; (ii) one solution with very high $\left[\mathrm{Ca}^{2+}\right]_{\mathrm{i}}$ saturating all buffers to calculate $\mathrm{R}_{\max }$; (iii) one solution with free a $\left[\mathrm{Ca}^{2+}\right]_{\mathrm{i}}$ of $1.04 \mu \mathrm{M}$ (close to the $\mathrm{K}_{\mathrm{d}}$ of fura-4F) and two other intermediate solutions (for example see Table 2-5 and 2-6) to check the calibration quality. Free $\left[\mathrm{Ca}^{2+}\right]_{\mathrm{i}}$ was calculated knowing the content of calibration solutions with the help of the custom-written macro FreCon V3.1beta by Dr. Tao $\mathrm{Xu}$ and Dr. Jacob Sorensen) for the Igor Pro software (V4.01; Wavemetrics Inc., Lake Oswego OR, USA), taking into account all absolute $\mathrm{Ca}^{2+}$ buffer concentrations.

Table 2-5. Stock solutions for in vitro calibration of fura-4F

\begin{tabular}{|c|c|}
\hline Stock solution & Concentration (mM) \\
\hline $\mathrm{CaCl}_{2}$ & 50 and 100 \\
\hline $\mathrm{K}_{2}$-EGTA & 100 \\
\hline $\mathrm{K}_{2}$ - HEDTA & 100 \\
\hline
\end{tabular}

Table 2-6. Example of the calibration solutions for fura-4F

\begin{tabular}{|c|c|c|c|c|c|c|c|c|}
\hline Solution & $K_{2}-\mathbf{H I}$ & DTA & & $\mathrm{aCl}_{2}$ & dd- $\mathrm{H}_{2} \mathrm{O}$ & $\begin{array}{c}\text { K-gluc. } \\
(2 \times)\end{array}$ & $\begin{array}{c}\mathrm{K}_{2^{-}} \\
\text {EGTA }\end{array}$ & $\begin{array}{c}\text { pH } \\
\text { adjusted }\end{array}$ \\
\hline$\left[\mathrm{CaCl}_{2}\right]_{\text {free }}$ & $\begin{array}{l}\mathrm{c}_{\text {total }} \\
{[\mathrm{mM}]}\end{array}$ & $\begin{array}{l}\mathrm{V}_{\text {add }} \\
{[\mu \mathrm{l}]}\end{array}$ & $\begin{array}{c}\mathrm{c}_{\text {total }} \\
{[\mathrm{mM}]}\end{array}$ & $\begin{array}{c}\mathrm{V}_{\text {add }} \\
{[\mu \mathrm{l}]} \\
\text { (mM stock) }\end{array}$ & $\begin{array}{l}\mathrm{V}_{\text {add }} \\
{[\mu \mathrm{l}]}\end{array}$ & $\begin{array}{l}\mathrm{V}_{\text {add }} \\
{[\mu \mathrm{l}]}\end{array}$ & $\begin{array}{c}\mathrm{V}_{\text {add }} \\
{[\mu \mathrm{l}]} \\
\text { (mM stock) }\end{array}$ & \\
\hline $\begin{array}{l}0 \mu \mathrm{M} \\
\left(\mathrm{R}_{\min }\right)\end{array}$ & - & - & - & - & 120 & 150 & $\begin{array}{c}30 \\
(50)\end{array}$ & 7.24 \\
\hline $0.51 \mu \mathrm{M}$ & 10 & 30 & 1 & $6(50)$ & 109.2 & 150 & - & 7.23 \\
\hline $1.04 \mu \mathrm{M}$ & 10 & 30 & 1.8 & $\begin{array}{l}10.8 \\
(50)\end{array}$ & 108.9 & 150 & - & 7.22 \\
\hline $3.07 \mu \mathrm{M}$ & 10 & 30 & 3.7 & $\begin{array}{c}11.1 \\
(100)\end{array}$ & 114 & 150 & - & 7.21 \\
\hline $\begin{array}{l}10 \mathrm{mM} \\
\left(\mathrm{R}_{\max }\right)\end{array}$ & - & - & 10 & $30(100)$ & 120 & 150 & - & 7.2 \\
\hline
\end{tabular}

Calculations of the calibration solutions were done for the total volume of $\mathrm{V}_{\text {total }}=$ $300 \mu \mathrm{L}$. Solutions of $\mathrm{HCl}(0.01$ or $1 \mathrm{M})$ and $\mathrm{KOH}(0.01$ or $1 \mathrm{M})$ were used to adjust the $\mathrm{pH}$ 
to $~ 7.2$. Fluorescent $\mathrm{Ca}^{2+}$ indicator fura- $4 \mathrm{~F}$ was used at nominal final concentration of 100 $\mu \mathrm{M}$.
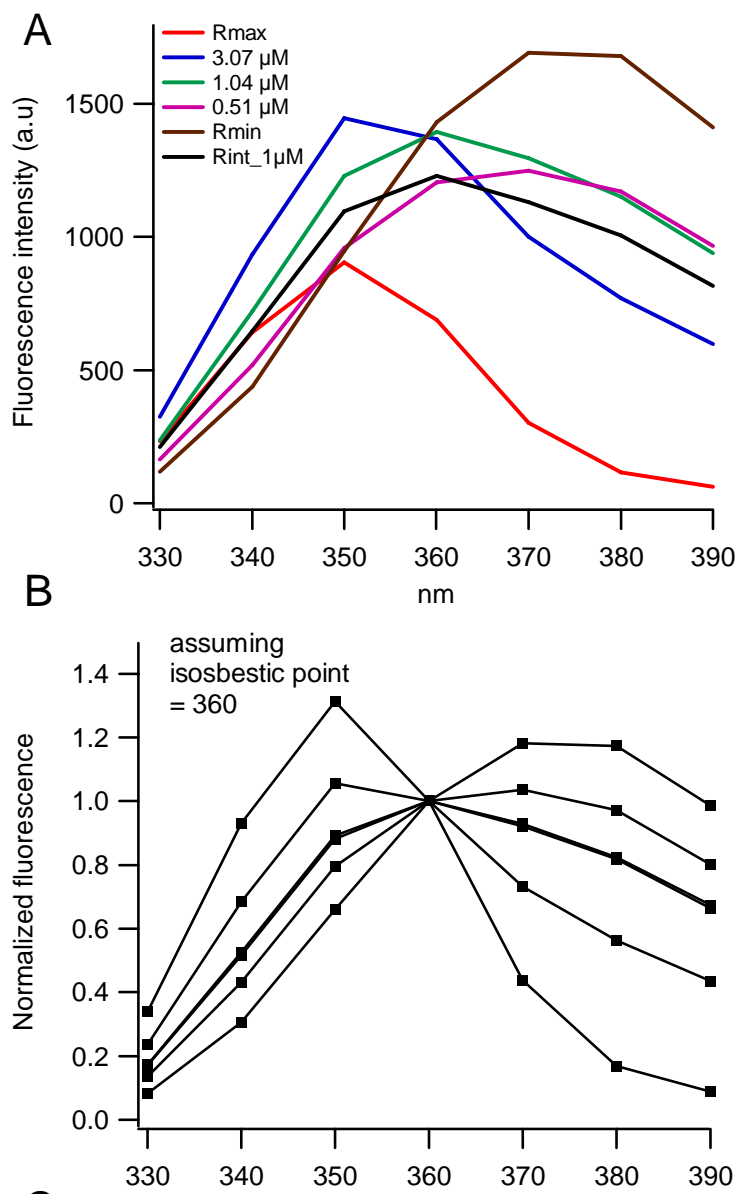

C

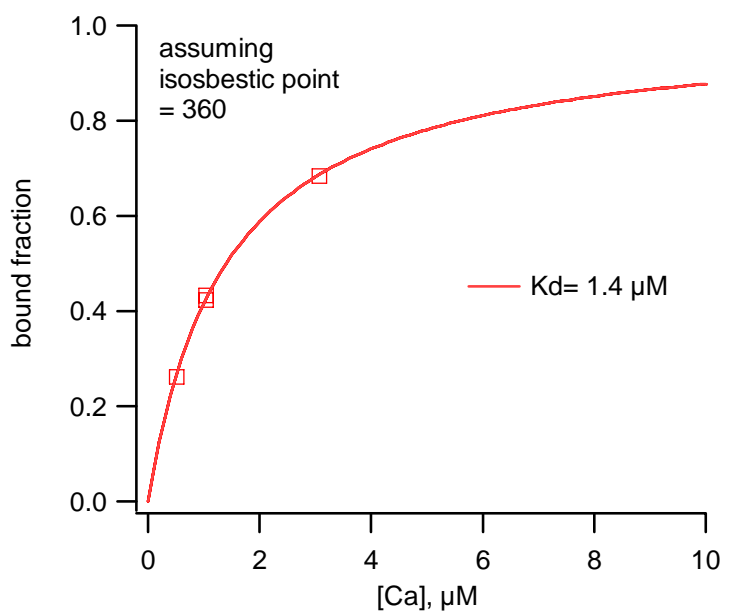

Figure 2-4. In vitro calcium calibration. $A$, Fluorescence spectra of fura-4F at five different $\mathrm{Ca}^{2+}$ concentrations, obtained from fluorescence intensity measurements of the calibration solutions at wavelength ranging from 330 to $390 \mathrm{~nm} B$, The same fluorescence spectra as in $A$, but normalized to the isosbestic point that corresponds to excitation wavelength $360 \mathrm{~nm}$. $C$, Estimation of the fura- $4 \mathrm{~F} \mathrm{~K}_{\mathrm{D}}$, obtained from Michaelis- Menten fitting of the $\mathrm{Ca}^{2+}$-bound fraction of fura- $4 \mathrm{~F}$ for each free calcium concentration. 
Each calibration solution was filled into a small quartz glass cuvette (path length 50 $\mu \mathrm{m})$. The fluorescence intensities of each calibration solution (Table 2-6) were measured at excitation wavelength ranging from 330 to $390 \mathrm{~nm}$ with steps of $10 \mathrm{~nm}$. The background-corrected absolute and normalized fluorescence spectra of these solutions are shown in the Fig. 2-4A and Fig. 2-4B, respectively. Spectra were normalized to fluorescence intensity at the isosbestic point that corresponds to a single wavelength, at which the excitation efficiency of the dye molecules does not depend on the concentration of $\mathrm{Ca}^{2+}$ (in Fig. 2-4A this corresponds to the fluorescence intensity at excitation wavelength of $360 \mathrm{~nm}$, at which most of the calibration curves intersect). The $K_{D}$ of fura$4 \mathrm{~F}$ was obtained from the Michaelis-Menten fit of the $\mathrm{Ca}^{2+}$-bound fractions of fura-4F for each free $\left[\mathrm{Ca}^{2+}\right]$, which were calculated from the normalized fluorescence spectra as described in (Schneggenburger, 2004) (Fig. 2-4C).

\section{In vivo calcium calibration}

Based on the previous experience, a possible difference between in vitro and in vivo calibrations should become apparent in the estimation of $\mathrm{R}_{\min }$. Therefore, we restricted the in vivo calibration to $\mathrm{R}_{\min }$ and $\mathrm{R}_{1.04 \mu \mathrm{M}}$. To determine $\mathrm{R}_{\min }$, we loaded calyces with $\mathrm{R}_{\min }$ calibration solution (Table 2-6), made ratiometric measurements at 350/380 nm and averaged this ratios over the recording time. The final $R_{\min }$ value used in the equation (1) was obtained by averaging $R_{\min }$ values, measured in five cells. $R_{\max }$ values were obtained from in vitro measurements, because calyces of Held did not endure internal dialysis with high $\mathrm{CaCl}_{2}(10 \mathrm{mM})$. The $\mathrm{K}_{\text {eff }}$ was estimated by measuring the average fluorescence ratio $\mathrm{R}$ at an intermediate $\mathrm{Ca}^{2+}$ concentration $\left(1.04 \mu \mathrm{M}\right.$, which should be close to the $\mathrm{K}_{\mathrm{D}}$ of fura-4F) from the different cells and rearranging Equation (1) for $\mathrm{K}_{\mathrm{eff}}$. Loading of the cells with this $\mathrm{Ca}^{2+}$ concentration will induce $\mathrm{Ca}^{2+}$ extrusion mechanisms (via various

$\mathrm{Na}^{+}-\mathrm{Ca}^{2+}$ exchangers), which can cause a wrong $\mathrm{R}_{1.04 \mu \mathrm{M}}$ estimation. For the $\mathrm{R}_{1.04 \mu \mathrm{M}}$ in vivo calibration, we, therefore, decreased the activity of $\mathrm{Na}^{+}-\mathrm{Ca}^{2+}$-exchangers by using $\mathrm{Na}^{+}$-free extracellular recording solution, which was prepared by substituting $\mathrm{NaCl}$, $\mathrm{NaHCO}_{3}$ and $\mathrm{NaH}_{2} \mathrm{PO}_{4}$ with equimolar amounts (150 mM, Table 2-7) of $N$-methyl-Dglucamine (NMDG). The $\mathrm{pH}$ was adjusted to 7.4 with $\mathrm{HCl}$. 
Table 2-7. Extracellular solution for in vivo $R_{1.04 \mu \mathrm{M}}$ calibration $\left(V_{\text {total }}=200 \mathrm{~mL}\right)$

\begin{tabular}{|c|c|c|c|}
\hline Solution & MW [g/mol] & Amount to add & $\begin{array}{c}\text { Concentration } \\
\text { [mM] }\end{array}$ \\
\hline $\mathrm{K}_{2}$-HEDTA & 278.26 & $\begin{array}{c}2 \mathrm{~mL} \\
(100 \mathrm{mM} \text { stock })\end{array}$ & 1 \\
\hline $\mathrm{CaCl}_{2}$ & 110.99 & $\begin{array}{c}1.36 \mathrm{~mL} \\
(50 \mathrm{mM} \text { stock })\end{array}$ & 0.34 \\
\hline $\mathrm{NaCl}$ & 58.44 & $0.1169 \mathrm{~g}$ & 10 \\
\hline $\mathrm{KCl}$ & 74.55 & $0.0373 \mathrm{~g}$ & 15 \\
\hline $\mathrm{HEPES}$ & 238.3 & $0.7149 \mathrm{~g}$ & 150 \\
\hline $\mathrm{NMDG}$ & 195.2 & $5.5437 \mathrm{~g}$ & \\
\hline $\mathrm{HCl}$ to adjust $\mathrm{pH}=7.4$ & & $28.4 \mathrm{~mL}$ & $(1 \mathrm{M} \mathrm{stock})$ \\
\hline
\end{tabular}

\subsection{Data analysis}

Data analysis carried out in IgorPro 4.09 (WaveMetrics, Lake Oswego, OR). PTP was standardly expressed as the relative EPSC amplitude at the time of peak PTP, according to the following equation: $\mathrm{PTP}=\left(\mathrm{EPSC}_{\mathrm{PTP}} / \mathrm{EPSC}_{\text {control }}\right) \times 100$. This corresponds to the following relationship: $\mathrm{PTP}=(p / b) \times 100$ (Fig. 3-4B). In Figure 3-4D, the absolute increment of EPSC amplitude during the peak of PTP was analyzed, which corresponds to the amplitude value $i$ in Figure 3-4B. The control EPSC amplitude was determined individually for each PTP induction, by averaging the second (or sometimes third) up to the fifth EPSC-amplitude preceding the $100 \mathrm{~Hz}$ train. The first one or two EPSCs were not included in the analysis, because these EPSCs were often larger than the subsequent ones, indicating that some cumulative depression occurred even at the low frequency $(0.1$ $\mathrm{Hz}$ ) at which the control EPSCs were elicited (von Gersdorff et al., 1997). The decay times of PTP and residual $\left[\mathrm{Ca}^{2+}\right]_{\mathrm{i}}$ were estimated by fits with single-exponential functions. For these fits, the baseline values were constrained to the average of the last three or four data points in each series. Average data are reported as mean $\pm \mathrm{SEM}$, with the exception of the plots in Figures $3-3 D$ and 3-7, which show mean \pm SD values. Statistical significance was evaluated with Student's $t$ test, unless otherwise noted. 


\section{RESULTS}

\subsection{Identification of posttetanic potentiation at the calyx of Held}

The aim of this work was to study activity-dependent longer-lasting forms of synaptic potentiation at the calyx of Held, which could play a potential role in the development of this synapse.

Figure 3-1A-C shows an experiment designed to test whether brief trains of $100 \mathrm{~Hz}$ stimulation induce long-lasting potentiation at the calyx of Held. In these experiments, we first assessed baseline synaptic strength with double stimuli (inter-stimulus interval, 10 $\mathrm{ms}$ ), repeated five times every $10 \mathrm{~s}$ (Fig. 3-1A). Subsequently, a $100 \mathrm{~Hz}$ train of $4 \mathrm{~s}$ duration was applied (Fig. 3-1B). Thereafter, the double stimuli were resumed at $0.1 \mathrm{~Hz}$, to probe the development of synaptic strength (Fig. 3-1C). During the $100 \mathrm{~Hz}$ train, EPSCs strongly depressed (Fig. 3-1B, top). The EPSC amplitudes at the end of the 100 $\mathrm{Hz}$ train were depressed to $2.8 \pm 0.8 \%$ ( $n=6$ cells) of the control EPSC amplitude. The earliest EPSCs after the $100 \mathrm{~Hz}$ train, corresponding to the light gray traces in Figure 3$1 C$, were still depressed, but later EPSCs recovered from depression and then showed a marked, approximately twofold overshoot in amplitude at $\sim 20-30 \mathrm{~s}$ after the $100 \mathrm{~Hz}$ train. Thereafter, synaptic strength returned to baseline over the next 8-10 stimuli. Figure 3-1D shows the corresponding plot of the first and second EPSC amplitude before and after the $100 \mathrm{~Hz}$ train. The transient potentiation of the first EPSC amplitude is reminiscent of PTP, which has been described at the neuromuscular junction (Magleby and Zengel, 1975) at crayfish neuromuscular synapses (Delaney et al., 1989), and at hippocampal synapses (McNaughton, 1982; Griffith, 1990).

During the peak of PTP, the first EPSC was potentiated to $202 \pm 31 \%$ of the baseline value ( $n=8$ cells; $4 \mathrm{~s}$ induction train; P4-P6), whereas the second EPSC, at the time of the maximal potentiation of the first EPSC, was decreased to $73 \pm 11 \%$ of its corresponding control value $(n=8$ cells) (Fig. $3-1 D, H)$. Thus, the paired-pulse ratio (EPSC2/EPSC1) was decreased at the peak of the EPSC potentiation (Fig. 3-1I), indicative of a presynaptic mechanism for PTP. Additional support for a presynaptic mechanism is given by the observation that immediately after the $100 \mathrm{~Hz}$ train, the frequency of mEPSCs was strongly increased (Fig. 3-1B, middle, $G$ ), whereas the amplitude distributions of mEPSCs were unchanged (Fig. 3-1E,F). In addition, the 


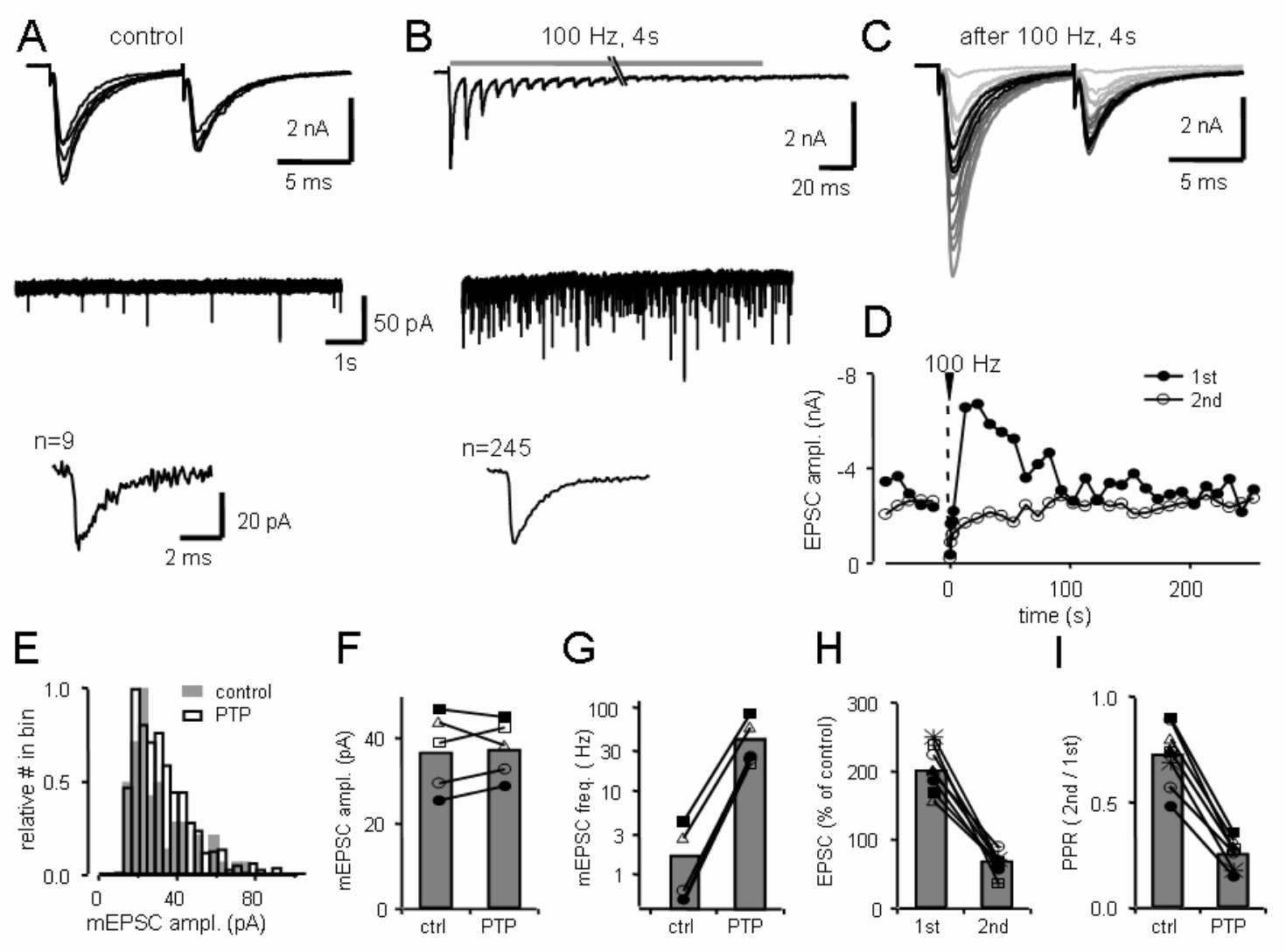

Figure 3-1. Posttetanic potentiation at the calyx of Held. A, Top, EPSCs in response to a pair of fiber stimulations separated by $10 \mathrm{~ms}$, repeated every $10 \mathrm{~s}$. The middle panel shows a $9.6 \mathrm{~s}$ stretch of postsynaptic current, and the bottom panel shows the average trace of $\mathrm{n}=9$ detected mEPSCs. $B$, EPSC in response to a $4 \mathrm{~s}, 100 \mathrm{~Hz}$ train of afferent fiber stimulation, applied $10 \mathrm{~s}$ after the last control EPSC shown in $A$. Only the first and the last 10 EPSCs in the train are shown, and the stimulation artifacts have been blanked for clarity. The middle panel shows a postsynaptic current record, starting $3.7 \mathrm{~s}$ after the end of the $100 \mathrm{~Hz}$ train. Note the strongly increased frequency of mEPSCs throughout the entire record. The bottom panel shows the average trace of all detected mEPSCs from this sweep $(\mathrm{n}=245) . C$, EPSCs in response to a pair of stimuli repeated every $10 \mathrm{~s}$ after the $100 \mathrm{~Hz}$ train. The traces are grayscale coded, with the earliest traces after the $100 \mathrm{~Hz}$ train shown in light gray. $D$, Time course of EPSC amplitudes for the experiment shown in $A-C$. Filled and open circles represent amplitudes of the first and second EPSC, respectively. Note the transient overshoot of the first EPSC amplitude. E, mEPSC amplitude distribution for the control period (hatched bars) and for a period of $30 \mathrm{~s}$ after the $100 \mathrm{~Hz}$ train (open bars), corresponding to the time of development of maximal PTP. The mean mEPSC amplitudes were 30 and $33 \mathrm{pA}$ for control and PTP, respectively. The data in $A-E$ are from a recording in a $\mathrm{P} 7$ rat. $F$, Mean of the mEPSC amplitude distributions, plotted for individual cells for control conditions and after induction of PTP. G, Mean mEPSC frequencies (freq.) derived from individual cells before and after PTP induction. Note the strong increase in mEPSC frequency after the $100 \mathrm{~Hz}$ train. $\mathrm{H}$, Maximal potentiation of the first and second EPSC amplitude for $\mathrm{n}=8$ cells. $I$, Paired-pulse ratio (EPSC2/EPSC1) for the control period and during maximal potentiation of the EPSCs. The data shown in $F-I$ were obtained from recordings in $\mathrm{P} 4-\mathrm{P} 7$ rats. 
finding that PTP was absent during whole-cell recording of a presynaptic calyx (see below, Fig. 3-10) also indicates that PTP at the calyx of Held has a presynaptic origin, similar to that at other synapses (Zucker and Regehr, 2002).

Thus, although we initially looked for long-lasting potentiation (LTP), we found a very prominent posttetanic potentiation (PTP) of EPSCs. After PTP decayed, we did not find evidence for an additional component of potentiation. These experiments, however, were done under postsynaptic voltage-clamp conditions and we cannot exclude at present that with postsynaptic current-clump recordings, which would have allowed the activation of postsynaptic NMDA receptors, a longer-lasting form of potentiation, like short-term potentiation (STP) (Malinow and Tsien, 1990; Malinow and Mainen, 1996; Wu et al., 1996) or LTP would have been uncovered (see Discussion). However, since longerlasting forms of potentiation, including PTP and augmentation, were not known before at the calyx of Held, we decided to characterize PTP in more detail, and to study its underlying presynaptic mechanisms.

We next investigated how the amplitude and the time course of PTP depended on the duration of the induction trains (Fig. 3-2). PTP was induced repetitively in a given cell, with varying lengths of the $100 \mathrm{~Hz}$ trains. We found that the amplitude, as well as the duration of PTP, increased after prolonging the $100 \mathrm{~Hz}$ induction trains. In the example of Figure 3-2A, a short $100 \mathrm{~Hz}$ train of $0.2 \mathrm{~s}$ duration induced noticeable PTP of $150 \%$ of control, which, on average, was $136 \pm 6.6 \%$ for the age group of P4-P6 $(n=10$ cells) (Fig. 3-2B). Prolonging the $100 \mathrm{~Hz}$ induction trains led to larger PTP with slowed decay time constants (Fig. 3-2B,C). When the length of the induction trains was prolonged beyond $1 \mathrm{~s}$, the amplitude of PTP was not further increased ( $p>0.5$ for all pair wise comparisons between 2, 4, and $8 \mathrm{~s}$ trains), suggesting that PTP was maximal for induction trains of $2 \mathrm{~s}$ or longer.

\subsection{Developmental regulation of posttetanic potentiation}

The data presented in Figures 3-1 and 3-2 were obtained from the calyx of Held synapses from young rats (P4 -P6). It is known, however, that the functional properties of transmission at the calyx of Held undergo pronounced developmental changes before and after the onset of hearing around P12 in rodents (Taschenberger and von Gersdorff, 2000; Iwasaki and Takahashi, 2001; Joshi and Wang, 2002). To investigate whether the 
properties of PTP might change during postnatal development, we studied PTP in two older age groups, at P8-P10 and at P12-P14 (Fig. 3-3).

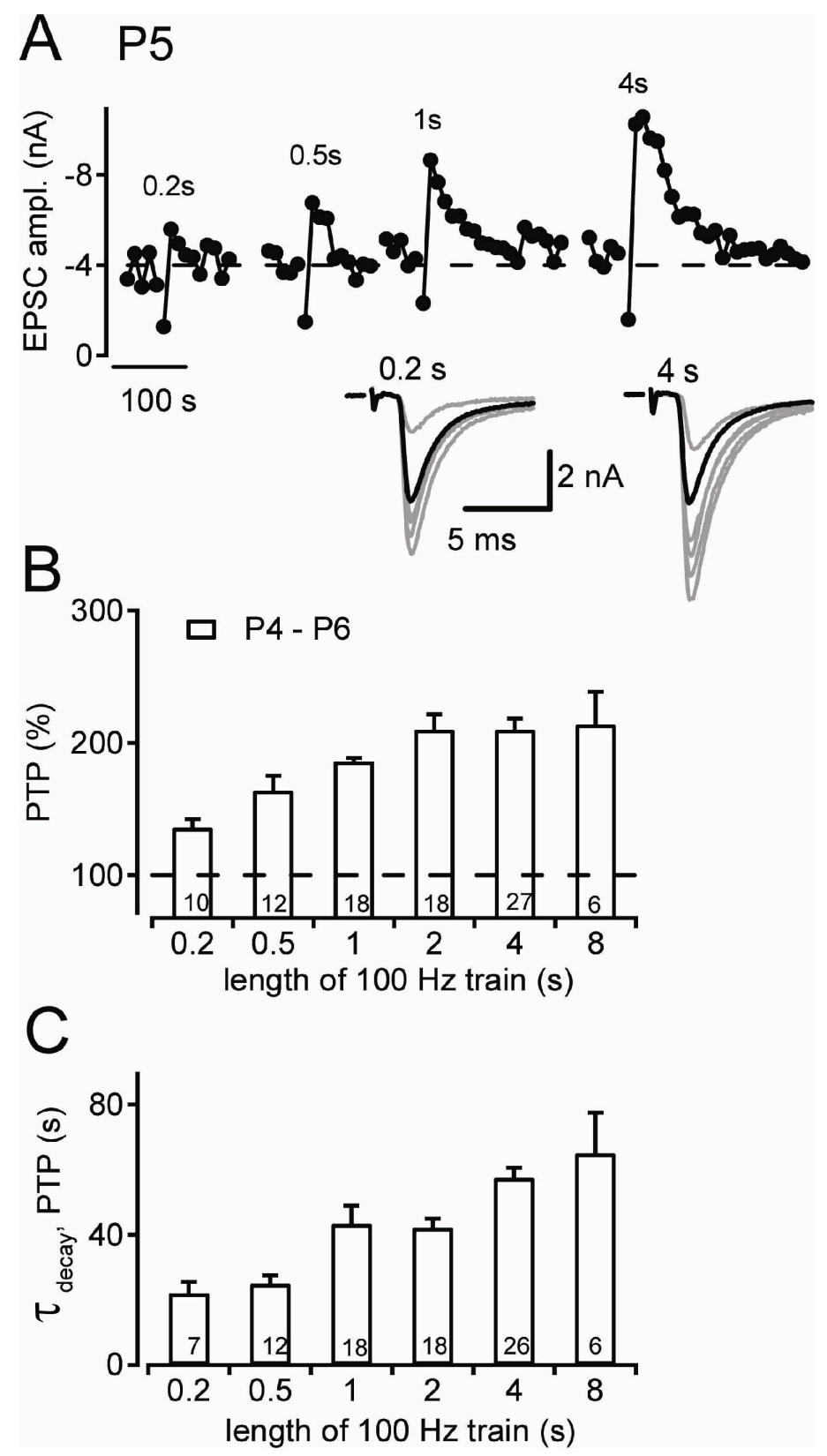

Figure 3-2. Dependence of PTP amplitude and duration on the length of $100 \mathrm{~Hz}$ induction train. $A$, An experiment at P5, in which PTP was induced several times as in Fig.3-1. The lengths of the $100 \mathrm{~Hz}$ induction trains are indicated. The traces at the bottom are the averaged control EPSCs before induction (black trace; $\mathrm{n}=5$ ) and the first 10 EPSCs after the induction of PTP (light grey). $B$, Normalized amplitude of PTP as a function of the length of the $100 \mathrm{~Hz}$ induction train for the age group of P4 -P6. The number of cells investigated is indicated for each bar. $C$, Dependence of the decay time constant of PTP, estimated from fitting the decay phase of PTP with single-exponential functions, as a function of the length of the 100 $\mathrm{Hz}$ induction train. Error bars represent SEM. 

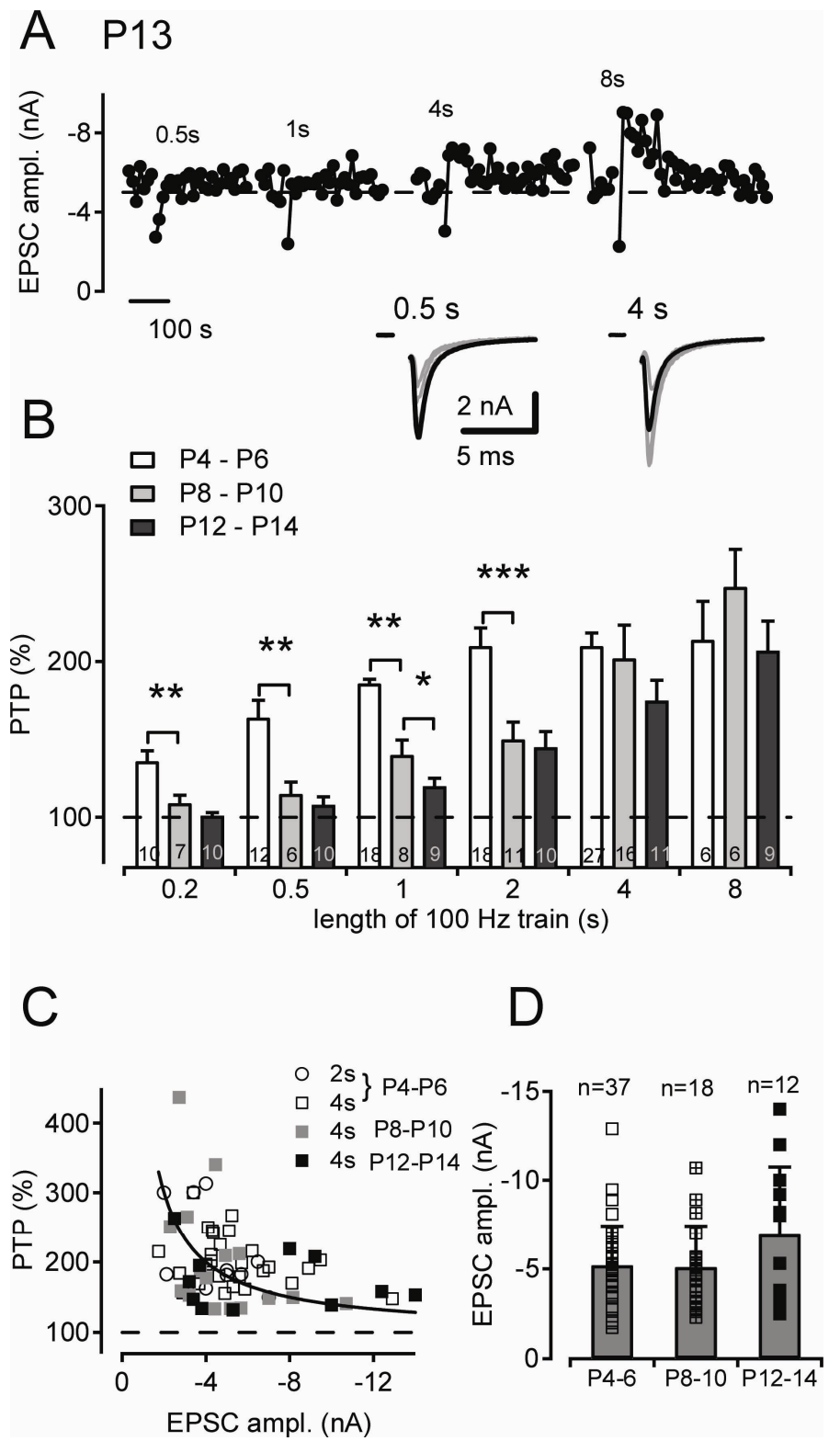

Figure 3-3. Developmental regulation of PTP at the calyx of Held. A, An experiment at P13, in which PTP was induced with $100 \mathrm{~Hz}$ trains of indicated lengths. Note that the shorter $100 \mathrm{~Hz}$ trains $(0.5 \mathrm{~s}, 1 \mathrm{~s})$ did not induce notable PTP in this cell. The inset shows sample traces for the 0.5 and $4 \mathrm{~s}$ induction trains. $B$, Amplitude of PTP as a function of the length of the $100 \mathrm{~Hz}$ induction train, separated for the age groups of P4 -P6 (open bars; replotted from Fig. 3-2B), P8 -P10 (gray bars), and P12-P14 (black bars). Note that the short $100 \mathrm{~Hz}$ trains of $0.2-2 \mathrm{~s}$ induced significantly larger PTP at P4 -P6 than in the older age groups. Asterisks indicate a significant statistical difference determined in pair wise comparisons $\left({ }^{*} \mathrm{p}<0.05 ;{ }^{* *} \mathrm{p}<\right.$ $0.01 ;{ }^{* * *} \mathrm{p}<0.001$; unpaired $\mathrm{t}$ test). Error bars represent SEM. $C$, Scatter plot of PTP amplitude as a function of the control EPSC amplitude. For the data obtained at P4-P6, results from 2 and 4 s induction trains are shown, whereas in the older age groups, only $4 \mathrm{~s}$ induction trains were analyzed, with the meaning of each symbol as indicated. The data set was fitted by an inverse function. Note the tendency toward smaller PTP for initially large EPSCs. D, Plot of average control EPSC amplitudes from individual cells for each age group. The average \pm SD of each data set is shown superimposed. 
At these later developmental stages, we also observed PTP, but longer induction trains were needed to obtain PTP with similar amplitudes as in younger animals. In the example of Figure 3-3A, a recording from a P13 animal is shown. Note that $100 \mathrm{~Hz}$ trains with 0.5 and $1 \mathrm{~s}$ durations did not induce noticeable PTP at this developmental stage, but PTP was induced by longer induction trains.

Figure 3-3B plots the average PTP amplitude as a function of the length of the induction train for all three age groups investigated here. In the older age groups (P8-P10 and P12-P14), PTP in response to the short trains was significantly smaller as compared to PTP at P4-P6 (0.2-2 s; $p<0.01$ or 0.001$)$ (Fig. 3-3B). With $100 \mathrm{~Hz}$ induction trains of 4 and $8 \mathrm{~s}$, however, PTP was not significantly different between the age groups $(p>0.5$ for all comparisons). Thus, the maximal amount of PTP was not changed during development, but longer $100 \mathrm{~Hz}$ trains were needed in the older animals to induce a given amount of PTP. This data show that the threshold for PTP induction is lower for synapses at P4-P6 compared with the older age groups investigated here (P8-P10 and P12-P14).

In Figure 3-3C, we plotted the amplitude of PTP in response to $4 \mathrm{~s}$ induction trains (or $2 \mathrm{~s}$ in some cases) as a function of the control EPSC amplitude in each cell. We found that PTP tended to be smaller in cells with large control EPSC amplitudes, indicating that some presynaptic or postsynaptic resource might become limiting for the full expression of PTP, when the initial EPSC amplitude is large. In agreement with previous findings (Taschenberger and von Gersdorff, 2000), we found that the average EPSC amplitudes were not different between P4 and P14 ( $p>0.1$ ), although the EPSC amplitudes showed a quite large scatter between individual cells (Fig. 3-3D). In the following experiments, we investigated the properties of PTP at young calyces of Held (P4 -P6), except for the results in Figure 3-10, in which P8-P10 rats were used.

To summarize, from these results we conclude that PTP is also expressed at mature synapses, although interestingly, the threshold for inducing PTP is lower in young animals. Since PTP depends on an elevation of $\mathrm{Ca}^{2+}$ in the nerve terminal (see below), it is possible that the higher threshold for PTP induction in more mature animals represents increased presynaptic $\mathrm{Ca}^{2+}$-buffering and $\mathrm{Ca}^{2+}$-extrusion in more mature animals (see Discussion). Because PTP was not described previously at the calyx of Held, we decided to investigate PTP further at young calyces (P4-P6), where plasticity was more prominent. 


\subsection{Presynaptic $\mathrm{Ca}^{2+}$ requirements for PTP}

\subsubsection{The Effect of EGTA-AM on PTP}

To investigate whether PTP at the calyx of Held depends on a presynaptic $\left[\mathrm{Ca}^{2+}\right]_{\mathrm{i}}$ increase, we tested whether PTP is sensitive to the membrane-permeable $\mathrm{Ca}^{2+}$ chelator EGTA-AM (Fig. 3-4). EGTA-AM enters the terminals by uptake and "trapping". EGTA accumulates intracellularly following the cleavage of the AM-ester by unspecific esterases (Cummings et al., 1996) and due to this accumulation the intracellular free EGTA concentration is probably higher than the bath concentration of EGTA-AM. PTP was induced by $100 \mathrm{~Hz}$ trains of 4 and $1 \mathrm{~s}$ duration applied in an alternating sequence (Fig. 3-4A). After establishing control PTP for each induction length, $200 \mu \mathrm{M}$ EGTA-AM was applied to the bath. Shortly after the start of EGTA-AM application, the baseline synaptic strength decreased, and it continued to decrease for $>900 \mathrm{~s}$ (Fig. 3-4A), indicating the continued accumulation of cytoplasmic EGTA. Concomitant with the decrease of baseline synaptic strength, PTP also decreased. This can be seen by comparing PTP under control conditions (Fig. 3-4B), with PTP induced 27 min after the start of the EGTA-AM application (Fig. 3-4C).

In these experiments, we analyzed the baseline synaptic strength, which corresponds to the amplitude value $b$ in Figure 3-4B, the absolute amount of PTP, which corresponds to the amplitude value $i$, and the relative PTP, given by $(p / b) \times 100$ (Fig. 3-4B) (see Methods, "Data analysis" section). Figure 3-4D plots the average EPSC amplitude and absolute PTP before and during the continuous application of $200 \mu \mathrm{M}$ EGTA-AM $(n=6$ cells). Baseline synaptic strength was reduced from a control value of $4.4 \pm 0.3$ to $0.7 \pm$ $0.1 \mathrm{nA}$, as analyzed from the baseline EPSC amplitudes averaged from the 10th, 11th, and 12th induction (Fig. 3-4D, bracket), corresponding to a time of $>20$ min after the start of EGTA-AM application. The suppression of baseline synaptic strength by EGTA is consistent with previous findings at the calyx of Held (Borst and Sakmann, 1996; Fedchyshyn and Wang, 2005). In parallel with the decrease in baseline synaptic strength, the absolute PTP decreased both for $4 \mathrm{~s}$ and $1 \mathrm{~s}$ induction trains (Fig. 3-4D, open and filled symbols). The relative PTP (Figure 3-4E, open and closed symbols) decreased faster for $1 \mathrm{~s}$ induction trains as compared to the $4 \mathrm{~s}$ trains. This differential onset of the effect of EGTA-AM was probably a consequence of the larger $\mathrm{Ca}^{2+}$ influx caused by the longer induction trains. It is likely that the approximately four-fold larger $\mathrm{Ca}^{2+}$ influx 
during the $4 \mathrm{~s}$ trains saturated the intracellular EGTA, as long as the intracellular concentration of EGTA had not reached a critical value.
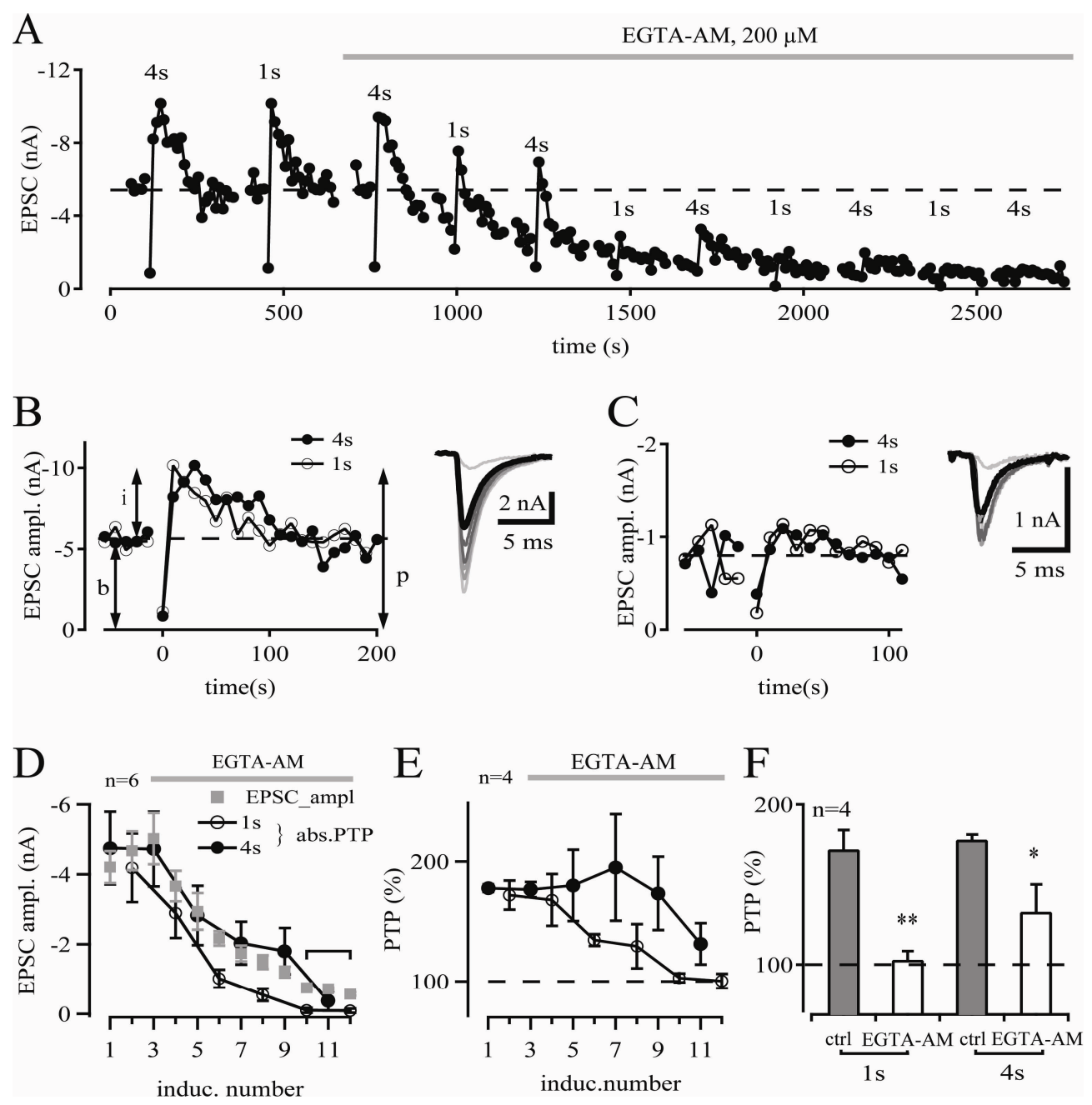

Figure 3-4. PTP and baseline synaptic strength are strongly reduced by the slow $\mathrm{Ca}^{2+}$ buffer EGTA. A, Plot of EPSC amplitudes versus time in an experiment in which PTP was induced with $100 \mathrm{~Hz}$ trains of 1 and 4 $\mathrm{s}$ in an alternating sequence. EGTA-AM $(200 \mu \mathrm{M})$ was applied at the indicated time. $B$, EPSC amplitudes during PTP in response to 1 and $4 \mathrm{~s} 100 \mathrm{~Hz}$ trains under control conditions. The amplitude values $b$, i, and $\mathrm{p}$ were used to calculate absolute and relative PTP in $D$ and $E$. The traces on the right show the average EPSC before (black trace) and single EPSCs after (gray traces) PTP induction with a $1 \mathrm{~s} 100 \mathrm{~Hz}$ train. $C$, Same as $B$, but taken $27 \mathrm{~min}$ after the onset of the EGTA-AM application. $D$, Time plot of the average EPSC amplitude (gray symbol) and the absolute. PTP (corresponding to the amplitude value i in $B$ ). Open and filled symbols are absolute PTP for 1 and $4 \mathrm{~s}$ induction trains, respectively. The data are from $\mathrm{n}=6$ cells except the last three data points ( $\mathrm{n}=4$ cells). $E$, Plot of the relative PTP, calculated according to $(\mathrm{p} / \mathrm{b}) \times 100$ (see $B$ ). Open and filled symbols are for 1 and $4 \mathrm{~s}$ induction trains, respectively. Average data from $\mathrm{n}=4$ cells. $F$, Relative PTP in control conditions (gray bars) and after prolonged ( $>30 \mathrm{~min}$ ) application of EGTA-AM (open bars). Asterisks indicate statistical significance ( ${ }^{*} \mathrm{p}<0.05$; ${ }^{* *} \mathrm{p}<0.01$; paired t-test). Error bars represent SEM. The data shown in this figure were obtained from P4 -P6 rats. 
In Figure $3-4 F$, relative PTP is plotted for control conditions (gray bars) and after application of EGTA-AM for $n=4$ cells that could be recorded for $>30$ min after the application of $200 \mu \mathrm{M}$ EGTA-AM. Prolonged bath application of EGTA-AM led to a significant reduction of PTP for both lengths of induction trains $(p=0.009$ and 0.048 for 1 and $4 \mathrm{~s}$ trains) (Fig. 3-4F).

We also observed an interesting effect of EGTA-AM on synaptic transmission during the $100 \mathrm{~Hz}$ trains used to induce PTP. In Fig. 3-5A and 3-5B typical examples of 1 s, $100 \mathrm{~Hz}$ stimulation trains are shown for the control condition and during EGTA-AM application, respectively. As was described above, application of EGTA-AM caused a large reduction in the size of the baseline transmission (Fig. 3-4A), which is reflected here as the reduced amplitude of the $1^{\text {st }}$ EPSC in train (Fig. 3-5B) Interestingly, the depression of EPSCs, which is usually observed at the calyx of Held during repetitive stimulation, was also reduced. To quantitatively estimate EPSC depression, we analyzed the first 50 stimuli during HFS trains. EPSC amplitudes and cumulative EPSC amplitudes were plotted versus time as shown in Fig.3-5C (control in black, EGTA-AM in red) and 3-5D, correspondingly. The lines were fitted to the region of cumulative EPSC amplitudes for times in the middle $\left(25^{\text {th }}-50^{\text {th }}\right.$ stimuli) of $1 \mathrm{~s} 100 \mathrm{~Hz}$ train and back-extrapolated to time 0 (Fig.3-5D). The slope of the lines indicated the amplitude of phasic EPSCs averaged over the corresponding time interval. Average data are summarized in Fig. $3-5 E$ and $3-5 F$. All EPSC amplitudes were normalized to the peak amplitude of the first EPSC in the control 1 s $100 \mathrm{~Hz}$ train (Fig.3-5A). EGTA-AM application decreased the baseline transmission on average to $44 \pm 4 \%$ (mean \pm SEM; $\mathrm{p}<0.001, \mathrm{n}=6$ paired $t$-test; Fig.3$5 E)$. In Fig. $3-5 F$ we compared the average EPSC peak-amplitude normalized to the $1^{\text {st }}$ EPSC in the absence of EGTA both for control (black bars) and for EGTA-AM (open bars). We found that incubation of the slices with EGTA-AM led to a significantly higher $(\mathrm{p}<0.01$, paired $t$-test; $\mathrm{n}=6)$ steady-state of the phasic release $\left(5.4 \pm 0.6 \%\right.$ for $25^{\text {th }}-50^{\text {th }}$ stimuli (Fig. 3-5F, left pair of bars); $4.6 \pm 0.7 \%$ for $75^{\text {th }}-100^{\text {th }}$ stimuli (Fig. 3-5F, right pair of bars) $)$ in contrast to the control conditions $(2.5 \pm 0.5 \%$ and $2.1 \pm 0.4 \%$, correspondingly). Thus, surprisingly, EGTA increased the absolute EPSC amplitude during the steady-state phase of depression. Since EGTA is $\mathrm{Ca}^{2+}$ buffer with a slow $\mathrm{Ca}^{2+}$ binding rate, this might imply that endogenous calcium binding proteins with slow $\mathrm{Ca}^{2+}$ binding might be advantageous to maintain phasic EPSCs during prolonged high frequency trains. 


\section{A}

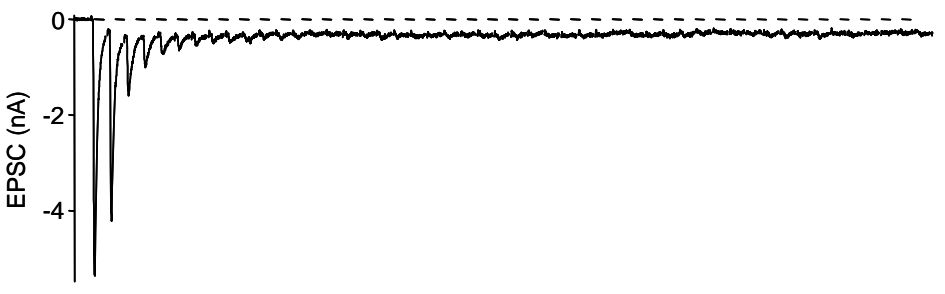

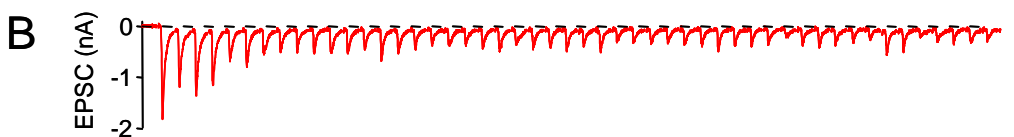

C

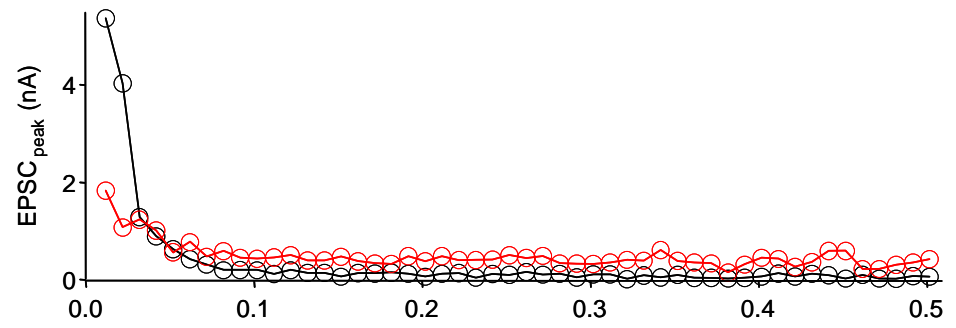

D

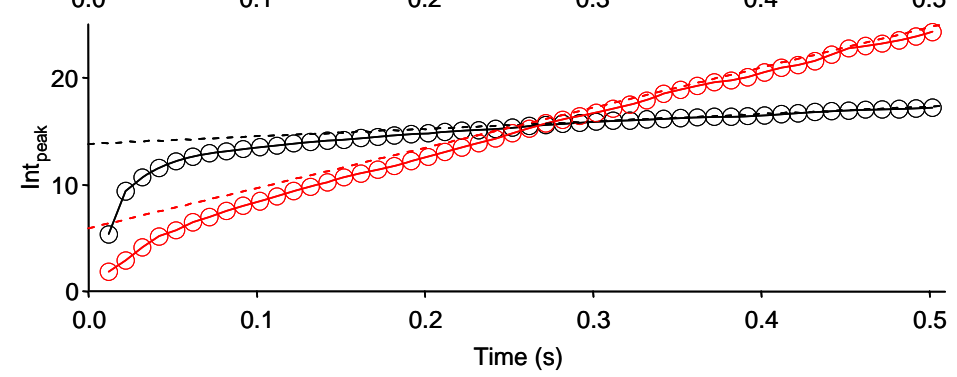

E

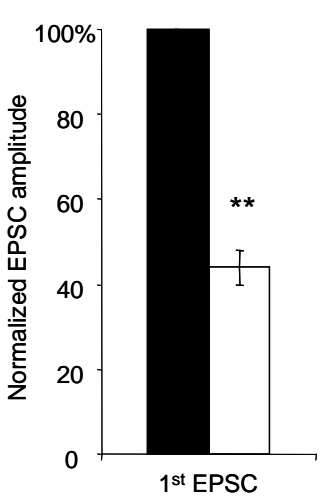

$\mathrm{F}$

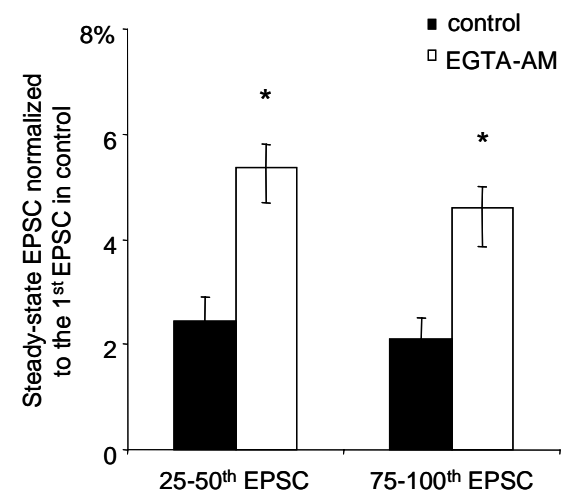

Figure 3-5. Effect of slow $\mathrm{Ca}^{2+}$ buffer EGTA on the depression during PTP induction train. In $A$ and $B$, responses of a cell, presented in Fig.3-4A, are shown to the first 50 stimuli of $1 \mathrm{~s} 100 \mathrm{~Hz}$ train in the control conditions (2nd induction, Fig.3-4A) and during EGTA-AM application (6th induction), correspondingly. $C$, Analysis of peak EPSC amplitudes, shown in $A$ and $B$. D, Peak EPSC amplitudes were integrated to give a plot of cumulative EPSC amplitudes. Data points were fitted by a line (dotted line) and back extrapolated to time 0 . Estimation of a steady-state depression was obtained by analyzing cumulative EPSC amplitudes in the middle (25th-50th responses) and at the end (75th -100th) of the $1 \mathrm{~s} 100 \mathrm{~Hz}$ train. $E$ and $F$, Average $(\mathrm{n}=6)$ normalized EPSC amplitudes are summarized in bar graphs for the 1st $(E), 25$ th-50th (lest bar group) and 75th-100th (right) responses $(F)$. Asterisks indicate statistical significance $\left({ }^{*} \mathrm{p}<0.01 ;{ }^{*} \mathrm{p}<0.001\right.$; paired $t$ test). Error bars represent SEM. 
In addition, we observed "standing" current, which appeared during prolonged 100 $\mathrm{Hz}$ stimulation, was also significantly suppressed by treatment with $200 \mu \mathrm{M}$ EGTA-AM (Fig.3-5A and 3-5B, see induction trains). This standing current probably represents a mixture of glutamate spillover current and asynchronous release.

Similar observations were made by Otsu and colleagues (2004) in hippocampal autaptic excitatory neurons, in which HFS led to a strong depression of the evoked release during the train and a parallel increase in asynchronous release. They proposed that depression of evoked release is attributed to depletion of the readily releasable pool (RRP) of vesicles, and that during HFS a competition occurs between asynchronous and synchronous release, with both competing release modes for newly recovered RRP vesicles. However, the ability of asynchronous release to use recently recovered quanta would slow the recovery of phasic release, because relatively few quanta would be able to accumulate within the RRP and be available for the phasic release.

\subsubsection{Presynaptic residual $\left[\mathrm{Ca}^{2+}\right]_{\mathrm{i}}$ dynamics associated with PTP}

We next aimed at imaging presynaptic $\left[\mathrm{Ca}^{2+}\right]_{\mathrm{i}}$ during and after the induction of PTP to directly visualize the $\left[\mathrm{Ca}^{2+}\right]_{\mathrm{i}}$ signal that might underlie the transmitter release potentiation during PTP. For this purpose, we initially performed presynaptic $\mathrm{Ca}^{2+}$ imaging in simultaneous presynaptic and postsynaptic whole-cell recordings. We found, however, that during presynaptic whole-cell recording, PTP was absent (see below, Fig. 3-10). We therefore used an alternative $\mathrm{Ca}^{2+}$-imaging approach, in which calyces were first loaded with fura-4F during a short whole-cell recording episode (60 - $120 \mathrm{~s}$ ), using a pipette solution containing $200 \mu \mathrm{M}$ fura-4F (see Methods). After removing the presynaptic patch pipette, a whole-cell recording of the postsynaptic cell was made with a different pipette. This allowed us to measure PTP and to image the presynaptic $\left[\mathrm{Ca}^{2+}\right]_{\mathrm{i}}$ simultaneously from the fura-4F fluorescence signal arising from the calyx (Fig. 3-6A).

We imaged $\left[\mathrm{Ca}^{2+}\right]_{\mathrm{i}}$ at low sampling rates before and after the $100 \mathrm{~Hz}$ train and at higher sampling rate during the $100 \mathrm{~Hz}$ induction train (Fig. 3-6B). In the recording shown in Figure 3-6, a $100 \mathrm{~Hz}$ train of $2 \mathrm{~s}$ duration was applied to induce PTP. During the $100 \mathrm{~Hz}$ train, presynaptic $\left[\mathrm{Ca}^{2+}\right]_{\mathrm{i}}$ rose in a biphasic manner and reached a value of $9.5 \mu \mathrm{M}$ (range, 3-10 $\mu \mathrm{M}$ between cells) shortly after the end of the $100 \mathrm{~Hz}$ train (Fig. 3-6B, inset). Thereafter, $\left[\mathrm{Ca}^{2+}\right]_{\mathrm{i}}$ dropped to $\sim 300 \mathrm{nM}$ within $0.5 \mathrm{~s}$ and then recovered much more slowly (Fig. 3-6B, arrow). 

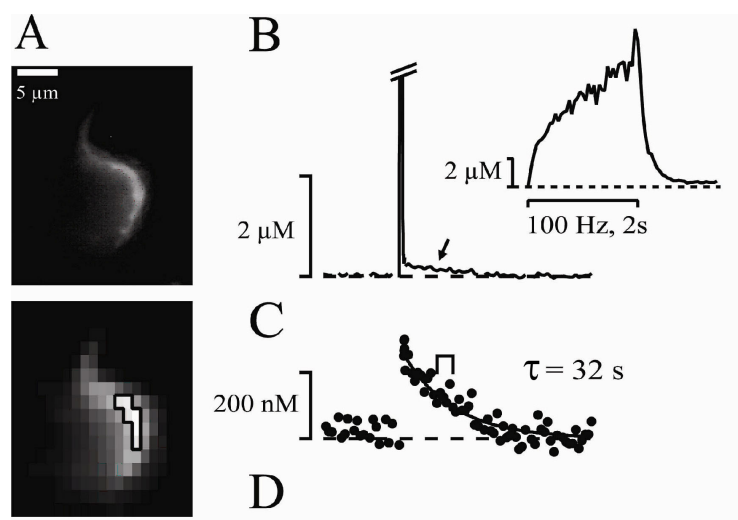

$\mathrm{D}$
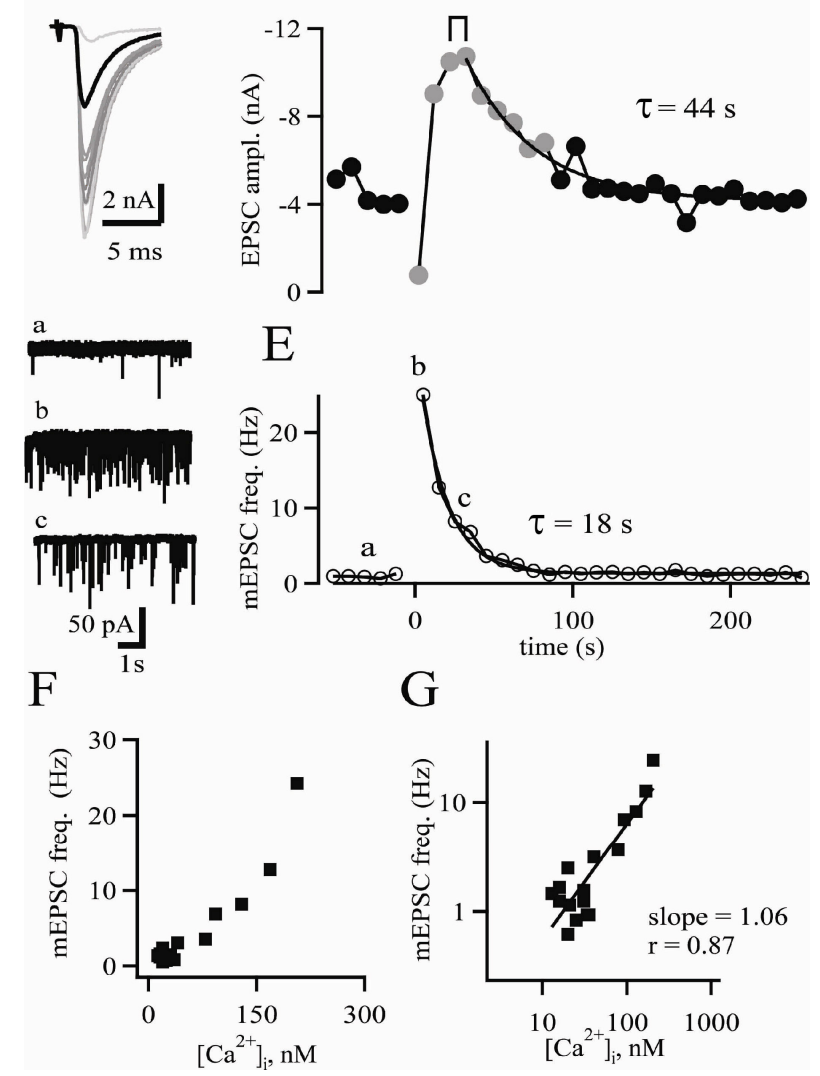

G

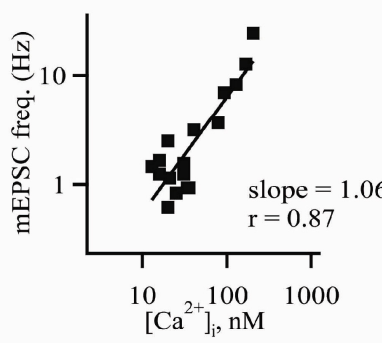

Figure 3-6. Presynaptic $\left[\mathrm{Ca}^{2+}\right]_{\mathrm{i}}$ dynamics associated with PTP. The fluorescent $\mathrm{Ca}^{2+}$ indicator fura-4F was preloaded into calyces by a brief whole-cell recording episode. A, Fluorescence images taken after the experiment (high resolution; top) and during the experiment (bottom). $n=7$ superpixels used for deriving the $\left[\mathrm{Ca}^{2+}\right]_{\mathrm{i}}$ traces shown in $B$ and $C$ are indicated. $B-E$, Time course of $\left[\mathrm{Ca}^{2+}\right]_{\mathrm{i}}(B, C)$, of EPSC amplitudes $(D)$, and of mEPSC frequency $(E)$. At time point 0 , a $2 \mathrm{~s} 100 \mathrm{~Hz}$ train was applied. In $B,\left[\mathrm{Ca}^{2+}\right]_{\mathrm{i}}$ is shown for the entire protocol and for an expanded time during the $100 \mathrm{~Hz}$ train (inset). In $C$, the $\left[\mathrm{Ca}^{2+}\right]_{\mathrm{i}}$ scale is increased, such that only $\left[\mathrm{Ca}^{2+}\right]_{\mathrm{i}}$ up to $350 \mathrm{nM}$ is visible. With this scale, the slow component of decay of residual $\left[\mathrm{Ca}^{2+}\right]_{\mathrm{i}}$ becomes clearly visible, which was fitted by an exponential function with time constant $\tau=$ $32 \mathrm{~s}$. The decay of PTP in $D$ was also fitted with an exponential function, giving $\tau=44 \mathrm{~s}$. Horizontal brackets in C and D. indicate the time of maximal PTP. The traces in $D$ show the EPSCs before and after induction of PTP. In $E$, mEPSCs are shown for the time points indicated with $\mathrm{a}, \mathrm{b}$, and $\mathrm{c}$ in the time plot of E. F, Plot of mEPSC frequency as a function of presynaptic $\left[\mathrm{Ca}^{2+}\right]_{\mathrm{i}}$ during the decaying phase of PTP. $G$, Same data as in $F$, but on double-logarithmic scales. The logarithmized data were fitted with a line, giving a slope of 1.06. The data in this figure were obtained from a P5 rat. 
The slowest phase of $\left[\mathrm{Ca}^{2+}\right]_{\mathrm{i}}$ recovery can be seen more clearly in Figure 3-6C, which displays the $\left[\mathrm{Ca}^{2+}\right]_{\mathrm{i}}$ signal at a higher gain. The late phase of the $\left[\mathrm{Ca}^{2+}\right]_{\mathrm{i}}$ decay was fitted with an exponential function, with a time constant of $32 \mathrm{~s}$ in this example (Fig. 3$6 C$ ). In this recording, the baseline synaptic strength was $4.1 \mathrm{nA}$, and the EPSC amplitude rose to $10.6 \mathrm{nA}$ at the peak of PTP, corresponding to a relative PTP of $260 \%$ (Fig. 3-6D). PTP then decayed with an estimated time constant of $44 \mathrm{~s}$ (Fig. 3-6D).

In these experiments, we also measured the average frequency of mEPSCs before and after PTP induction, with the aim to relate these to the presynaptic $\left[\mathrm{Ca}^{2+}\right]_{\mathrm{i}}$. In the recording of Figure 3-6, the mEPSC frequency rose to a peak value of $25 \mathrm{~Hz}$ in the $10 \mathrm{~s}$ interval immediately after the $100 \mathrm{~Hz}$ train and then returned to baseline values $(\sim 1 \mathrm{~Hz})$ with an estimated time constant of $18 \mathrm{~s}$ (Fig. 3-6E). A plot of mEPSC frequency versus $\left[\mathrm{Ca}^{2+}\right]_{\mathrm{i}}$ for the time after PTP induction is shown in Figure 3-6, $F$ and $G$, on natural and double-logarithmic scales, respectively. There was a good correlation between mEPSC frequency and presynaptic $\left[\mathrm{Ca}^{2+}\right]_{\mathrm{i}}$ measured during the slowest phase of the decay of residual $\left[\mathrm{Ca}^{2+}\right]_{\mathrm{i}}$ (Fig. 3-6G), indicating that the increase in mEPSC frequency was driven by presynaptic residual $\left[\mathrm{Ca}^{2+}\right]_{\mathrm{i}}$. The logarithmized data set of Figure 3-6G was fitted by linear regression, giving a slope of $1.73 \pm 0.2$ (range, $0.68-2.49 ; n=9$ measurements in $n=5$ cells; $\left[\mathrm{Ca}^{2+}\right]_{\mathrm{i}}$ range of $40-270 \mathrm{nM}$ ). This slope is significantly lower than the high power relationship of $\sim 4-5$, with which $\mathrm{Ca}^{2+}$ regulates transmitter release in a range of 2-8 $\mu \mathrm{M}\left[\mathrm{Ca}^{2+}\right]_{\mathrm{i}}$, as estimated by $\mathrm{Ca}^{2+}$ uncaging at the calyx of Held (Bollmann et al., 2000; Schneggenburger and Neher, 2000; Felmy et al., 2003). This indicates that elevations of $\left[\mathrm{Ca}^{2+}\right]_{i}$ close to the resting value regulate the rate of transmitter release with a significantly smaller $\mathrm{Ca}^{2+}$ cooperativity $(\sim 1)$, in agreement with a recent study at the calyx of Held (Lou et al., 2005).

The $\mathrm{Ca}^{2+}$-imaging experiments showed that the slowest phase of the decay of residual $\left[\mathrm{Ca}^{2+}\right]_{\mathrm{i}}$ has a similar time course as the decay of PTP (Fig. 3-6C,D), as observed previously at the crayfish neuromuscular junction (Delaney et al., 1989; Delaney and Tank, 1994). Figure 3-7A plots the decay time constants of PTP and residual $\left[\mathrm{Ca}^{2+}\right]_{\mathrm{i}}$ for the entire data set $(n=18$ measurements in five cells). Shorter $100 \mathrm{~Hz}$ trains, represented by open and light gray symbols in Figure 3-7A, induced rapidly decaying PTP, whereas longer $100 \mathrm{~Hz}$ trains, represented by dark gray and black symbols, tended to induce longer-lasting PTP, in agreement with the results shown in Figure 3-2C. There was a good correlation between the decay time constant of PTP and the decay time constant of residual $\left[\mathrm{Ca}^{2+}\right]_{\mathrm{i}}(r=0.81)$ (Fig. 3-7A), suggesting that the time course of decay of residual 
$\left[\mathrm{Ca}^{2+}\right]_{\mathrm{i}}$ determines the decay of PTP. Note, however, that most data points were located above the unity line (Fig. 3-7A, dotted line). This indicates that on average, the decay of PTP was slightly slower compared with the decay of residual $\left[\mathrm{Ca}^{2+}\right]_{\mathrm{i}}$.
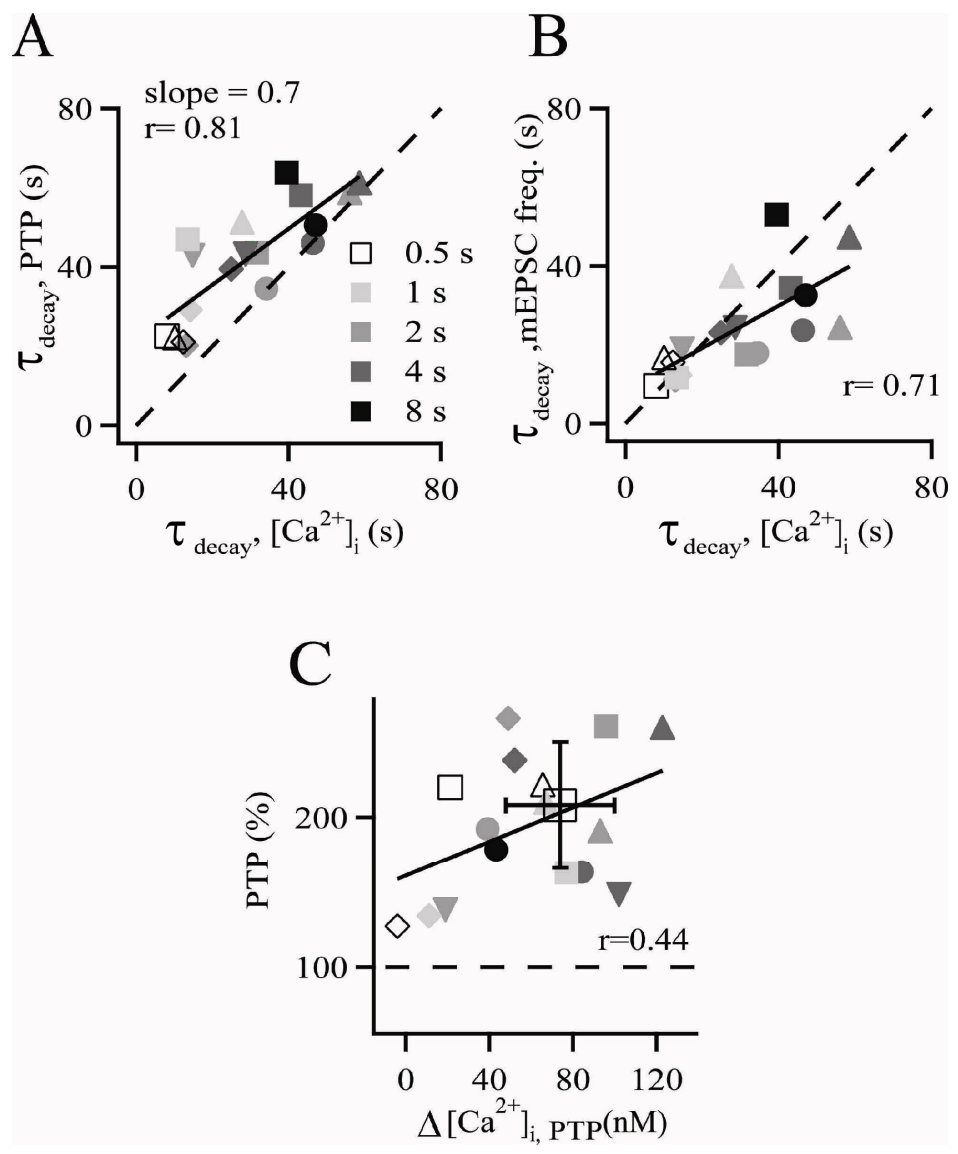

Figure 3-7. The $\mathrm{Ca}^{2+}$ dependence of PTP at the calyx of Held. $A$, Plot of the decay time constants of PTP as a function of the decay time constants of presynaptic residual $\left[\mathrm{Ca}^{2+}\right]_{i}$. The data points are grayscale coded according to the length of the $100 \mathrm{~Hz}$ induction train, as indicated. The data were fitted by linear regression. $B$, Decay time constant of mEPSC frequency as a function of the decay time constant of presynaptic residual $\left[\mathrm{Ca}^{2+}\right]_{\mathrm{i}}$. The data were fitted by linear regression. In $A$ and $B$, the dashed line represents the unity slope line. $C$, Plot of the PTP amplitudes as a function of the presynaptic $\left[\mathrm{Ca}^{2+}\right]_{\mathrm{i}}$ at the time of maximal PTP. Linear regression gave a correlation coefficient of $r=0.44 .\left[\mathrm{Ca}^{2+}\right]_{i}$ is given as the increment over baseline $\left[\mathrm{Ca}^{2+}\right]_{\mathrm{i}}$. The average $\pm \mathrm{SD}$ of all data points $40 \mathrm{nM}\left[\mathrm{Ca}^{2+}\right]_{\mathrm{i}}$ are superimposed. The data in this figure were obtained from $\mathrm{P} 4-\mathrm{P} 6$ rats.

There was also a good correlation of the decay time constants of mEPSC frequency with the decay time constants of presynaptic residual $\left[\mathrm{Ca}^{2+}\right]_{\mathrm{i}}($ Fig. $3-7 B)$. In this case, however, the data points fell below the unity line, indicating that decay time constants of the mEPSC frequency tended to be smaller than the decay time constant of the underlying residual $\left[\mathrm{Ca}^{2+}\right]_{\mathrm{i}}$. This is expected if the exponent in the power relationship relating 
mEPSC frequency to $\left[\mathrm{Ca}^{2+}\right]_{\mathrm{i}}$ is somewhat larger than 1 , and indeed, this value was 1.73 on average (see above; Fig. 3-6G). In Figure 3-7C, the amplitude of PTP is plotted as a function of residual $\left[\mathrm{Ca}^{2+}\right]_{\mathrm{i}}$, measured at the time when PTP was maximal (at $\sim 20-30 \mathrm{~s}$ after the $100 \mathrm{~Hz}$ train) (Fig. 3-6C, D, brackets). It can be seen that robust potentiation of EPSCs of $\sim 200 \%$ is observed for elevations of residual $\left[\mathrm{Ca}^{2+}\right]_{\mathrm{i}}$ as low as $40-120 \mathrm{nM}$ over base line $\left[\mathrm{Ca}^{2+}\right]_{\mathrm{i}}$. The average of the data points $>40 \mathrm{nM}\left[\mathrm{Ca}^{2+}\right]_{\mathrm{i}}$ indicates that for an average $\left[\mathrm{Ca}^{2+}\right]_{\mathrm{i}}$ increment of $74 \pm 26 \mathrm{nM}$, PTP was $208 \pm 42 \%$ of control (Fig. 3-7C, see average \pm SD data point). Thus, a relatively small elevation of basal $\left[\mathrm{Ca}^{2+}\right]_{\mathrm{i}}$ after a highfrequency train induces a robust potentiation of transmitter release during PTP. The correlation between the amplitude of PTP and the increase in residual $\left[\mathrm{Ca}^{2+}\right]_{\mathrm{i}}$ in this plot was not strong, however $(r=0.44)$ (Fig. 3-7C). This might indicate the influence of other factors on the relative PTP amplitude. For example, we have already shown above (Fig.33C) that the PTP amplitude inversely dependent on the baseline synaptic strength of a given cell. Thus, cells with different EPSC amplitudes might introduce additional scatter in the plot of Fig. 3-7C.

\subsection{Glutamate spillover and PTP}

Repetitive stimulation of glutamatergic synapses might lead to accumulation of glutamate in the synaptic cleft and its diffusion either to neighboring synapses or retrogradly to the nerve terminal. This phenomenon is known as "spillover" (Diamond, 2002). Glutamate spillover exerts its effect via activation of either NMDA receptors (as opposed to AMPA receptors, because NMDA receptors have a much higher affinity for glutamate, therefore lower concentrations of glutamate can be effective) or metabotropic glutamatergic receptors (mGluRs) (Asztely et al., 1997). Special attention was attracted to the G-protein-coupled mGluRs, which were shown to be involved in a broad spectrum of physiological functions, such as the generation of slow excitatory and inhibitory synaptic potentials, modulation of synaptic transmission, and integration and plasticity (Coutinho and Knopfel, 2002). The calyx of Held expresses mGluRs (group II and III), in particular mGluR 2/3 and mGluR 4, which are presynaptically localized and might contribute to an autoreceptor function (Pilkington et al.). Takahashi and colleagues (Takahashi et al., 1996) have shown that these receptors are negatively coupled to calyceal P/Q-type voltage-gated $\mathrm{Ca}^{2+}$ channels, which elicit release at this synapse. von Gersdorff, 1997 \#62\} investigated whether synaptically released glutamate might feed back onto mGluRs 
and contribute to depression. They found that antagonists of these receptors only slightly ( $\sim 6 \%)$ altered depression induced by short $10 \mathrm{~Hz}$ stimulus trains.
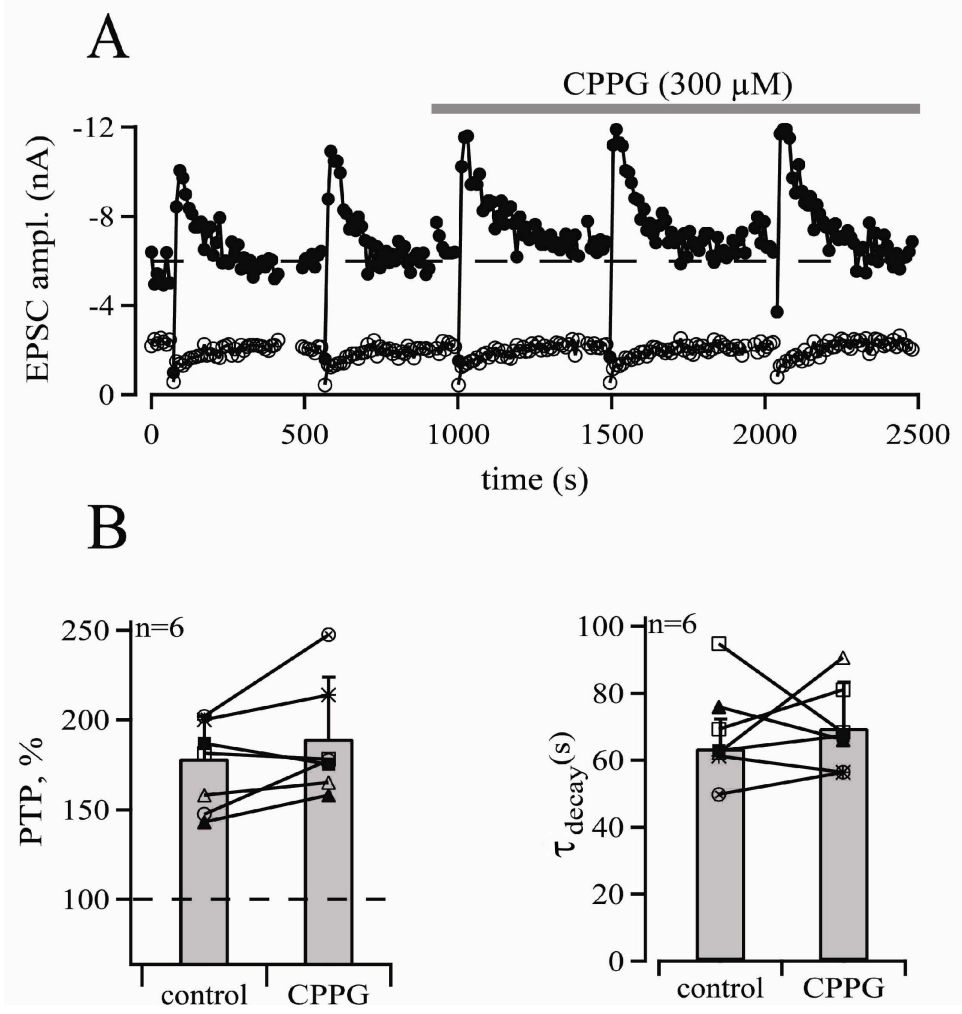

Figure 3-8. Glutamate spillover does not contribute to PTP at the calyx of Held. $A$, The time course of the 1st (closed circles) and the 2nd (open circles) EPSC amplitudes from the paired pulses, used to check the transmission during PTP induction protocol $(4 \mathrm{~s}, 100 \mathrm{~Hz})$, which was applied several times in this example cell. CPPG $(300 \mu \mathrm{M})$ was applied at the indicated time. $B$, Summarized data are shown for the relative PTP amplitudes (left histogram plot) and decay times (right histogram plot) in control condition and after application of CPPG. Error bars represent SD.

In this study, to induce PTP, we applied prolonged (1-4 s) $100 \mathrm{~Hz}$ stimulation to the calyces, which might cause significant accumulation of glutamate in the extra-synaptic space and activate presynaptic metabotropic glutamate receptors. To investigate a possible role of glutamate spillover in PTP at the calyx of Held, we used a specific group III mGluR antagonist-CPPG ((RS)-a-cyclopropyl-4-phosphonophenylglycine) at a concentration $(300 \mu \mathrm{M})$, which was shown in a previous study of the same laboratory (von Gersdorff et al., 1997) to completely suppress the inhibitory effect of $50 \mu \mathrm{M}$ of the group III mGluR agonist L(+)-2-amino-4-phosphonobutyric acid (L-AP4). PTP was induced by $100 \mathrm{~Hz}$ trains of $4 \mathrm{~s}$ duration (Fig. 3-8A). After establishing control PTP by two consecutive 4 s $100 \mathrm{~Hz}$ trains, which induced PTP of similar amplitude (Fig.3-8A), $300 \mu \mathrm{M}$ CPPG was applied to the bath. However, no difference was observed between 
control conditions and after CPPG application neither on PTP amplitude (control, $179 \pm$ $24 \%$; CPPG, $190 \pm 34 \%$, n=6 cells; Fig. $3-8 B$ ) nor on its decay time (control, $64 \pm 9 \mathrm{~s}$; CPPG, $70 \pm 14 \mathrm{~s}$; Fig.3-8C). These results suggest that glutamate spillover does not play a significant role in modulating PTP at the calyx of Held.

\subsection{Mechanisms of PTP at the calyx of Held}

In order to understand the mechanisms underlying the posttetanic potentiation at the calyx of Held, quantal parameters and their changes have to be evaluated. The synaptic response in terms of a voltage-clamped excitatory postsynaptic current (EPSC) is determined by the quantal size q (or mEPSC amplitude), number of synaptic vesicles $\mathrm{N}$, available for release, and by the probability $\mathrm{p}_{\mathrm{r}}$ that an available vesicle will be released (Sakaba et al., 2002):

$$
E P S C=q \times p_{r} \times N
$$

The observed potentiation of synaptic transmission during PTP might be due to a change in any of these three parameters. For example, q reflects postsynaptic changes such as number or sensitivity of the postsynaptic receptors. $\mathrm{N}$ mainly depends on the number of docked and fusion-competent vesicles at each active zone, multiplied by the overall number of active zones. The factor $\mathrm{N}$, as defined here, corresponds to the readily releasable pool (RRP) of vesicles. Release probability $\mathrm{p}_{\mathrm{r}}$ is highly influenced by intracellular $\left[\mathrm{Ca}^{2+}\right]_{\mathrm{i}}$ and by the properties of the release machinery. In turn, $\left[\mathrm{Ca}^{2+}\right]_{\mathrm{i}}$ changes might be affected by different factors, for example, by the action potential (AP) waveform and by the properties of the $\mathrm{Ca}^{2+}$ channels and by $\mathrm{Ca}^{2+}$ buffers. Therefore, in the following set of experiments we tested which quantal parameters undergo changes during PTP.

\subsubsection{PTP is mediated by an increase in release probability}

Based on the constant mEPSC amplitudes after $100 \mathrm{~Hz}$ induction trains (Fig. 3-1B, F), PTP was presynaptic in origin (an increase in the amount of quanta released), similar as at other synapses (Zucker and Regehr, 2002). Thus, an increase either in $p_{r}$ or in $N$ (or combination of both) might be involved. We next tested whether an increased size of the 
readily releasable pool (RRP) of vesicles contributed to the presynaptic mechanism of PTP (Fig. 3-9).
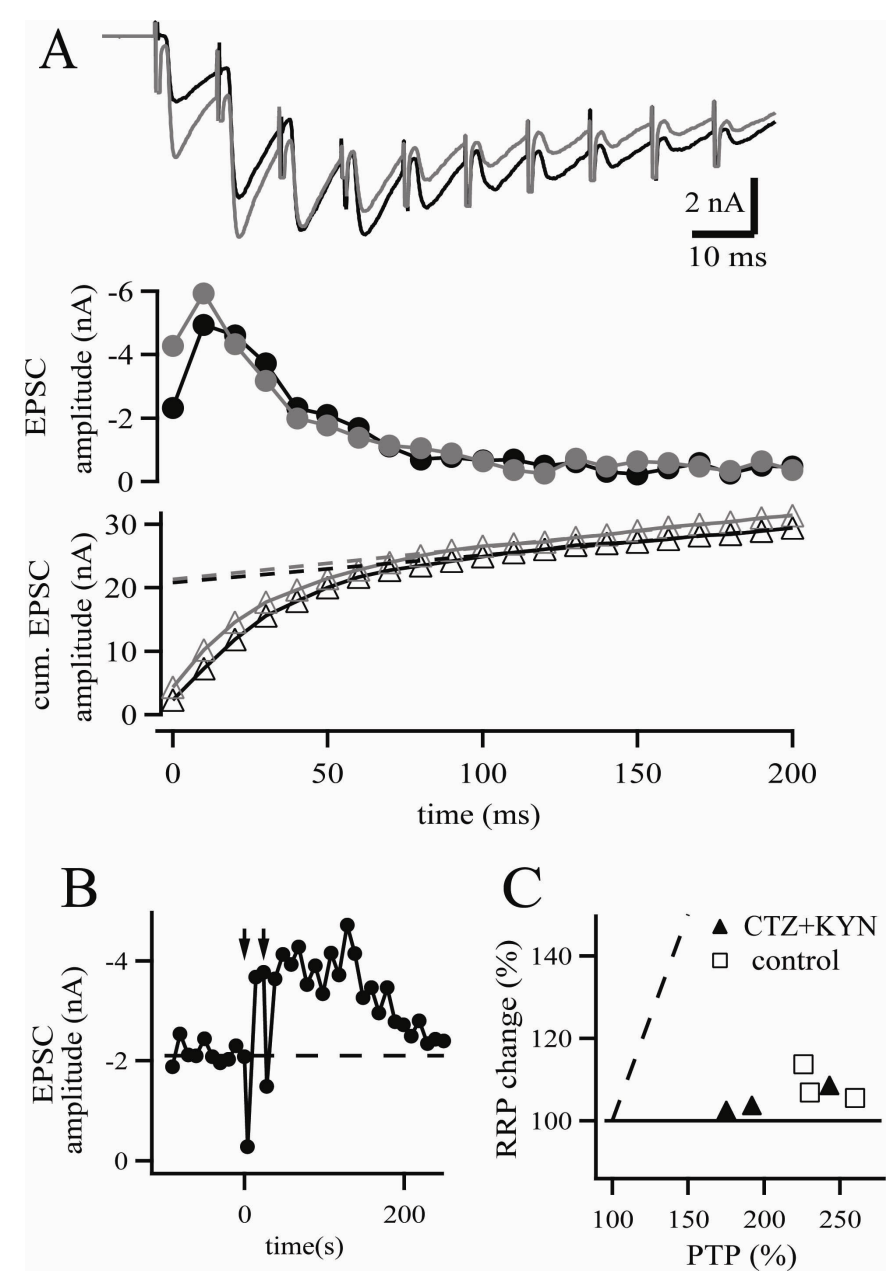

Figure 3-9. The readily releasable pool of vesicles is not significantly increased during PTP. A, Top: EPSCs in response to the fist 10 stimuli of the first (black) and the second (gray) $4 \mathrm{~s} 100 \mathrm{~Hz}$ train, both for the first $4 \mathrm{~s} 100 \mathrm{~Hz}$ train applied $20 \mathrm{~s}$ later. The middle panel shows the corresponding plot of EPSC amplitudes for the first 25 stimuli of each $100 \mathrm{~Hz}$ train, and the bottom panel shows the plot of cumulative EPSC amplitudes, fitted with lines and back extrapolated to time 0 to obtain a measure for the RRP. Black and gray symbols are for the first and second $100 \mathrm{~Hz}$ trains, respectively. $B$, Low time resolution plot of EPSC amplitudes for the experiment illustrated in $A$, where the two $4 \mathrm{~s} 100 \mathrm{~Hz}$ trains indicated by arrows. Note that the first $100 \mathrm{~Hz}$ train induced PTP of $\sim 170 \%$ of control, but the second $100 \mathrm{~Hz}$ train did not increase synaptic strength further. $C$, Plot of the relative pool size increase as a function of the PTP amplitude. The data points for cells measured in control extracellular solution and in the presence of $1 \mathrm{mM}$ KYN and $0.1 \mathrm{mM} \mathrm{CTZ} \mathrm{are} \mathrm{indicated.} \mathrm{The} \mathrm{dashed} \mathrm{line} \mathrm{indicates} \mathrm{the} \mathrm{unity} \mathrm{slope} \mathrm{line.} \mathrm{The} \mathrm{data} \mathrm{in} \mathrm{this} \mathrm{figure}$ were obtained in P4-P6 rats.

To do so, we used a method for measuring the size of the RRP, in which EPSC amplitude plots in response to $100 \mathrm{~Hz}$ trains are analyzed (Schneggenburger et al., 1999). The cumulative EPSC amplitude plots in response to $100 \mathrm{~Hz}$ trains were fitted with a line and 
the back-extrapolated EPSC amplitude value at time 0 was taken as a measure of the pool size (Fig. 3-9A, lower panel).

In these experiments, PTP was induced by a $4 \mathrm{~s} 100 \mathrm{~Hz}$ train, and the pool size for control conditions was estimated by analyzing the first 25 EPSCs of the first induction train (Fig. 3-9A, black trace and black symbols). The experiment shown in Fig.3-9A was

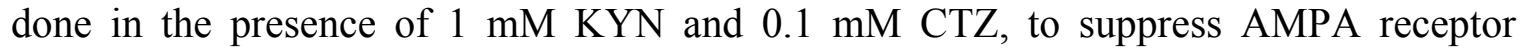
desensitization and saturation, which might compromise the pool size estimates (Neher and Sakaba, 2001). When PTP was maximal at $20-30 \mathrm{~s}$ after the first $100 \mathrm{~Hz}$ train, a second $100 \mathrm{~Hz}$ train with $4 \mathrm{~s}$ duration was applied to test whether the pool size was increased (Fig. 3-9B, second arrow). At the peak of PTP, the pool size was increased to $107 \pm 2 \%$ of its control value ( $n=6$ cells). This small increase in pool size can account only for a small fraction $(<10 \%)$ of the overall amount of PTP, which was $221 \pm 13 \%$ in these experiments $(n=6)$. This can also be seen in Figure 3-9C, which plots the relative increase of pool size as a function of the PTP for each cell. Note that the data points lie far below the unity line that is indicated by the dashed line. Some of these experiments $(n$ $=3$ cells) were also done in the absence of KYN and CTZ. However, similar results were obtained in the absence and presence of these drugs (Fig. 3-9C, open and filled symbols). We conclude that PTP induced by $100 \mathrm{~Hz}$ trains is mediated by an increased release probability $\left(\mathrm{p}_{\mathrm{r}}\right)$ from an essentially unchanged pool of readily releasable vesicles.

As mentioned above, the release probability $\mathrm{p}_{\mathrm{r}}$ dependents on intrinsic $\mathrm{Ca}^{2+}$ sensitivity of the release machinery (Bollmann et al., 2000; Schneggenburger and Neher, 2000; Lou et al., 2005), as well as on local $\left[\mathrm{Ca}^{2+}\right]_{\mathrm{i}}$, that is reached transiently at the sites of vesicle fusion. The increased local $\left[\mathrm{Ca}^{2+}\right]_{\mathrm{i}}$ could, in turn, be changed by: a) an increase in $\mathrm{Ca}^{2+}$ influx (for example, because of a change in the action potential (AP) waveform or otherwise an increase in $\mathrm{Ca}^{2+}$ current) or b) a reduced intracellular $\mathrm{Ca}^{2+}$ buffering (Felmy et al., 2003). To verify whether there is a change in $\mathrm{Ca}^{2+}$ influx it would be useful to study PTP under paired pre- and postsynaptic recordings.

\subsubsection{Whole-cell recordings of the presynaptic terminal suppress PTP}

In the next experiments, we investigated posttetanic potentiation (PTP) under conditions of presynaptic whole-cell recordings (Fig. 3-10). We used $\mathrm{K}^{+}$-containing presynaptic pipette solutions and recorded the calyces under current-clamp conditions while simultaneously recording from the postsynaptic principal neuron. 

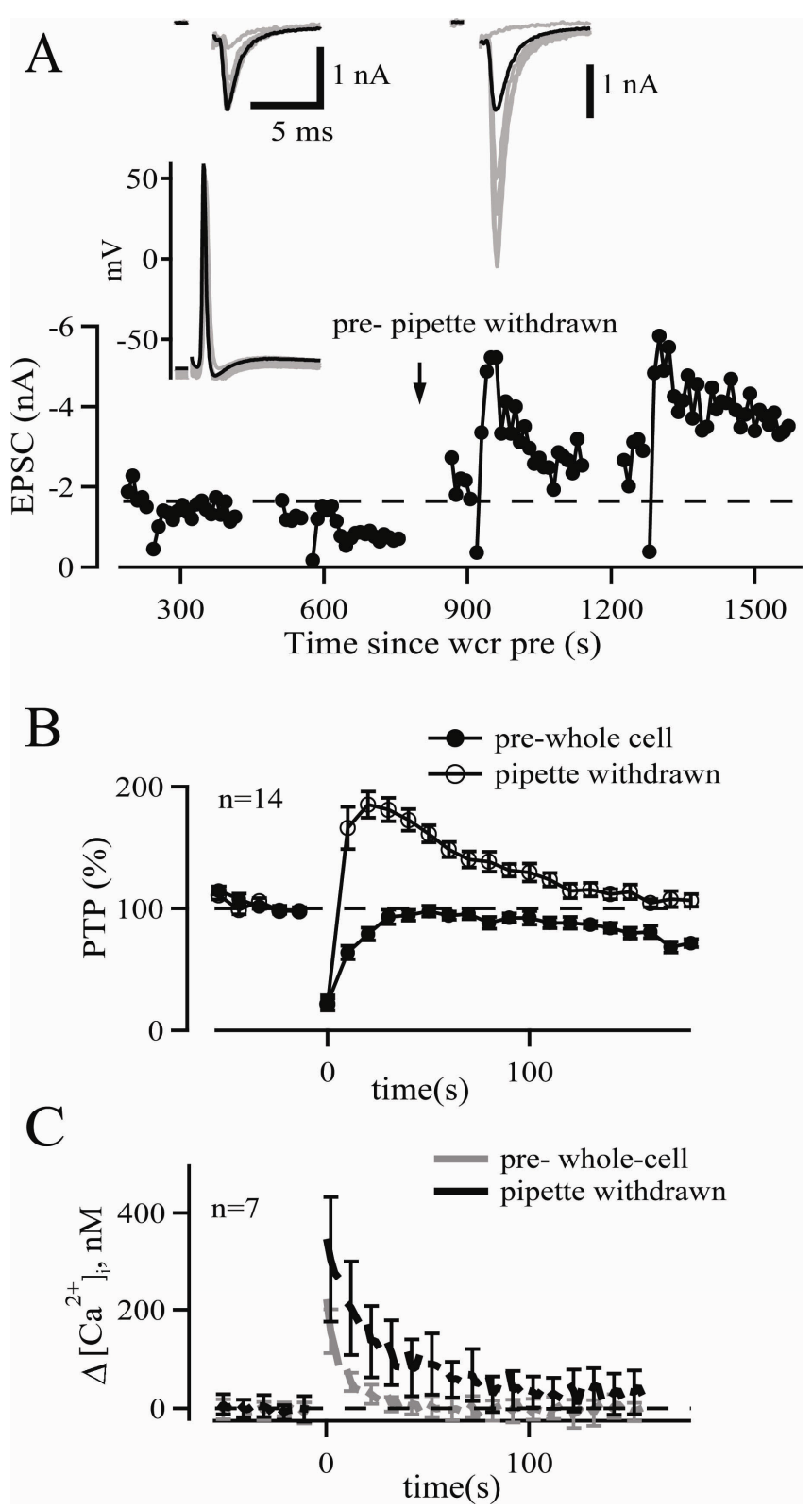

Figure 3-10. Whole-cell recording of the presynaptic nerve terminal reversibly suppresses PTP and accelerates the decay of residual $\left[\mathrm{Ca}^{2+}\right]_{\mathrm{i}}$. A, Time plot of EPSC amplitudes in the experiment, the PTP induction protocol (4 s, $100 \mathrm{~Hz}$ train) was given twice under conditions of presynaptic whole-cell recording (wcr pre) and another two times after withdrawal of the presynaptic pipette. The traces on the left show EPSCs and presynaptic APs for control (black traces) and after the induction of PTP (gray traces). The traces on the right show EPSCs for control (black traces) and after the induction of PTP (gray traces), after the presynaptic pipette was removed. $B$, Average time course of relative EPSC amplitude before and after $100 \mathrm{~Hz}$ trains of $4 \mathrm{~s}$ duration. Filled symbols are under presynaptic whole-cell recording; open symbols are after withdrawal of the presynaptic pipette in the same recordings. $C$, Average residual $\left[\mathrm{Ca}^{2+}\right]_{i}$ measured under conditions of presynaptic whole-cell recording (gray trace) and after pipette removal (black trace) for a subset of cells shown in $B .\left[\mathrm{Ca}^{2+}\right]_{\mathrm{i}}$ is shown as the increment over the baseline $\left[\mathrm{Ca}^{2+}\right]_{\mathrm{i}}$ recorded in each cell. The data in this figure were obtained from P8 -P10 rats. Error bars represent SEM. 
In the example of Figure $3-10 A$, a $4 \mathrm{~s} 100 \mathrm{~Hz}$ induction train was applied twice under conditions of presynaptic whole-cell recording. In both cases, only a slowly recovering phase of synaptic depression was observed, but we found that PTP was absent. This can also be seen in the inset of Figure 3-10A, which shows presynaptic action potentials and EPSCs before (black traces) and immediately after (gray traces) the $100 \mathrm{~Hz}$ train. After a recording time of $\sim 800 \mathrm{~s}$, the presynaptic patch pipette was withdrawn, and the PTP protocol was repeated twice. In this recording, strong PTP was observed already $\sim 2$ min after the withdrawal of the presynaptic pipette, and the amount of PTP was stable for the remaining recording period. In other cells, PTP recovered more gradually after withdrawal of the presynaptic pipette. In Figure 3-10B, the average time course of the relative EPSC amplitude is shown for conditions of presynaptic whole-cell recordings (filled symbols) and after removal of the presynaptic patch pipette (open symbols; $n=14$ cells; P8-P10). PTP observed after pipette withdrawal was similar to PTP observed in the absence of presynaptic recordings. Thus, PTP reached its peak $\sim 20-30 \mathrm{~s}$ after the $100 \mathrm{~Hz}$ induction train, and the average PTP decayed with a time constant of $57 \mathrm{~s}$ (Fig. 3-10B, open symbols). At the peak of PTP, the average relative PTP was $183 \pm 10 \%$ (Fig.3-10B), similar as for PTP observed under control conditions with $4 \mathrm{~s} 100 \mathrm{~Hz}$ trains at the same age (P8-P10; see Fig. 3-3B, gray bars). During presynaptic whole-cell recording, however, the relative EPSC amplitude was only $86 \pm 5 \%$ of control at $20-30 \mathrm{~s}$ after the $100 \mathrm{~Hz}$ induction train. and thus, depression occurred instead of PTP. The difference between the two recording conditions was highly significant ( $p<0.01$; paired t-test).

The recovery of PTP observed after withdrawal of the presynaptic pipette (Fig. 3$10 A, B)$ suggests that presynaptic whole-cell recording prevented the build-up of an intracellular signal necessary for PTP, rather than leading to an irreversible loss of intracellular messenger molecule(s). We therefore tested whether presynaptic whole-cell recording altered the presynaptic $\mathrm{Ca}^{2+}$ signaling. To do so, in a subset of the recordings, we imaged presynaptic $\left[\mathrm{Ca}^{2+}\right]_{\mathrm{i}}$ with $100 \mu \mathrm{M}$ fura-4F during presynaptic whole-cell recording and after removal of the presynaptic pipette. The average residual $\left[\mathrm{Ca}^{2+}\right]_{i}$ traces obtained for $n=7$ cells are shown in Figure 3-10C, both under presynaptic whole-cell recording (gray trace) and after pipette withdrawal (black trace). The decay of residual $\left[\mathrm{Ca}^{2+}\right]_{\mathrm{i}}$ was significantly faster under conditions of whole-cell recording (time constant, 9 $\pm 2 \mathrm{~s})$ than after withdrawal of the presynaptic pipette $(28 \pm 4 \mathrm{~s} ; n=7 ; p=0.007$; Wilcoxon two-sample test). Under whole-cell conditions, the average decay of residual $\left[\mathrm{Ca}^{2+}\right]_{\mathrm{i}}$ was so fast, that at the time of maximal PTP (20-30 s after the induction train), the 
increment of residual $\left[\mathrm{Ca}^{2+}\right]_{\mathrm{i}}$ over baseline $\left[\mathrm{Ca}^{2+}\right]_{\mathrm{i}}$ had decayed to $25 \pm 15 \mathrm{nM}$ over baseline (Fig. 3-10C, gray trace). In contrast, after pipette removal, the increment in residual $\left[\mathrm{Ca}^{2+}\right]_{\mathrm{i}}$ over baseline $\left[\mathrm{Ca}^{2+}\right]_{\mathrm{i}}$ was $113 \pm 65 \mathrm{nM}$ (Fig. $3-10 C$, black trace). This suggested that the faster decay of residual $\left[\mathrm{Ca}^{2+}\right]_{\mathrm{i}}$ under conditions of whole-cell recordings contributes to the absence of PTP when presynaptic whole-cell recordings are made.

The absence of PTP, when the presynaptic cell is whole-cell patch-clamped, did not allow us to quantify whether changes in AP waveform, or a change in $\mathrm{Ca}^{2+}$ current during each AP contributed to PTP, since PTP was not observed under these conditions. Therefore, in the following experiments we tried to modify the presynaptic recording conditions to obtain PTP. First, we loaded calyces with intracellular solution, containing $300 \mu \mathrm{M}$ L-glutamate, which according to the study of (Ishikawa et al., 2002) abolishes the "wash-out" of baseline synaptic transmission and even potentiated spontaneous and evoked release at the calyx of Held. However, even with $300 \mu \mathrm{M}$ L-glutamate in the presynaptic pipette ( $n=3)$, we could not obtain PTP (data not shown).

The next trial was to use perforated patch-clamp technique, which was shown to be less invasive to the cell (see Methods).

\subsubsection{Perforated presynaptic patch-clamp recordings}

As was shown above, our presynaptic whole-cell recordings at the calyx of Held reversibly suppressed PTP. One of the reasons might be the observed acceleration of residual $\left[\mathrm{Ca}^{2+}\right]_{\mathrm{i}}$ (Fig.3-10C) that might be caused by a direct diffusion of $\mathrm{Ca}^{2+}$ into the recording patch pipette (Pusch and Neher, 1988). In addition, it is also possible that presynaptic whole-cell recording impaired the function of intracellular signaling pathways like PKC pathway, which might be involved in PTP (see below). Therefore, to achieve conditions as close as possible to the physiological ones, in the following experiments we applied perforated-patch technique to presynaptic cells, which better preserves the cytosolic cellular composition (see Methods section 2.1.4), using Amphotericin B as a pore-forming agent. In our initial experiments we performed only presynaptic recordings to, first, establish perforated patch clamp in the calyx and, second, to test whether presynaptic calcium current $\left(\mathrm{I}_{\mathrm{Ca}}\right)$ undergoes changes after prolonged HFS in this condition. As described above, an increase in $\mathrm{I}_{\mathrm{Ca}}$ is one possible mechanism for PTP. Once the seal was formed and the patch was perforated, cells were voltage-clamped 
to $-70 \mathrm{mV}$ and continuously perfused with an extracellular ringer solution that contained TTX, TEA (see 2.1.2 section in Methods) to isolate presynaptic $\mathrm{I}_{\mathrm{Ca}}$. The PTP protocol was applied, but instead of afferent fiber stimulation with a bipolar electrode, short (0.5-1 $\mathrm{ms}$ ) depolarizations from a holding potential $-70 \mathrm{mV}$ to $+28 \mathrm{mV}$ were used. $\mathrm{I}_{\mathrm{Ca}}$ were recorded and online corrected by a P/4 protocol (Fig.3-11).

Analysis of $\mathrm{I}_{\mathrm{Ca}}$ peak amplitude showed that after HFS $\mathrm{I}_{\mathrm{Ca}}$ at the time point, where usually the peak of PTP was observed ( 30s after HFS), was in average $93 \pm 0.5 \%(n=3$; mean \pm SEM) of the control value (Fig.3-11, red circle). These experiments gave similar results to the work of Forsythe and colleagues (Forsythe et al., 1998), who showed that EPSC recovery from depression, observed after prolonged HFS in paired whole-cell preand postsynaptic recordings, was accompanied by slow recovery of presynaptic $\mathrm{I}_{\mathrm{Ca}}$ from inactivation, which $\mathrm{I}_{\mathrm{Ca}}$ undergo during HFS.

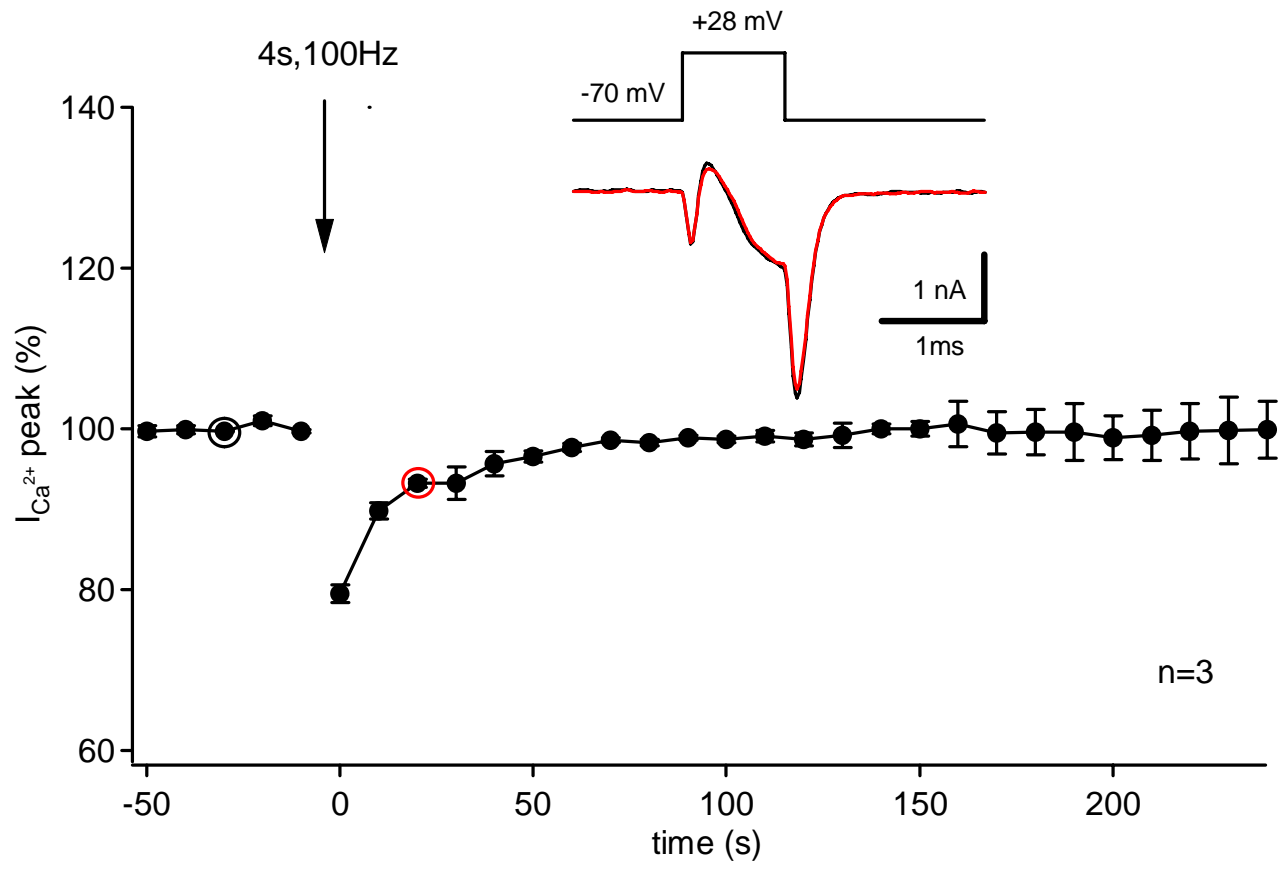

Figure 3-11. Presynaptic perforated patch-clamp recordings. PTP induction train was applied to the calyx of Held by using $1 \mathrm{~ms}$ depolarization pulses from the holding potential of $-70 \mathrm{mV}$ to $+28 \mathrm{mV}$. The presynaptic $\mathrm{Ca}^{2+}$ current $\left(\mathrm{I}_{\mathrm{Ca}}\right)$ was measured. The amplitude of the $\mathrm{I}_{\mathrm{Ca}}$ was normalized to the control value, obtained by averaging of first five points before HFS $(4 \mathrm{~s}, 100 \mathrm{~Hz})$. Black circles represent average time course $(n=3)$ of relative $I_{\text {Ca }}$ peak amplitude before and after HFS (an arrow shows time, at which HFS was applied). Inset shows superimposed $\mathrm{I}_{\mathrm{Ca}}{ }^{2+}$ traces for control (black trace) and after PTP induction (red trace).

The results with presynaptic perforated patch recording suggest that the $\mathrm{Ca}^{2+}$ current was unchanged or even slightly decreased at the time when PTP is usually maximal ( 20-30 s following the $100 \mathrm{~Hz}$ train). However, it would have been desirable to make 
presynaptic perforated patch recordings, paired with simultaneous postsynaptic recordings to prove that under these conditions PTP is indeed expressed. We tried to do these experiments, but because they were technically very difficult and time-consuming, they could not be finished within the frame of this work. In the next set of experiments, we used a pharmacological approach to shed light on the PTP mechanism(s) at the calyx of Held.

\subsubsection{Involvement of phospholipase-C/protein kinase-C in PTP}

The previous experiments suggest that either the massive spatially averaged intracellular $\left[\mathrm{Ca}^{2+}\right]_{\mathrm{i}}$ rise during PTP induction train $(\sim 3-10 \mu \mathrm{M})$, or the lower, but much longer-lasting residual $\left[\mathrm{Ca}^{2+}\right]_{\mathrm{i}}$ could induce PTP. Investigation of PTP mechanisms at various synapses revealed a wide range of molecular targets participating in PTP. Initial attention was focused on $\mathrm{Ca}^{2+} /$ calmodulin - dependent protein kinase type II (CaMKII), which was shown to be involved in PTP in squid giant terminal (Augustine et al., 1994; Zucker and Regehr, 2002). However, in CaMKII KO mice PTP and facilitation remain intact (Stevens et al., 1994). A recent study at hippocampal mossy fiber terminals pointed out a role of protein kinase C (PKC) in mediation of PTP (Brager et al., 2003). Based on experiments with PKC-selective inhibitors, the authors provided an evidence for an involvement of $\mathrm{Ca}^{2+}$-dependent PKC in PTP expression at these central nervous system synapses.

We, therefore, used pharmacological tools to examine whether posttetanic potentiation at the calyx of Held synapse is mediated via PLC/PKC pathway. Pretreatment of the slices (incubation for $30 \mathrm{~min}$ ) with PKC inhibitor Ro-31-8220 (3 $\mu \mathrm{M})$ significantly blocked PTP from the control level of $180 \pm 10 \%(\mathrm{n}=7)$ down to $116 \pm$ $5 \%(\mathrm{n}=15, \mathrm{p}<0.001, t$-test; Fig.3-12A and Fig.3-15), without affecting the baseline transmission. In the Fig.3-12A the average time course of the relative EPSC amplitude is shown for control condition (filled black symbols, $n=7$ ) and a different group of cells obtained in slices that were preincubated for $>30 \mathrm{~min}$ in Ro-31-8220 (filled gray symbols; $n=15$ cells; P8-P10).

Since the amplitude of PTP is inversely related to the control EPSC amplitude (Fig. 3-3C), to do not overestimate an effect of this inhibitor on PTP, we distributed data, presented in Fig.3-12A, for both control and Ro-318220 into two groups each: cells with large $(>-6 \mathrm{nA})$ and small initial EPSC amplitude $(<-6 \mathrm{nA})$. These data are presented in 
Fig.3-12A as black (for control) and gray (for Ro-31-8220) traces and show the dynamic range of PTP in the control condition and after pretreatment with PKC inhibitor.

In Figure 3-12B, we plotted the amplitude of PTP in response to $4 \mathrm{~s}$ induction trains as a function of the control EPSC amplitude for both conditions. We noticed that almost half of the cells, preincubated in $3 \mu \mathrm{M}$ Ro-31-8220, had basal EPSC amplitude in average higher than in control cells (control, $-5.1 \pm 2.5 \mathrm{nA}$; Ro-31-8220, $-6.7 \pm 2.7 \mathrm{nA}$ ), although this difference was not significantly significant ( $\mathrm{p}>0.1, t$-test).

Interestingly, Ro-31-8220 not only decreased PTP, but also delayed its peak by $\sim 40$ s (Fig.3-12A). These data show that Ro-31-8220, in addition to PTP suppression, might also interfere with recovery of evoked release from depression, caused by HFS.

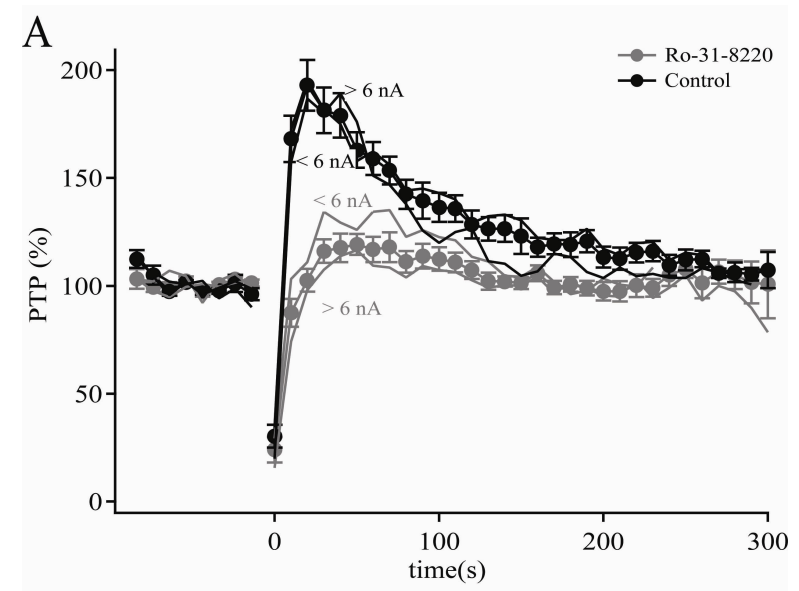

B

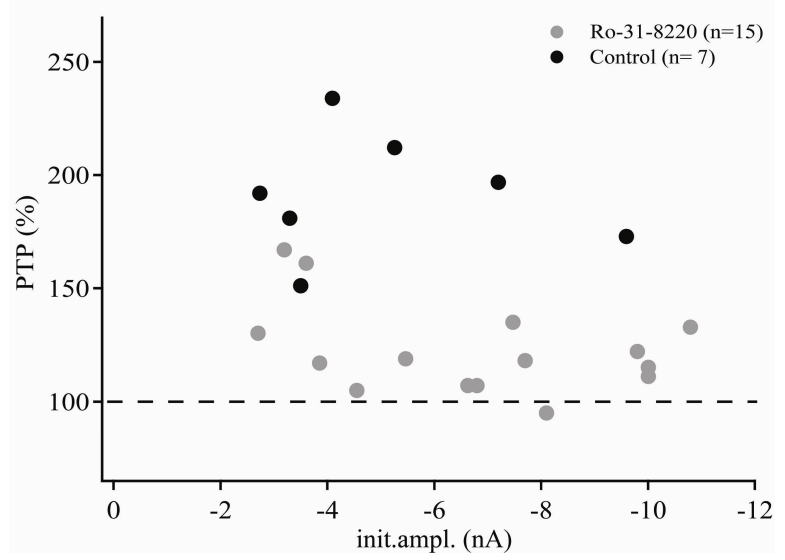

Figure 3-12. Effect of Ro-31-8220 on PTP. $A$, Averaged time course of EPSC amplitudes is shown for control cells (black symbols) conditions $(\mathrm{n}=7)$ and for cells incubated with Ro-31-8220 ( $\mathrm{n}=15)$. Continuous black and gray traces show the dynamic range for PTP in both conditions, obtained by sorting the data into 2 groups based on their initial amplitude. The basal EPSC amplitude with the value of $-6 \mathrm{nA}$ was chosen as a threshold for separation. Error bars represent SEM. $B$, Scatter plot of PTP amplitude as a function of the control EPSC amplitude. The same color code was used for control and Ro-31-8220 data. PTP was significantly blocked by Ro31-8220, despite slightly higher initial EPSC amplitude in the case of Ro-31-8220 application compared to control.

In order to examine the role of PKC in recovery from depression, we applied pairs of trains $(\mathrm{n}=25$ stimuli, at $100 \mathrm{~Hz})$ to the presynaptic terminal at different intervals $(1 ; 4 ; 10$ and $20 \mathrm{~s}$ ) between trains and recorded EPSCs from the postsynaptic cell (Fig.3-13A). Synaptic responses displayed strong depression during HFS (control, Fig.3-13A, upper left panel). 


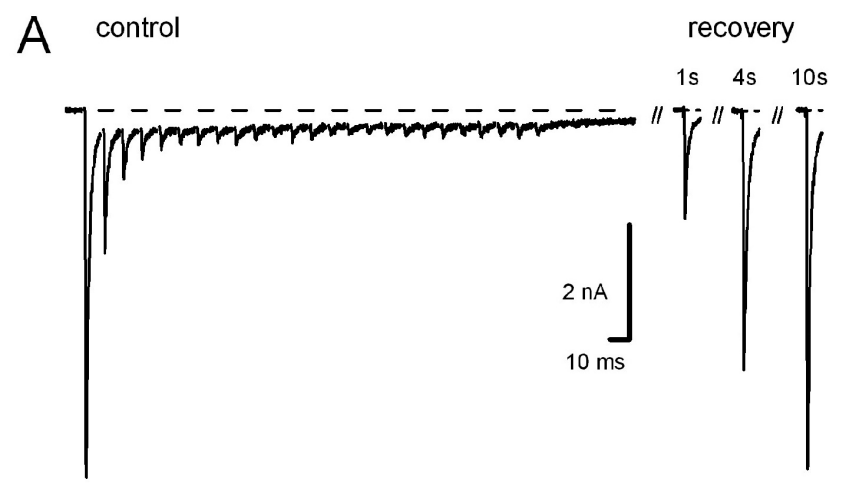

Ro-31-8220, $3 \mu \mathrm{M}$

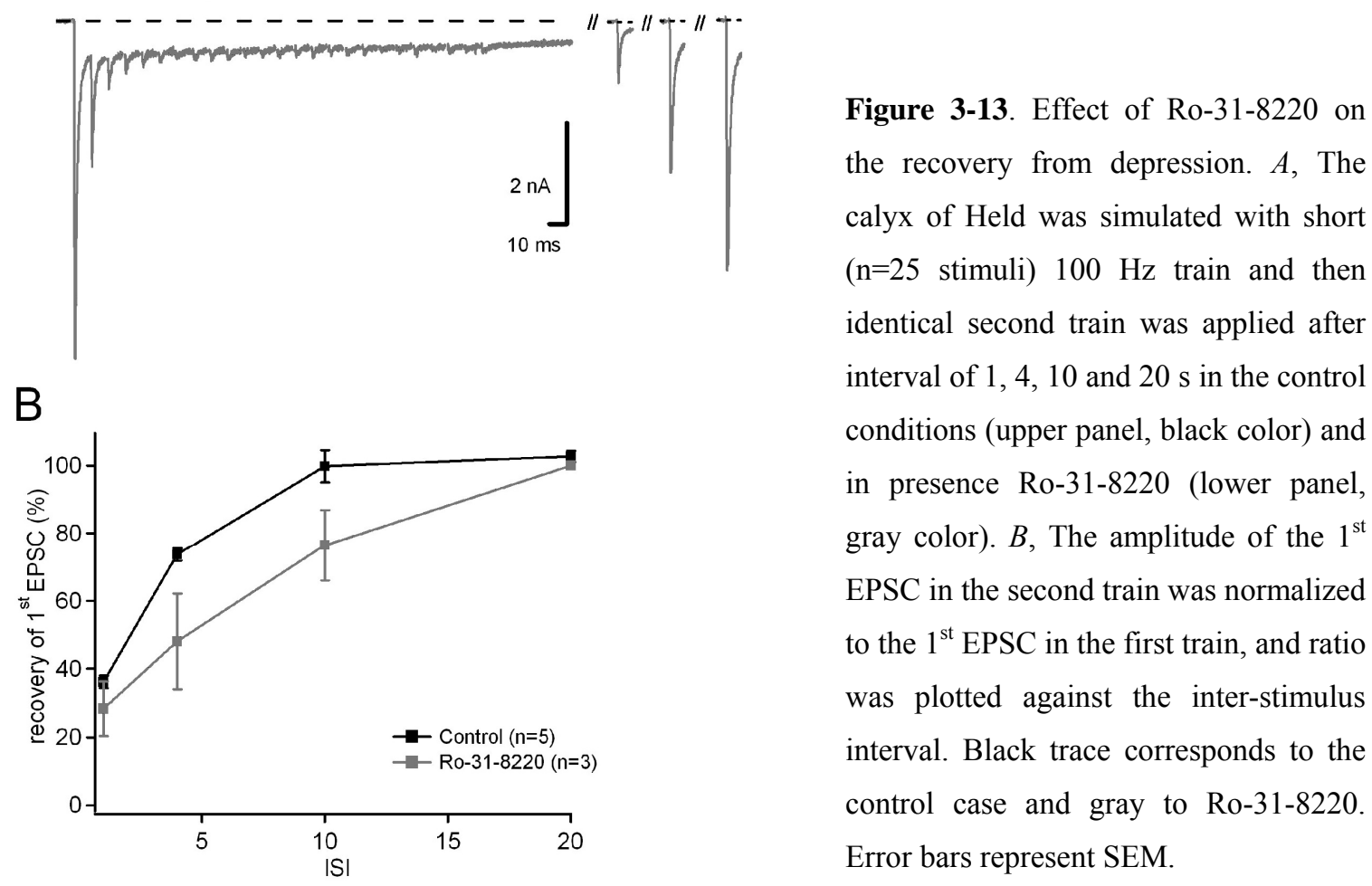

In the control conditions $36 \pm 2 \%(n=5)$ of the response was recovered with an interval of 1s and complete recovery was already observed at 10s ISI (Fig.3-13A, upper panel, right). In the presence of Ro-31-8220, the depression during the train was not altered (Fig.313A, lower panel, left). However, the recovery of the response, despite its variation between the cells, was, on average, slower than in control conditions (Fig.3-13A, lower panel, right). For comparison, EPSC response with 10s ISI between trains recovered to 76 $\pm 10 \%(\mathrm{n}=3)$, while in control already full recovery was observed. Ratios of the $1 \mathrm{st}$ response during the second over the first trains were plotted against the stimulation interval in Fig. 3-13B (control, $n=5$; Ro-31-8220, $n=3$ ). The difference in the recovery at 4 and 10 s between control and Ro-31-8220 was about 30\%. These preliminary results 
suggest that protein kinase $\mathrm{C}$ might be involved in recovery of evoked responses from depression under normal conditions.

It should be mentioned that Ro-31-8220 is an inhibitor, which blocks preferentially $\mathrm{Ca}^{2+}$-independet (novel) PKCs. Therefore, to identify particular PKC isoform(s) that might be involved in PTP at the calyx of Held, we applied several other PKC antagonists. Their effect on the PTP amplitude is summarized in the Fig.3-15. First, we tested another broad-spectrum PKC inhibitor - Bisindolylmaleimide I (BIS; $10 \mu \mathrm{M})$. The application of BIS blocked PTP by more than $50 \%$ (control, $169 \pm 7 \%$; BIS, $128 \pm 2 \%, \mathrm{p}<0.001$, mean \pm SEM; Fig.3-14 and 3-15). Similar to Ro-31-8202, BIS delayed PTP peak expression time for $\sim 30-40 \mathrm{~s}$ (Fig.3-14).

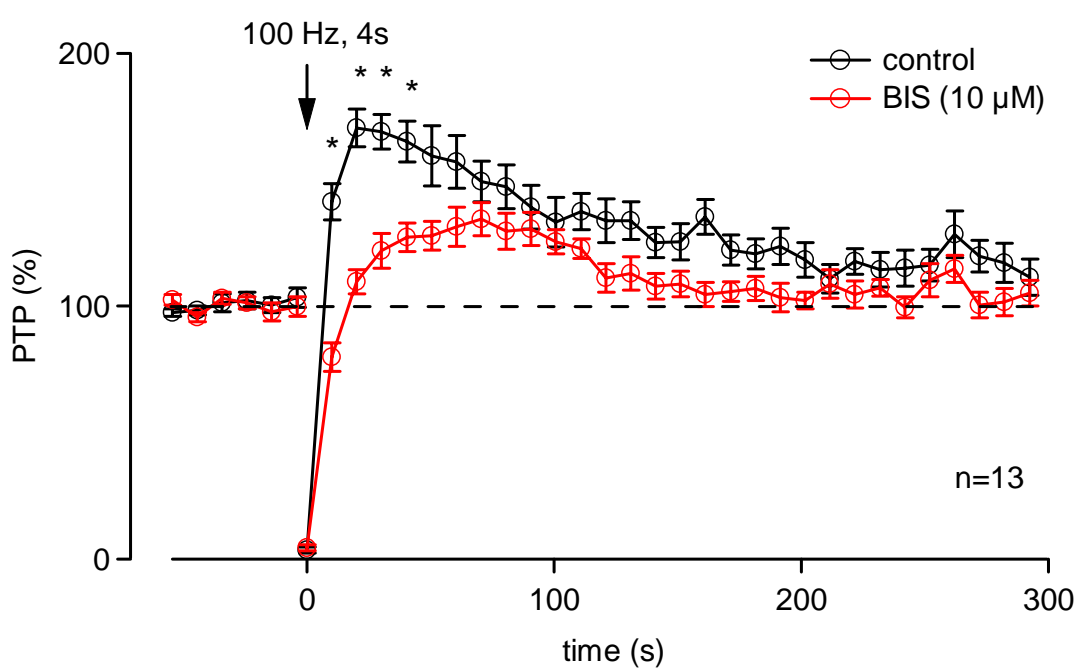

Figure 3-14. Effect of broad-spectrum PKC antagonist BIS on PTP. An averaged (n=13) time course of EPSC amplitudes is shown for control (black circles) and cells treated with BIS (red circles). Application of this inhibitor blocked PTP (* $\mathrm{p}<0.001$, paired $t$-test), induced with $4 \mathrm{~s} 100 \mathrm{~Hz}$ train, and delayed its peak. Error bars represent SEM.

In the next experiments, we applied $10 \mu \mathrm{M}$ Gö-6976, which specifically inhibits conventional ( $\mathrm{PKC}_{\alpha}, \mathrm{PKC}_{\beta \mathrm{I}}$ ). However, no effect was observed (Fig.3-15, control, $153 \pm$ $10 \%$; Gö-6976, $186 \pm 27 \%, p>0.1$ ). A further increase of the concentration (up to 20 $\mu \mathrm{M})$ or a longer incubation time led to same results.

Another blocker that we tried was Calphostin $\mathrm{C}(20 \mu \mathrm{M})$, the most potent and frequently used C1-domain antagonist. C1-domain is a cystein-rich region, which is present not only in all PKCs, but also in Munc-13-1 proteins where it mediates the effect of diacylglycerol (DAG) and phorbol esters (Betz et al., 1998). The application of Calphostin C had no effect on the PTP amplitude (217 $\pm 30 \%$ for control; $226 \pm 25 \%$ for 
Calphostin C; Fig.3-15). However, it should be mentioned that preincubation of the slices with this blocker led to a significant decrease in their quality, so that it was hard to perform these experiments. The absence of Calphostin $\mathrm{C}$ effect, therefore, should not indicate that PKC or Munc-13 are not involved in PTP, because the more selective PKC inhibitors Ro-31-8220 and BIS did have an effect (see above).

As was mentioned above, $\mathrm{Ca}^{2+} /$ calmodulin-dependent protein kinase type II (CaMKII), was shown to be involved in PTP in squid giant terminal (Augustine et al., 1994; Zucker and Regehr, 2002). We tested this possibility for the PTP at the calyx of Held, by application of $20 \mu \mathrm{M}$ Calmidazolium, the calmodulin blocker. But, it also failed to suppress PTP. The averaged PTP amplitude during application of Calmidazolium was $184 \pm 10 \%$ and did not differ significantly ( $\mathrm{p}>0.1$, paired $t$-test) from the control values of $168 \pm 11 \%$ (Fig.3-15).

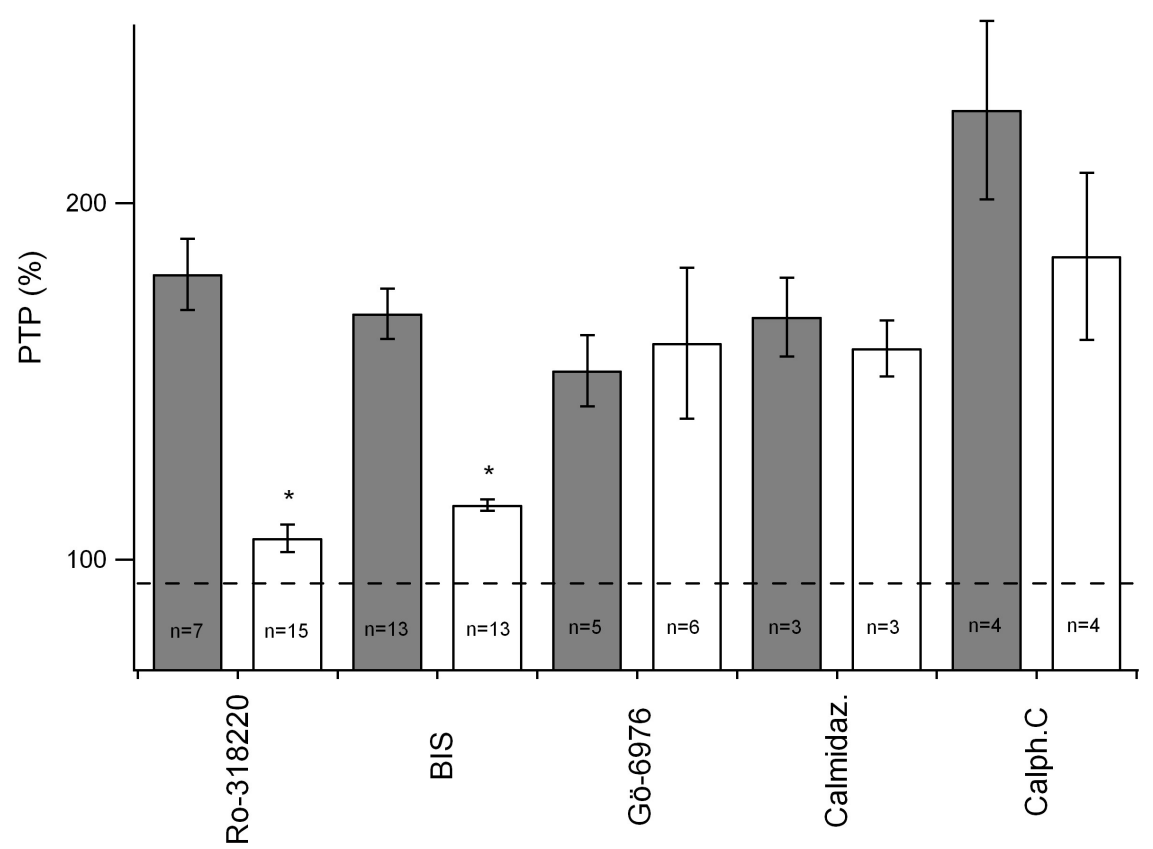

Figure 3-15. Involvement of PLC/PKC pathway in posttetanic potentiation. Bar diagram shows the degree of EPSC potentiation at the calyx of Held in the absence (control, gray bars) and presence (open bars) of various drugs. Slices were preincubated (30 to $60 \mathrm{~min}$ ) and then continuously perfused with different PKC inhibitors. PTP protocol was applied at $100 \mathrm{~Hz}$ for $4 \mathrm{~s}$. PTP amplitudes were measured and compared between untreated and preincubated slices. Among applied inhibitors only Ro-31-8220 and BIS were able to decrease PTP $(* \mathrm{p}<0.001$, paired $t$-test). Gö-6976, Calmidazolium and Calphostin C were ineffective in blocking potentiation.

To summarize, we found an involvement of PKC in PTP at the calyx of Held from our pharmacological experiments. However, we could not draw a conclusion about the specific PKC isoforms that might be involved in PTP. The fact that Gö-6976 (the 
inhibitor of conventional PKCs) and Calphostin C (that blocks DAG binding to PKCs and Munc-13-1) did not work, could either mean that we had problems with drug specificity at the calyx of Held or (in the case of Gö-6976) that a "novel" PKC isoforms might be involved. Indeed, the expression of the novel $\mathrm{PKC}_{\varepsilon}$ isoform, for example, was previously shown at the calyx of Held in (Saitoh et al., 2001). 



\section{Discussion}

In the present work, we aimed to answer the question whether activity-dependent long-term forms of synaptic plasticity exist at the calyx of Held, which could play role in its formation and/or maturation?

Our hypothesis was based on recent knowledge about synapse development, obtained from the studies in other brain regions. It was shown that initial connections are formed largely through molecular mechanisms that depend on intrinsic developmental programs (Kandler and Friauf, 1993; Russell and Moore, 1995; Cohen-Cory, 2002; Crowley and Katz, 2002). For example, in Munc-18 knockout mice neurotransmitter release is completely abolished, but the loss of Munc-18 does not influence the initial synapse formation in the mouse embryo (Verhage et al., 2000). At the same time, it has become clear that electrical activity is essential for the development of neuronal circuits too. Both spontaneous and experience-driven activities exert critical influence on synaptic maturation and refinement of neuronal circuits (Friauf and Lohmann, 1999; Zhang and Poo, 2001; Cohen-Cory, 2002; Ene et al., 2003). The immature synapse may be pre- or postsynaptically "silent" unless sufficient depolarization is provided. For example, studies in cortex and hippocampus showed that newly formed glutamatergic synapses are mediated by NMDA receptors and more synapses acquire AMPA receptors as the neuron matures (Cohen-Cory, 2002). The depolarization may result in the recruitment of AMPA receptors to the synapse in a manner similar to that found in the induction of long-term potentiation (LTP) (Liao et al., 1995; Wu et al., 1996; Isaac et al., 1997). On the other hand, in the mossy fiber pathway region LTP has been found to depend on $\mathrm{Ca}^{2+}$ influx into the presynaptic cell after HFS and NMDA receptors have only a minor role in synaptic plasticity (Tsien and Malinow, 1990).

To test our hypothesis we applied HFS of varying length to the calyx of Held synapse and probed long-term plasticity of synaptic responses. We observed posttetanic potentiation of EPSCs, but longer ( $>2 \mathrm{~min}$ ) lasting LTP-like potentiation was absent. But, if postsynaptic NMDA receptors would play a role, it remains possible that postsynaptically induced form of LTP is also present at the calyx, since our recordings were done under postsynaptic voltage-clamp recordings, which blocks current flow through NMDA-receptor channels. Indeed, young calyces express high density of NMDA 
receptors (Takahashi, 2005), whose number decreases when synapse matures. This possibility can be investigated in the future studies.

Instead, HFS induced robust posttetanic potentiation (PTP) at the calyx of Held, which shared properties with short-term enhancement in other central synapses. Because this form of synaptic plasticity was previously overlooked at the calyx of Held (but see (Habets and Borst, 2005)), we decided to study PTP in more detail and learn about its underlying mechanisms by using different experimental approaches. We found that a residual ( 40-120 nM) $\left[\mathrm{Ca}^{2+}\right]_{\mathrm{i}}$ signal in the presynaptic terminal with a surprisingly small amplitude decays in parallel with PTP, and that whole-cell recording of the presynaptic nerve terminal abolishes PTP. These findings suggest that additional intracellular signaling components, besides a simple accumulation of residual free $\left[\mathrm{Ca}^{2+}\right]_{\mathrm{i}}$, might contribute to the generation of PTP at the calyx of Held. Indeed, we found that inhibition of protein kinase C (PKC) suppresses PTP. Thus, during periods of high-frequency activity, residual $\mathrm{Ca}^{2+}$ builds-up and associated intracellular messengers like PKC are activated.

\subsection{Identification and developmental regulation of PTP at the calyx of Held}

Brief $100 \mathrm{~Hz}$ trains of up to a few seconds duration caused robust PTP of synaptic strength at the calyx of Held (Fig.3-1). The unchanged mEPSC amplitudes during PTP and the finding that PTP was suppressed by presynaptic whole-cell recording indicate that this potentiation of synaptic strength was presynaptic in origin, similar to PTP at other synapses (Zucker and Regehr, 2002).

The decay time constant of PTP depended on the length of the induction train, with time constants in the range of 20-60 s (Fig. 3-2). This distinguishes this form of synaptic enhancement from augmentation, which decays with a shorter decay time constant $(\sim 8 \mathrm{~s})$, independent of the strength of the induction train (Magleby and Zengel, 1976). Recently, it was shown (Habets and Borst, 2005) that prolonged $20 \mathrm{~Hz}$ trains induce a longerlasting form of PTP at the calyx of Held, with decay time constant of $\sim 9 \mathrm{~min}$. This form of PTP was associated with an $\sim 30 \%$ increase in the size of the readily released pool (RRP), whereas in our study, the RRP was increased by $\sim 10 \%$ (Fig. 3-9). Both studies show that PTP at the calyx of Held is mediated by an increased release probability without strongly increased RRP, similar to augmentation in hippocampal synapses (Stevens and Wesseling, 1999). It seems possible, though, that during longer-lasting 
forms of PTP the pool size is increased more substantially ( $-30 \%)$ (Habets and Borst, 2005) compared with the shorter forms of PTP studied here.

We showed that PTP was induced more easily in calyces of Held of young rats (P4 -P6) compared with two older age groups studied right before and after the onset of hearing at around P12 in rodents (P8-P10 and P12-P14) (Fig. 3-3). This adds PTP to a series of functional developmental changes at the calyx of Held, which include the presynaptic AP width, the kinetics of AMPA-receptor- mediated EPSCs, and the amount of synaptic depression (Taschenberger and von Gersdorff, 2000; Iwasaki and Takahashi, 2001; Joshi and Wang, 2002). These developmental changes are thought to help the calyx of Held to reliably transmit trains of high-frequency action potentials. Given the role of presynaptic $\mathrm{Ca}^{2+}$ in PTP, it is likely that the developmental regulation of PTP is caused by an increased $\mathrm{Ca}^{2+}$ buffering and $\mathrm{Ca}^{2+}$ extrusion at the calyx of Held (Chuhma and Ohmori, 2001). Indeed, the shift of PTP induction toward longer $100 \mathrm{~Hz}$ trains during development (Fig. 3-3B) was analogous to the effect of EGTA-AM application in young calyces of Held. EGTA-AM blocked PTP induced by weak induction more readily than PTP induced by a stronger induction protocol ( 1 vs. $4 \mathrm{~s} 100 \mathrm{~Hz}$ trains) (Fig. 3-4E, F). It is thus tempting to speculate that an increase in the expression of an endogenous $\mathrm{Ca}^{2+}$ buffer with slow binding kinetics, such as parvalbumin (Lee et al., 2000), might contribute to the developmental regulation of PTP. Parvalbumin is expressed at the calyx of Held (Felmy and Schneggenburger, 2004), and its onset of expression at around P8 in rats (Lohmann and Friauf, 1996) (Felmy and Schneggenburger, 2004) coincides well with the downregulation of PTP observed here.

Thus, these results show that PTP, an additional form of synaptic plasticity, which was found at the calyx of Held, is developmentally regulated and could be expressed in two different time-scales, depending on the stimulation protocol: fast decaying, within $\sim 1$ min (induced by 1-4 s $100 \mathrm{~Hz}$ stimulation in our study); and longer decaying, within $\sim 9$ min (induced by $20 \mathrm{~Hz}$ stimulation for $5 \mathrm{~min}$, (Habets and Borst, 2005)).

The question arises what could be the physiological role of PTP in the developing calyces of Held? It was shown from in vivo recordings that globular bushy cells in the aVCN, which give rise to calyces of Held, have spontaneous firing rates in the range of 1 - $100 \mathrm{~Hz}$, and sound stimulation further increases their firing rates up to a few hundred $\mathrm{Hz}$ (Friauf and Ostwald, 1988; Spirou et al., 1990; Smith et al., 1991; Kopp-Scheinpflug et al., 2003). The activity patterns of a VCN neurons in developing rodents before the onset of airborne hearing at around P12 (Jewett and Romano, 1972; Blatchley et al., 1987) 
have, to our knowledge, not been recorded yet. However, rhythmic patterned activity, maybe driven by spontaneous electrical activity of inner hair cells (Beutner and Moser, 2001) has been reported in other species. Such a pre-sensory rhythmic activity in the auditory system might contribute to the maintenance, and refinement of synaptic connections in the auditory pathway. It is possible that induction of PTP and the associated activation of intracellular signalling pathways, like the protein kinase-C pathway, reflect a non-associative mechanism of functional re-enforcement of synapses, which precedes longer-lasting functional and morphological changes of excitatory synapses during postnatal development.

On the other hand, PTP, as one of the forms of short-term enhancement (STE), will also contribute to shape the information-processing characteristics at the calyx of Held in certain cases, but are not related to the development of this synapse.

\subsection{Presynaptic $\mathrm{Ca}^{2+}$-dependence of PTP}

Various lines of evidence suggest that PTP is driven by elevations of presynaptic $\left[\mathrm{Ca}^{2+}\right]_{\mathrm{i}}$ in the low nanomolar range $(\sim 40-120 \mathrm{nM})$ (Fig. 3-7C). First, PTP and the slowest decay phase of a residual $\left[\mathrm{Ca}^{2+}\right]_{\mathrm{i}}$ signal decayed in parallel with similar time constants (Fig.3-6C, 3-7A), in agreement with previous $\mathrm{Ca}^{2+}$-imaging studies (Delaney et al., 1989; Regehr et al., 1994). Second, PTP was suppressed by the membrane-permeable $\mathrm{Ca}^{2+}$ chelator EGTA-AM, although EGTA-AM also reduced the baseline synaptic strength, in agreement with previous studies in young (< P10) rats (Borst and Sakmann, 1996) (Fedchyshyn and Wang, 2005)(Fig. 3-4). These experiments show that the prolonged presence of residual $\left[\mathrm{Ca}^{2+}\right]_{\mathrm{i}}$ with an increment of $\sim 80 \mathrm{nM}$ over baseline $\left[\mathrm{Ca}^{2+}\right]_{\mathrm{i}}$ is necessary for PTP. Recently, another work appeared, supporting the idea that small but prolonged intraterminal $\mathrm{Ca}^{2+}$ elevations can enhance transmitter release up to 2-fold (Awatramani et al., 2005). The authors manipulated the resting potential of the calyx terminal by depolarizing the terminal from a holding potential of $-80 \mathrm{mV}$ to -60 or $65 \mathrm{mV}$ for several seconds. Such depolarization of the membrane potential led to an activation of $\mathrm{P} / \mathrm{Q}$-type $\mathrm{Ca}^{2+}$ channels, a gradual rise in the background level of $\mathrm{Ca}^{2+}(\sim 50-100 \mathrm{nM})$, and caused a 2-fold increase in the amplitude of the glutamatergic EPSC. Neither the depolarization nor this small change in $\mathrm{Ca}^{2+}$ altered the spike-evoked $\mathrm{Ca}^{2+}$ influx; however, they were sufficient to increase significantly the probability of glutamate release, with no effect on the readily releasable pool of vesicles. Thus, similar 
requirements $(\sim 100 \mathrm{nM})$ of residual $\left[\mathrm{Ca}^{2+}\right]_{\mathrm{i}}$ for PTP induction and for a short-term depolarization-induced enhancement (STDE), observed by (Awatramani et al., 2005), suggest that PTP and STDE might share common mechanism(s).

In addition, an importance of intracellular presynaptic $\mathrm{Ca}^{2+}$ elevations for PTP induction can be seen from our experiments, where presynaptic whole-cell recordings were done in combination with postsynaptic voltage-clamp (Fig.3-10). Presynaptic whole-cell recordings suppressed PTP, which was probably caused by the accelerated decay of residual $\left[\mathrm{Ca}^{2+}\right]_{i}$ (Fig. 3-10C), and not primarily by a "wash out" of an intracellular signalling molecule into the patch pipette. This is because PTP readily recovered after removal of the presynaptic pipette (Fig. 3-10), opposite to what would be expected for an irreversible loss of a diffusible signalling molecule from the cytoplasm. Presynaptic whole-cell recording likely caused a diffusion of $\mathrm{Ca}^{2+}$, and possibly also $\mathrm{Na}^{+}$, into the recording patch pipette (Pusch and Neher, 1988) and thereby accelerated the decay of residual $\left[\mathrm{Ca}^{2+}\right]_{\mathrm{i}} \cdot \mathrm{Na}^{+}$accumulation during trains of presynaptic action potentials (APs) contributes to the residual $\left[\mathrm{Ca}^{2+}\right]_{\mathrm{i}}$ signal by compromising the function of $\mathrm{Na}^{+}-$ dependent $\mathrm{Ca}^{2+}$-clearance mechanisms (Zhong et al., 2001). It is possible that diffusion of $\mathrm{Na}^{+}$into the measuring patch pipette suppressed the accumulation of $\mathrm{Na}^{+}$, thereby leading to the observed faster decay of residual $\mathrm{Ca}^{2+}$. Thus, the accelerated decay of the residual $\left[\mathrm{Ca}^{2+}\right]_{\mathrm{i}}$ signal most likely underlies the suppression of PTP during presynaptic whole-cell recording, although it remains possible that presynaptic whole-cell recording also impaired the function of intracellular signalling pathways, such as the protein-kinase $\mathrm{C}$ pathway, which might be involved in PTP. Indeed, we show that PKC blockers suppress PTP (Fig. 3-12 - 15; see below for discussion).

While studying the $\mathrm{Ca}^{2+}$-dependence of PTP, we observed an additional involvement of residual $\left[\mathrm{Ca}^{2+}\right]_{\mathrm{i}}$ in the mechanisms of short-term depression, which is observed during HFS at the calyx of Held (Borst et al., 1995; von Gersdorff et al., 1997; Forsythe et al., 1998; Schneggenburger et al., 1999). This progressive decline in the size of synchronous release (phasic) during HFS, which has been attributed primarily to the depletion of a pool of readily releasable vesicles, was accompanied by a "standing" current, which probably represented both asynchronous (mEPSC-like) release and a glutamate spillover current. Interestingly, application of EGTA-AM blocked the "standing current" during HFS (Fig.3-5), which points towards the possibility that the observed "standing" current is primarily a consequence of asynchronous release. Analysis of EPSC depression, measured during PTP induction trains $(100 \mathrm{~Hz}, 4 \mathrm{~s})$, showed that 
bath application of EGTA-AM blocked the $1^{\text {st }}$ EPSC by $\sim 44 \%$. Surprisingly, the phasic EPSC during the steady-state of depression was increased (Fig.3-5). Such a different sensitivity of phasic and asynchronous release to EGTA-AM was described previously in other studies (Lu and Trussell, 2000; Hagler and Goda, 2001; Otsu et al., 2004). It was proposed that asynchronous release is triggered by a relatively low $\left[\mathrm{Ca}^{2+}\right]_{\mathrm{i}}$ (than phasic that can be maintained during the interval between repeated APs. Phasic release, which requires high $\left[\mathrm{Ca}^{2+}\right]_{\mathrm{i}}$ associated with microdomains, would be expected to occur briefly $(<$ $1 \mathrm{~ms}$ ) in association with each AP (Bollmann et al., 2000; Schneggenburger and Neher, 2000). It is possible, as suggested in (Otsu et al., 2004), that if $\mathrm{Ca}^{2+}$ build-up increases the rate of asynchronous release, relatively few recovered RRP vesicles would be able to accumulate for phasic release during the brief time between successive stimuli in a train, leading to decrease in phasic release. This counterplay between synchronous and asynchronous release might represent an important mechanism, by which synapses are able to maintain synaptic transmission when driven with high frequencies. The slow $\mathrm{Ca}^{2+}$ EGTA will reduce the spatially averaged $\left[\mathrm{Ca}^{2+}\right]_{\mathrm{i}}$ rise more strongly than the microdomain $\left[\mathrm{Ca}^{2+}\right]_{\mathrm{i}}$, and thereby shift the release from asynchronous to phasic mode. Interestingly, endogenous $\mathrm{Ca}^{2+}$ buffers with slow $\mathrm{Ca}^{2+}$ binding kinetics, like parvalbumin, might play a similar role. Parvalbumin is expressed at calyceal terminals from postnatal day six (P6) onwards and its up-regulation with development might increase the presynaptic $\mathrm{Ca}^{2+}$ buffering strength (Felmy and Schneggenburger, 2004). This could be especially relevant for such high fidelity synapses like the calyx of Held, which is "designed" to reliably localize high-frequency sounds.

\subsection{Probing the PTP mechanisms at the calyx of Held}

Given the evidence that PTP is caused by small elevations of presynaptic $\left[\mathrm{Ca}^{2+}\right]_{\mathrm{i}}$ by $\sim 80 \mathrm{nM}$, how do such small $\left[\mathrm{Ca}^{2+}\right]_{\mathrm{i}}$ elevations increase the transmitter release probability? Considering the estimates of the local $\left[\mathrm{Ca}^{2+}\right]_{\mathrm{i}}$ reached transiently at the $\mathrm{Ca}^{2+}$ sensor for vesicle fusion ( $\sim 10-20 \mu \mathrm{M})$ (Bollmann et al., 2000; Schneggenburger and Neher, 2000), it is seen that only a negligible fraction of the overall release potentiation is explained by summation of residual $\left[\mathrm{Ca}^{2+}\right]_{i}$ with the local $\left[\mathrm{Ca}^{2+}\right]_{\mathrm{i}}$ signal. We would expect a PTP of only $104 \%$ of control for a residual $\left[\mathrm{Ca}^{2+}\right]_{\mathrm{i}}$ of $100 \mathrm{nM}$, assuming a peak local $\left[\mathrm{Ca}^{2+}\right]_{\mathrm{i}}$ of 10 $\mu \mathrm{M}$ and a fourth power relationship between transmitter release and $\left[\mathrm{Ca}^{2+}\right]_{\mathrm{i}}$. It is also unlikely that the increased release probability underlying PTP is caused by the same 
mechanism that causes $\mathrm{Ca}^{2+}$ - dependent short-term facilitation. It has been shown that brief $(\sim 20 \mathrm{~ms})\left[\mathrm{Ca}^{2+}\right]_{\mathrm{i}}$ elevations by $\sim 500-600 \mathrm{nM}$ cause an approximately twofold enhancement of transmitter release during short-term facilitation at the calyx of Held (Fig. $7 B$ in (Felmy et al., 2003)). Thus, the $\left[\mathrm{Ca}^{2+}\right]_{\mathrm{i}}$ increment needed to cause a given enhancement is $\sim 5-10$ times higher for facilitation compared with PTP, making it likely that the two forms of short-term plasticity are mediated by different $\mathrm{Ca}^{2+}$-dependent mechanisms (Zucker and Regehr, 2002). Short-term facilitation at the calyx of Held has been proposed to result from a mechanism of $\mathrm{Ca}^{2+}$ summation, aided by supralinearities caused by (partial) saturation of a fast endogenous $\mathrm{Ca}^{2+}$ buffer (Felmy et al., 2003). However, a mechanism of $\mathrm{Ca}^{2+}$-buffer saturation is unlikely to cause significant amounts of PTP, because the small elevation of $\left[\mathrm{Ca}^{2+}\right]_{\mathrm{i}}$ during PTP $(\sim 120 \mathrm{nM}$ at most $)$ should not significantly saturate endogenous $\mathrm{Ca}^{2+}$ buffers.

Therefore, in the next experiments, we performed direct presynaptic recordings to identify which of above discussed $\mathrm{Ca}^{2+}$-dependent mechanisms might be relevant for PTP at the calyx of Held.

\subsubsection{Role of changes in presynaptic calcium currents}

Calyceal calcium currents facilitate calcium-dependently (Borst and Sakmann, 1998; Cuttle et al., 1998). They could activate more rapidly in the presence of residual calcium. Therefore, to quantify the possible contribution of facilitation and inactivation of calcium currents, direct measurements of calcium currents and calcium influx during an AP after the establishment of PTP are necessary. However, as it was already mentioned above, it was not possible to test these mechanisms in whole-cell recordings, because presynaptic whole-cell recordings suppressed PTP completely (Fig.3-10). Therefore, we used perforated-patch clamp at the calyx of Held, which could better preserve intracellular signalling pathways. The channels, formed by Amphotericin B (the antibiotic used here for perforation), are permeable to the monovalent cations and $\mathrm{Cl}^{-}$, but not to divalent ions such as $\mathrm{Ca}^{2+}$, which is an important signaling molecule in the cell. In these experiments, we applied HFS, which normally induced PTP, and measured presynaptic $\mathrm{I}_{\mathrm{Ca}}$. However, no increase in $\mathrm{I}_{\mathrm{Ca}}$ peak amplitude was observed (Fig. 3-11). Instead, $\mathrm{I}_{\mathrm{Ca}}$ strongly inactivated during the train and was not yet fully recovered at the time when the peak of PTP was usually observed ( 20-30 s following HFS train). Such inactivation of presynaptic calcium currents was also observed during our whole-cell recordings (not 
shown) and was previously described by (Forsythe et al., 1998), who studied the role of $\mathrm{I}_{\mathrm{Ca}}$ inactivation in short-term depression at the calyx of Held. Thus, it seems that even under the more "physiological" conditions of perforated patch clamp recordings, $\mathrm{I}_{\mathrm{Ca}}$ undergoes inactivation, and slow recovery from inactivation following HFS. Therefore, PTP is probably not mediated by a modulation of presynaptic $\mathrm{Ca}^{2+}$ currents (which could, for example, occur after the activation of PKC). Nevertheless, it remains possible that changes in AP waveform occur during PTP that then lead to an increased $\mathrm{I}_{\mathrm{Ca}}$. To test this, it would be desirable to perform presynaptic perforated patch recordings under currentclamp, and simultaneous postsynaptic recordings to measure PTP. However, because these experiments were technically very challenging, we were not able to obtain conclusive results within the frame of this work.

Concerning the role of AP waveform in modulation of Ca-influx, we did not observe changes in AP waveform during presynaptic whole-cell recordings (Fig. 3-10A). This, however, does not necessarily argue against AP broadening, because PTP was absent under this experimental condition. Indeed, evidence for a change in presynaptic AP waveform during a longer-lasting form of PTP has been observed recently by (Habets and Borst, 2005).

\subsubsection{Involvement of second messengers}

Another mechanism by which changes in synaptic strength could occur at the presynaptic terminal involves intracellular second messenger-dependent regulation of protein interactions within the release machinery. Various protein kinases have been implicated in the regulation of transmitter release (Greengard et al., 1993; Vaughan et al., 1998). Cyclic AMP-dependent protein kinase (PKA), protein kinase C (PKC) and $\mathrm{Ca}^{2+}$ and calmodulin-dependent protein kinase II (CaMKII) stimulate neurotransmitter release in various neuronal preparations. In our study, the involvement of PKC was investigated, because it was shown to be important for PTP in other brain regions (Alle et al., 2001; Brager et al., 2003).

PKC is a $\mathrm{Ca}^{2+}$ and phospholipid-dependent kinase. To date, eleven mammalian isoforms of PKC have been identified and divided into three subclasses: conventional, novel and atypical, based on their structure and properties (Newton, 2001; Rhee, 2001). PKC is highly expressed in brain and distributes differentially in neurons in an isoformspecific manner. Although all of the PKC subtypes exhibit broad substrate specificity and 
most likely regulate many aspects of cell function, they differ dramatically in their ability to be regulated by cellular levels of $\mathrm{Ca}^{2+}$ and various phospholipids. Some subtypes, like conventional ones, are highly sensitive to $\mathrm{Ca}^{2+}$, whereas others are relatively insensitive. Several regulatory domains have been identified within the PKC molecule: 1) a C1 domain, which is a cystein-rich region that is present in all PKC isoforms and mediates the effect of diacylglycerol (DAG) and phorbol esters; 2) a C2 domain, which mediates the $\mathrm{Ca}^{2+}$-binding property of PKC. In conventional and novel PKCs, $\mathrm{C} 1$ is present in a tandem repeat, named $\mathrm{C} 1 \mathrm{~A}$ and $\mathrm{C} 1 \mathrm{~B}$. The $\mathrm{C} 2$ domain in conventional PKCs binds membranes in a $\mathrm{Ca}^{2+}$-dependent manner, however, novel $\mathrm{C} 2$ domains do not bind $\mathrm{Ca}^{2+}$.

Phorbol esters, which activate all known PKC isoforms, induced a profound enhancement of transmitter release from a wide variety of neuronal preparations and also at the calyx of Held synapse (Hilfiker and Augustine, 1999; Hori et al., 1999; Lou et al., 2005). Phorbol esters have been a valuable tool in PKC research. However, recently it was shown that phorbol esters can potentiate transmitter release also via Munc-13, a brain-specific protein essential for neurotransmitter release and specifically localized to presynaptic terminals. It contains a DAG/phorbol ester binding domain $(\mathrm{C} 1)$ and two $\mathrm{C} 2$ domains homologous those of PKCs (Augustin et al., 1999; Rosenmund et al., 2002). Munc-13-1 interacts with syntaxin 1 and with DOC2, a C2-domain-containing protein of the putative regulator of neurotransmitter release (Orita et al., 1997). Based on various lines of evidences, it was suggested that Munc-13-1 plays an essential role in the priming step after vesicle docking (Augustin et al., 1999) and Munc-13-1 is involved in phorbol ester-induced potentiation of glutamate release in addition to the PKC-pathway (Rhee et al., 2002).

It is likely that during PTP at the calyx of Held, $\mathrm{Ca}^{2+}$ either acts at a high-affinity site relatively tightly associated with the release machinery, but distinct from the low- to intermediate-affinity site that drives vesicle fusion, and causes an increase in the effective $\mathrm{Ca}^{2+}$ sensitivity of vesicle fusion, in agreement with previous ideas about the action of residual $\mathrm{Ca}^{2+}$ (Zucker and Regehr, 2002). Such a high-affinity site could be formed by $\mathrm{Ca}^{2+} /$ calmodulin interacting with the presynaptic vesicle priming factor Munc-13 (Junge et al., 2004). However, because PTP was not accompanied by a pool size increase (Fig.39), one would have to postulate a post-priming role for Munc-13 activated by $\mathrm{Ca}^{2+} /$ calmodulin. To test the role of PKC, we used a pharmacological approach and treated slices with different PKC inhibitors (Fig.3-12 - 15). The broad-spectrum PKC inhibitor BIS was able to block PTP by $\sim 50 \%$ (Fig. 3-14, 3-15). However, the most 
prominent effect was observed with Ro-31-8220, which suppressed PTP by 70\% (Fig.3$12,3-15)$. In addition, the peak of the residual potentiation was delayed after Ro-31-8220 (Fig.3-12) and BIS treatment (Fig.3-14), which points towards a possible role of PKC not only in potentiation, but also in acceleration of the recovery rate of EPSCs from depression after a high frequency. The recovery process was tested in the presence of the PKC inhibitor Ro-31-8220 by analyzing EPSC responses at different interstimulus intervals. We found that Ro-31-8220 slowed down the recovery from depression (Fig.315), which proposes an involvement of PKC in the recovery from depression. PKC might regulate this process via phosphorylation-dephosphorylation events of certain substrate proteins. However, the slowing of recovery from short-term depression can also be due to the inhibition of PTP itself because, as was suggested by John Wesseling (personal communication), the recovery from depression might be speeded up by short-term enhancement, like augmentation (or, in our case, PTP) of transmitter release.

To test what can be the possible mechanism(s) of PKC activation and which particular PKC isoforms are involved in PTP, we performed additional pharmacological experiments. For example, to answer the question whether it is the $\mathrm{C} 1$ or the $\mathrm{C} 2$ domain (or, may be both), which might be modulated during PTP, we first used Calphostin C, an antagonist which competes with DAG and phorbol esters for the binding to the $\mathrm{C} 1$ domain of PKCs. Acute application or incubation of the slices with Calphostin $\mathrm{C}$ had no effect on PTP (Fig.3-15). However, we could not draw a conclusion from these experiments, because preincubation with this blocker was also accompanied by the degradation of the slices. Therefore, the Calphostin $\mathrm{C}$ effect could be overlooked, because of the cytotoxicity of this antagonist, or another reason might be that it could not reach the intracellular space of the terminal from extracellular medium.

It is known that calmodulin can mediate various actions of $\mathrm{Ca}^{2+}$ in the cells, for example, such as activation of $\mathrm{Ca}^{2+}$-dependent adenylate cyclases 1 and 8 (AC1 and $\mathrm{AC8}), \mathrm{PLC}_{\delta}, \mathrm{CaMKII}$ or CaM-binding site on Munc-13. To test whether increase in intracellular $\mathrm{Ca}^{2+}$ concentration during PTP might promote calmodulin activation, we applied Calmidazolium (calmodulin blocker). However, no effect on PTP was observed (Fig.3-15). These results either suggest that calmodulin-mediated pathway does not play a significant role in PTP.

In another line of pharmacological experiments, we tried to verify, which PKC isoforms might be involved in PTP induction. Application of Gö-6976, a specific inhibitor of conventional PKCs $\left(\mathrm{PKC}_{\alpha}, \mathrm{PKC}_{\beta \mathrm{I}}\right)$ had no effect on PTP (Fig.3-15). These 
results suggest that $\mathrm{Ca}^{2+}$-independent (novel) PKC isoforms might play role in PTP at the calyx of Held. Indeed, it was shown that novel $\mathrm{PKC}_{\varepsilon}$ isoform is expressed in this synapse and that activation of $\mathrm{PKC}_{\varepsilon}$ by phorbol esters might cause its translocation toward the synaptic side of the terminal (Saitoh et al., 2001). However additional pharmacological investigations together with immunocytochemistry are necessary to investigate this question further.

Concerning the role of the PKC pathway in PTP, it is interesting to know how PKC can exert its action to increase the transmitter release. What could be the potential molecular targets? It seems that mechanisms of PKC-dependent regulation of release are different among different preparations. For example, the activation of PKC by phorbol esters increase the readily-released pool (RRP) in hippocampal neurons (Stevens and Sullivan, 1998), whereas it increases the $\mathrm{Ca}^{2+}$ sensitivity of secretion rather than RRP size in chick ciliary ganglion (Yawo, 1999). At the calyx of Held, application of phorbol esters, which can potentially target both PKC and Munc-13 (see above), increases the $\mathrm{Ca}^{2+}$ sensitivity of vesicle fusion ( $\mathrm{Wu}$ and $\mathrm{Wu}, 2001$; Lou et al., 2005) and, in addition, slightly increases the presynaptic $\mathrm{Ca}^{2+}$ current (Lou et al., 2005).

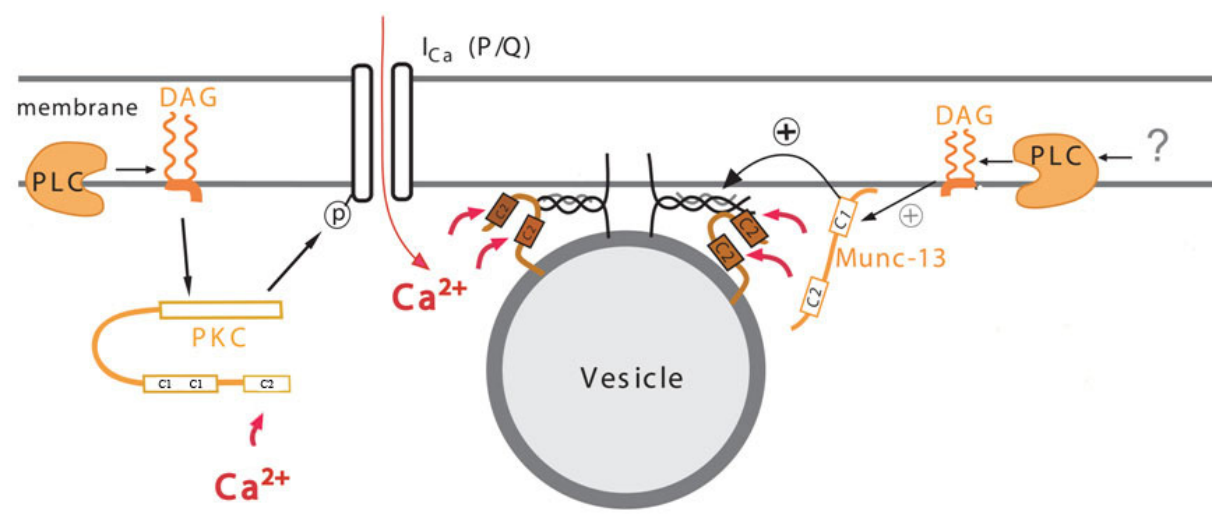

Figure 4-1. Schematic representation of possible PTP mechanisms at the calyx of Held. Accumulation of presynaptic residual $\left[\mathrm{Ca}^{2+}\right]_{\mathrm{i}}$ is very important for PTP induction. It can trigger a series of different processes. Activation of the protein kinase C (PKC)-pathway might be one of them. PKC can modulate either $\mathrm{Ca}^{2+}$ influx, for example by phosphorylation of $\mathrm{Ca}^{2+}$ channels, or the $\mathrm{Ca}^{2+}$-sensitivity of the release machinery. A possible involvement of phospholipase-C (PLC), one of the products of which is diacylglycerol (DAG) that could activate both PKC and Munc-13, still has to be tested.

Thus, based on our study and on the current knowledge about $\mathrm{Ca}^{2+}$-dependent intracellular signalling during various forms of synaptic plasticity, we can discuss the mechanisms that might increase the amount of transmitter release during PTP at the calyx 
of Held (Fig.4-1). From one hand, elevated residual presynaptic $\left[\mathrm{Ca}^{2+}\right]_{\mathrm{i}}$ could activate $\mathrm{PKC}$ via direct $\mathrm{Ca}^{2+}$ binding to its $\mathrm{C} 2$ domain. Alternatively, PKC might be also regulated by DAG, which could be activated during PTP by certain mechanisms, for example, by activation of phospholipase C (PLC). There are four distinct PLC subfamilies, such as $\mathrm{PLC}_{\beta}, \mathrm{PLC}_{\gamma}, \mathrm{PLC}_{\delta}$ and $\mathrm{PLC}_{\varepsilon}$, which have been identified in mammals. All of these PLC isozymes require $\mathrm{Ca}^{2+}$ for the catalytic function of the hydrolysis of phosphatidylinositol 4,5-bisphosphate [PtdIns(4,5)P2] to inositol 1,4,5-trisphosphate and diacylglycerol in response to the activation of more than 100 different cell surface receptors (Rhee, 2001). The presence of distinct regulatory domains in PLC isoforms renders them susceptible to different modes of activation (Rhee, 2001): (i) for example, $\mathrm{PLC}_{\delta}$ is most sensitive to $\mathrm{Ca}^{2+}$ among other isoforms; (ii) the activation of $\mathrm{PLC}_{\beta}$ can be promoted by the activation of G-protein-coupled receptors; (iii) mobilization of $\mathrm{PLC}_{\gamma}$ is influenced by different neurotrophins via activation of receptor protein tyrosine kinases; (iiii) $\mathrm{PLC}_{\varepsilon}$ activation might be influenced by cyclic AMP level in the cell, which is regulated by $\mathrm{Ca}^{2+}$ dependent adenylyl cyclases of type 1 and 8 (Cooper, Mons and Karpen, 1995). As one can see, there is a big "net" of protein-protein interactions that could activate different intracellular signalling pathway, in particular the PKC pathway.

In turn, PKC activation could either increase the $\mathrm{Ca}^{2+}$ influx into the cell by direct phosphorylation of $\mathrm{Ca}^{2+}$ channels or enhance the $\mathrm{Ca}^{2+}$-sensitivity of vesicle fusion. Recently, Lou and coworkers (2005) proposed that the $\mathrm{Ca}^{2+}$-sensitivity might change via an increase in the "willingness" of vesicle to fuse, without a change in the $\mathrm{Ca}^{2+}$-binding properties of the $\mathrm{Ca}^{2+}$ sensor. Increased fusion willingness might be caused by lowering the energy barrier for fusion, a mechanism which was implicated in augmentation and in $\mathrm{Ca}^{2+}$-independent, hypertonicity-evoked transmitter release (Stevens and Wesseling, 1999). Lou and coworkers (2005) suggested that SNAREs and synaptotagmins, proteins representing the release machinery, might be such a $\mathrm{Ca}^{2+}$ sensor, which might be modulated by PKC phosphorylation. Indeed, the PKC phosphorylation site in SNAP-25 has been mapped to serine (Ser ${ }^{187}$ ) (Shimazaki et al., 1996; Genoud et al., 1999; Nagy et al., 2002; Rhee et al., 2002), which is located within the negatively charged C-terminal and between the cleavage sites for botulinum toxins $\mathrm{A}$ and $\mathrm{E}$. This region has been shown to be of critical importance for $\mathrm{Ca}^{2+}$-triggered exocytosis. Another $\mathrm{Ca}^{2+}$ sensor candidate might be synaptotagmin I or II. It was shown that point mutation in synaptotagmin I caused a twofold decrease in $\mathrm{Ca}^{2+}$ sensitivity of neurotransmitter, but didn't alter 
spontaneous release or the size of the readily releasable pool (Fernandez-Chacon et al., 2001).

On the other hand, Munc-13s were also shown to be capable to activate SNARE complex formation by unfolding syntaxin (Brose et al., 1995; Augustin et al., 1999) Munc-13s have a DAG binding site like PKC and binding of DAG to Munc-13 is thought to mediate augmentation of release in hippocampal neurons (Brose and Rosenmund, 2002). Although we found no significant increase in the readily-releasable pool (RRP) during PTP, the main mechanism by which Munc-13s exert its action to potentiate transmitter release, we do not exclude this possibility, especially for the longer-lasting form of PTP observed at the calyx of Held by (Habets and Borst, 2005). It is also possible that DAG (or phorbol ester) binding to Munc-13 lead to an increased "willingness" of fusion, may be if Munc-13 remains bound to SNARE proteins after vesicle priming.

However, future work needs to establish the exact mechanism of the release probability increase and the modulatory $\mathrm{Ca}^{2+}$-binding site(s) involved in the action of $\mathrm{Ca}^{2+}$ during PTP.

\subsection{Outlook and future experiments}

In this work posttetanic potentiation was identified at the calyx of Held, which was previously not described at this synapse. Possible mechanisms were investigated using different experimental approaches. $\mathrm{Ca}^{2+}$-imaging revealed that the transient increase of glutamate release during PTP was caused by elevations of intracellular $\mathrm{Ca}^{2+}$ in the presynaptic terminal. In addition, an involvement of the PKC pathway was shown by pharmacological experiments using different PKC antagonists.

The next step would be to examine which PKC isoform(s) might be involved in PTP and what are the molecular targets of their action. For example, immunocytochemistry can be applied to verify the expression of particular PKC isoform(s) at the calyx of Held. From another side, more pharmacological experiments could be done using antagonists specific for different PKCs inhibitors. A possible involvement of PLC also could be tested in the same way.

In another line of research an occlusion experiments could be performed, pursuing the question whether potentiation of transmitter release caused by phorbol esters (Lou et al., 2005), shares the same mechanisms with PTP. In order to explore this possibility, the degree of PTP needs to be tested during phorbol ester application. Perforated presynaptic 
patch-clamp in combination with postsynaptic whole-cell recordings could be performed to test whether PTP can be observed by this approach, and if yes, then one would have a possibility to examine presynaptic PTP mechanisms more directly. 


\section{Summary}

In this work, a hitherto overlooked form of short-term plasticity was identified at the calyx of Held, a glutamatergic excitatory synapse in the auditory brainstem pathway.

Brief trains of high frequency stimulation $(100 \mathrm{~Hz}$ for $1-8 \mathrm{~s})$, which were applied to the afferent fibers that give rise to the calyces of Held, induced robust potentiation of excitatory postsynaptic currents (EPSCs), following the well-known depression of synaptic transmission during high frequency trains. This transient overshoot of synaptic transmission at the calyx of Held shared many properties with posttetanic potentiation (PTP) at other synapses. At the peak of PTP, synaptic strength was increased about twofold and the decay of PTP lasted over 10s of seconds to more than 1 minute, depending on the length of the induction train. The unchanged mEPSC amplitudes during PTP and the finding that PTP was suppressed by whole-cell recording of the nerve terminal indicate its presynaptic origin.

PTP was induced more easily in synapses from young rats (postnatal days, P4 - P7) as compared to an older age group (P8 - P14), suggesting that PTP is developmentally regulated, and might play a role during the formation and/or maturation of the calyx of Held.

We next investigated the possible mechanisms underlying PTP. First, we found that PTP is mediated primarily via an increase in the release probability of the vesicles in the readily releasable pool (RRP), without a significant change in the size of RRP. Second, surprisingly low ( $~ 80 \mathrm{nM}$ at the peak of PTP), but prolonged elevations of residual $\left[\mathrm{Ca}^{2+}\right]_{\mathrm{i}}$ in the presynaptic terminal were responsible for the induction of PTP. This high efficacy of a small residual $\left[\mathrm{Ca}^{2+}\right]_{\mathrm{i}}$ signal during PTP, and the sensitivity of PTP to presynaptic whole-cell recording, which was accompanied by accelerated residual $\left[\mathrm{Ca}^{2+}\right]_{\mathrm{i}}$ decay, suggested that other presynaptic intracellular messengers besides $\mathrm{Ca}^{2+}$ might also be involved in PTP. Therefore, we tested the protein kinase C / Munc-13 pathway. And indeed, different pharmacological experiments identified a role of protein kinase $\mathrm{C}$ in the induction of PTP at the calyx of Held.

Thus, the calyx of Held represents a highly plastic synapse, which displays several forms of short-term plasticity that are very similar to those observed in other synapses of the central nervous system. The accessibility of this synapse to presynaptic recordings will allow understanding the mechanisms of short-term enhancement in the near future. 



\section{Acknowledgements}

First, I would like to thank my supervisor Prof. Dr. Ralf Schneggenburger for giving me a great opportunity to work in his laboratory and for his constant support, patience, constructive criticism and guidance during the whole $\mathrm{PhD}$ project. Sincere thanks to my $\mathrm{PhD}$ thesis committee members the head of the department Prof. Dr. Erwin Neher and Prof. Markus Missler for their critical suggestions and friendly support during the course of the project.

I am thankful to the founders and coordination team of the Neuroscience Program for their help, perfect organization of the study process and other activities, which gives a nice opportunity for international students to study and have interesting life in Göttingen.

Many thanks to all current and former members of the Laboratory of Synaptic Mechanisms (or Synaptic Dynamics and Modulation, the former name of this group in Göttingen): Marcus Wölfel, Felix Felmy, Martin Müller, Xue-Lin Lou, Ralf Schneggenburger, Sigrid Schmidt, Le Xiao, Yun-Yun Han, Zhizhong Dong, Sarah Magnin. The people from this wonderful group were always around to help, supported me and made my life in the laboratory unforgettable. Special thanks to Dr. Xue-Lin Lou and Dr. Takeshi Sakaba for the great discussions, help and teaching me of special practical "tricks" to get wonderful electrophysiological recordings. I would also like to thank Martin Müller for his help in the lab, patience in sharing the set-up and critical volunteered reading of the Methods part of this manuscript. Many thanks to our beautiful part of the group: Le Xiao and Yun-Yun for their enormous support during daily life and especially during the movement of our lab to Lausanne. I would like to thank Sigrid Schmidt, Frank Würriehausen and Frank Köhne for their kind technical assistance.

Many thanks to the people from the group of Microscopy of Synaptic Transmission: Martin Wienisch, Edward Lemke, Veronica Müller, Maria Krikunova, Jürgen Klingauf, Natalya Glyvuk, Yaroslav Tsytsyura, Peter Vanden Berghe for having a great time in the lab and outside. Big thanks to all my friends, especially to Zinayida Shevtsova for the great friendship, support and nice time in daily life.

My biggest gratitude goes to my dear parents, Natalia and Sergey Korogod, and my sister Tatiana Korogod for their endless love, care and enormous support, which make me happy throughout the life. Very special thanks to my farther. The scientific discussions with him brought my interest in such wonderful field of science as Neuroscience. And, I am endlessly grateful to my husband, Alexey Kochubey, for his great help and essential support in all aspects of my life. 



\section{References}

Albillos A, Neher E, Moser T (2000) R-Type Ca2+ channels are coupled to the rapid component of secretion in mouse adrenal slice chromaffin cells. J Neurosci 20:8323-8330.

Alle H, Jonas P, Geiger JR (2001) PTP and LTP at a hippocampal mossy fiberinterneuron synapse. Proc Natl Acad Sci U S A 98:14708-14713.

Asztely F, Erdemli G, Kullmann DM (1997) Extrasynaptic glutamate spillover in the hippocampus: dependence on temperature and the role of active glutamate uptake. Neuron 18:281-293.

Atwood HL, Wojtowicz JM (1999) Silent synapses in neural plasticity: current evidence. Learn Mem 6:542-571.

Augustin I, Rosenmund C, Sudhof TC, Brose N (1999) Munc13-1 is essential for fusion competence of glutamatergic synaptic vesicles. Nature 400:457-461.

Augustine GJ, Betz H, Bommert K, Charlton MP, DeBello WM, Hans M, Swandulla D (1994) Molecular pathways for presynaptic calcium signaling. Adv Second Messenger Phosphoprotein Res 29:139-154.

Awatramani GB, Price GD, Trussell LO (2005) Modulation of transmitter release by presynaptic resting potential and background calcium levels. Neuron 48:109-121.

AxonGuide (1993) The Axon Guide for Electrophysiology \& Biophysics Laboratory Techniques. In: (Sherman-Gold R, ed): Axon Instruments Inc.

Betz A, Ashery U, Rickmann M, Augustin I, Neher E, Sudhof TC, Rettig J, Brose N (1998) Munc13-1 is a presynaptic phorbol ester receptor that enhances neurotransmitter release. Neuron 21:123-136.

Beutner D, Moser T (2001) The presynaptic function of mouse cochlear inner hair cells during development of hearing. J Neurosci 21:4593-4599.

Blatchley BJ, Cooper WA, Coleman JR (1987) Development of auditory brainstem response to tone pip stimuli in the rat. Brain Res 429:75-84.

Bollmann JH, Sakmann B, Borst JG (2000) Calcium sensitivity of glutamate release in a calyx-type terminal. Science 289:953-957.

Borst, Sakmann (1996) Calcium influx and transmitter release in a fast CNS synapse. Nature 383:431-434.

Borst JG, Sakmann B (1998) Facilitation of presynaptic calcium currents in the rat brainstem. J Physiol 513 ( Pt 1):149-155.

Borst JG, Helmchen F, Sakmann B (1995) Pre- and postsynaptic whole-cell recordings in the medial nucleus of the trapezoid body of the rat. J Physiol 489 ( Pt 3):825-840.

Brager DH, Cai X, Thompson SM (2003) Activity-dependent activation of presynaptic protein kinase $C$ mediates post-tetanic potentiation. Nat Neurosci 6:551-552.

Brose N, Rosenmund C (2002) Move over protein kinase C, you've got company: alternative cellular effectors of diacylglycerol and phorbol esters. J Cell Sci 115:4399-4411. 
Brose N, Hofmann K, Hata Y, Sudhof TC (1995) Mammalian homologues of Caenorhabditis elegans unc-13 gene define novel family of $\mathrm{C} 2$-domain proteins. $\mathrm{J}$ Biol Chem 270:25273-25280.

Chen L, Trautwein PG, Shero M, Salvi RJ (1996) Tuning, spontaneous activity and tonotopic map in chicken cochlear ganglion neurons following sound-induced hair cell loss and regeneration. Hear Res 98:152-164.

Chuhma N, Ohmori H (1998) Postnatal development of phase-locked high-fidelity synaptic transmission in the medial nucleus of the trapezoid body of the rat. $\mathrm{J}$ Neurosci 18:512-520.

Chuhma N, Ohmori H (2001) Differential development of Ca2+ dynamics in presynaptic terminal and postsynaptic neuron of the rat auditory synapse. Brain Res 904:341344.

Chuhma N, Ohmori H (2002) Role of $\mathrm{Ca}(2+)$ in the synchronization of transmitter release at calyceal synapses in the auditory system of rat. J Neurophysiol 87:222-228.

Cohen-Cory S (2002) The developing synapse: construction and modulation of synaptic structures and circuits. Science 298:770-776.

Coutinho V, Knopfel T (2002) Metabotropic glutamate receptors: electrical and chemical signaling properties. Neuroscientist 8:551-561.

Crowley JC, Katz LC (2002) Ocular dominance development revisited. Curr Opin Neurobiol 12:104-109.

Cummings DD, Wilcox KS, Dichter MA (1996) Calcium-dependent paired-pulse facilitation of miniature EPSC frequency accompanies depression of EPSCs at hippocampal synapses in culture. J Neurosci 16:5312-5323.

Cuttle MF, Tsujimoto T, Forsythe ID, Takahashi T (1998) Facilitation of the presynaptic calcium current at an auditory synapse in rat brainstem. J Physiol 512 ( Pt 3):723729.

Delaney KR, Tank DW (1994) A quantitative measurement of the dependence of shortterm synaptic enhancement on presynaptic residual calcium. J Neurosci 14:58855902.

Delaney KR, Zucker RS, Tank DW (1989) Calcium in motor nerve terminals associated with posttetanic potentiation. J Neurosci 9:3558-3567.

Diamond JS (2002) A broad view of glutamate spillover. Nat Neurosci 5:291-292.

Edwards FA, Konnerth A, Sakmann B, Takahashi T (1989) A thin slice preparation for patch clamp recordings from neurones of the mammalian central nervous system. Pflugers Arch 414:600-612.

Ene FA, Kullmann PH, Gillespie DC, Kandler K (2003) Glutamatergic calcium responses in the developing lateral superior olive: receptor types and their specific activation by synaptic activity patterns. J Neurophysiol 90:2581-2591.

Fedchyshyn MJ, Wang LY (2005) Developmental transformation of the release modality at the calyx of held synapse. J Neurosci 25:4131-4140.

Felmy F, Schneggenburger R (2004) Developmental expression of the Ca2+-binding proteins calretinin and parvalbumin at the calyx of held of rats and mice. Eur $\mathrm{J}$ Neurosci 20:1473-1482. 
Felmy F, Neher E, Schneggenburger R (2003) Probing the intracellular calcium sensitivity of transmitter release during synaptic facilitation. Neuron 37:801-811.

Fernandez-Chacon R, Konigstorfer A, Gerber SH, Garcia J, Matos MF, Stevens CF, Brose N, Rizo J, Rosenmund C, Sudhof TC (2001) Synaptotagmin I functions as a calcium regulator of release probability. Nature 410:41-49.

Fisher SA, Fischer TM, Carew TJ (1997) Multiple overlapping processes underlying short-term synaptic enhancement. Trends Neurosci 20:170-177.

Forsythe ID, Tsujimoto T, Barnes-Davies M, Cuttle MF, Takahashi T (1998) Inactivation of presynaptic calcium current contributes to synaptic depression at a fast central synapse. Neuron 20:797-807.

Friauf E, Ostwald J (1988) Divergent projections of physiologically characterized rat ventral cochlear nucleus neurons as shown by intra-axonal injection of horseradish peroxidase. Exp Brain Res 73:263-284.

Friauf E, Lohmann C (1999) Development of auditory brainstem circuitry. Activitydependent and activity-independent processes. Cell Tissue Res 297:187-195.

Genoud S, Pralong W, Riederer BM, Eder L, Catsicas S, Muller D (1999) Activitydependent phosphorylation of SNAP-25 in hippocampal organotypic cultures. J Neurochem 72:1699-1706.

Goda Y, Stevens CF (1996) Synaptic plasticity: the basis of particular types of learning. Curr Biol 6:375-378.

Greengard P, Valtorta F, Czernik AJ, Benfenati F (1993) Synaptic vesicle phosphoproteins and regulation of synaptic function. Science 259:780-785.

Griffith WH (1990) Voltage-clamp analysis of posttetanic potentiation of the mossy fiber to CA3 synapse in hippocampus. J Neurophysiol 63:491-501.

Grynkiewicz G (1985) A new generation of Ca2+ indicators with greatly improved fluorescence properties.

\section{. J Biol Chem}

Habets RL, Borst JG (2005) Post-tetanic potentiation in the rat calyx of Held synapse. J Physiol 564:173-187.

Hagler DJ, Jr., Goda Y (2001) Properties of synchronous and asynchronous release during pulse train depression in cultured hippocampal neurons. J Neurophysiol $85: 2324-2334$.

Hallermann S, Pawlu C, Jonas P, Heckmann M (2003) A large pool of releasable vesicles in a cortical glutamatergic synapse. Proc Natl Acad Sci U S A 100:8975-8980.

Hilfiker S, Augustine GJ (1999) Regulation of synaptic vesicle fusion by protein kinase C. J Physiol 515 ( Pt 1):1.

Holz R, Finkelstein A (1970) The water and nonelectrolyte permeability induced in thin lipid membranes by the polyene antibiotics nystatin and amphotericin B. J Gen Physiol 56:125-145.

Hori T, Takai Y, Takahashi T (1999) Presynaptic mechanism for phorbol ester-induced synaptic potentiation. J Neurosci 19:7262-7267. 
Isaac JT, Crair MC, Nicoll RA, Malenka RC (1997) Silent synapses during development of thalamocortical inputs. Neuron 18:269-280.

Ishikawa T, Sahara Y, Takahashi T (2002) A single packet of transmitter does not saturate postsynaptic glutamate receptors. Neuron 34:613-621.

Iwasaki S, Takahashi T (2001) Developmental regulation of transmitter release at the calyx of Held in rat auditory brainstem. J Physiol 534:861-871.

Iwasaki S, Momiyama A, Uchitel OD, Takahashi T (2000) Developmental changes in calcium channel types mediating central synaptic transmission. J Neurosci 20:5965.

Jewett DL, Romano MN (1972) Neonatal development of auditory system potentials averaged from the scalp of rat and cat. Brain Res 36:101-115.

Johnson EW, Wernig A (1971) The binomial nature of transmitter release at the crayfish neuromuscular junction. J Physiol 218:757-767.

Joshi I, Wang LY (2002) Developmental profiles of glutamate receptors and synaptic transmission at a single synapse in the mouse auditory brainstem. J Physiol 540:861-873.

Junge HJ, Rhee JS, Jahn O, Varoqueaux F, Spiess J, Waxham MN, Rosenmund C, Brose $\mathrm{N}$ (2004) Calmodulin and Munc13 form a Ca2+ sensor/effector complex that controls short-term synaptic plasticity. Cell 118:389-401.

Kandler K, Friauf E (1993) Pre- and postnatal development of efferent connections of the cochlear nucleus in the rat. J Comp Neurol 328:161-184.

Kopp-Scheinpflug C, Fuchs K, Lippe WR, Tempel BL, Rubsamen R (2003) Decreased temporal precision of auditory signaling in Kcnal-null mice: an electrophysiological study in vivo. J Neurosci 23:9199-9207.

Lee SH, Schwaller B, Neher E (2000) Kinetics of Ca2+ binding to parvalbumin in bovine chromaffin cells: implications for $[\mathrm{Ca} 2+]$ transients of neuronal dendrites. J Physiol 525 Pt 2:419-432.

Liao D, Hessler NA, Malinow R (1995) Activation of postsynaptically silent synapses during pairing-induced LTP in CA1 region of hippocampal slice. Nature 375:400404.

Lohmann C, Friauf E (1996) Distribution of the calcium-binding proteins parvalbumin and calretinin in the auditory brainstem of adult and developing rats. J Comp Neurol 367:90-109.

Lohmann C, Ilic V, Friauf E (1998) Development of a topographically organized auditory network in slice culture is calcium dependent. J Neurobiol 34:97-112.

Lou X, Scheuss V, Schneggenburger R (2005) Allosteric modulation of the presynaptic $\mathrm{Ca} 2+$ sensor for vesicle fusion. Nature 435:497-501.

Lu T, Trussell LO (2000) Inhibitory transmission mediated by asynchronous transmitter release. Neuron 26:683-694.

Magleby KL, Zengel JE (1975) A dual effect of repetitive stimulation on post-tetanic potentiation of transmitter release at the frog neuromuscular junction. J Physiol 245:163-182. 
Magleby KL, Zengel JE (1976) Augmentation: A process that acts to increase transmitter release at the frog neuromuscular junction. J Physiol 257:449-470.

Malinow R, Tsien RW (1990) Presynaptic enhancement shown by whole-cell recordings of long-term potentiation in hippocampal slices. Nature 346:177-180.

Malinow R, Mainen ZF (1996) Long-term potentiation in the CA1 hippocampus. Science 271:1604-1606.

McNaughton BL (1982) Long-term synaptic enhancement and short-term potentiation in rat fascia dentata act through different mechanisms. J Physiol 324:249-262.

Meyer (1999) Untersuchungen zur Wahrscheinlichkeit der atransmitterfreisetzung an einer zentralen Synapse. Diploma thesis, Max-Plank-Institute for Biophysical Chemistry, Göttingen, Germany:88-89

Meyer AC, Neher E, Schneggenburger R (2001) Estimation of quantal size and number of functional active zones at the calyx of held synapse by nonstationary EPSC variance analysis. J Neurosci 21:7889-7900.

Nagy G, Matti U, Nehring RB, Binz T, Rettig J, Neher E, Sorensen JB (2002) Protein kinase C-dependent phosphorylation of synaptosome-associated protein of $25 \mathrm{kDa}$ at Ser187 potentiates vesicle recruitment. J Neurosci 22:9278-9286.

Neher E, Sakaba T (2001) Combining deconvolution and noise analysis for the estimation of transmitter release rates at the calyx of held. J Neurosci 21:444-461.

Newton AC (2001) Protein kinase C: structural and spatial regulation by phosphorylation, cofactors, and macromolecular interactions. Chem Rev 101:2353-2364.

Orita S, Naito A, Sakaguchi G, Maeda M, Igarashi H, Sasaki T, Takai Y (1997) Physical and functional interactions of Doc2 and Munc13 in Ca2+-dependent exocytotic machinery. J Biol Chem 272:16081-16084.

Otsu Y, Shahrezaei V, Li B, Raymond LA, Delaney KR, Murphy TH (2004) Competition between phasic and asynchronous release for recovered synaptic vesicles at developing hippocampal autaptic synapses. J Neurosci 24:420-433.

Paxinos G WC (1986) The rat brain atlas. Academic Press Inc USA, $2^{\text {nd }}$ edit.

Pilkington B, Cuttle MF, Chad J, O'Connor V (2001) Localization of presynaptic metabotropic glutamate receptors at the calyx of Held. Abstract. In: 673rd Meeting of Biochemical Society. University of Bristol.

Pusch M, Neher E (1988) Rates of diffusional exchange between small cells and a measuring patch pipette. Pflugers Arch 411:204-211.

Rae J, Cooper K, Gates P, Watsky M (1991) Low access resistance perforated patch recordings using amphotericin B. J Neurosci Methods 37:15-26.

Regehr WG, Delaney KR, Tank DW (1994) The role of presynaptic calcium in short-term enhancement at the hippocampal mossy fiber synapse. J Neurosci 14:523-537.

Reim K, Mansour M, Varoqueaux F, McMahon HT, Sudhof TC, Brose N, Rosenmund C (2001) Complexins regulate a late step in $\mathrm{Ca} 2+$-dependent neurotransmitter release. Cell 104:71-81.

Rhee JS, Betz A, Pyott S, Reim K, Varoqueaux F, Augustin I, Hesse D, Sudhof TC, Takahashi M, Rosenmund C, Brose N (2002) Beta phorbol ester- and 
diacylglycerol-induced augmentation of transmitter release is mediated by Munc13s and not by PKCs. Cell 108:121-133.

Rhee SG (2001) Regulation of phosphoinositide-specific phospholipase C. Annu Rev Biochem 70:281-312.

Rosenmund C, Sigler A, Augustin I, Reim K, Brose N, Rhee JS (2002) Differential control of vesicle priming and short-term plasticity by Munc13 isoforms. Neuron $33: 411-424$.

Russell FA, Moore DR (1995) Afferent reorganisation within the superior olivary complex of the gerbil: development and induction by neonatal, unilateral cochlear removal. J Comp Neurol 352:607-625.

Saitoh N, Hori T, Takahashi T (2001) Activation of the epsilon isoform of protein kinase $\mathrm{C}$ in the mammalian nerve terminal. Proc Natl Acad Sci U S A 98:14017-14021.

Sakaba T, Neher E (2001) Quantitative relationship between transmitter release and calcium current at the calyx of held synapse. J Neurosci 21:462-476.

Satzler K, Sohl LF, Bollmann JH, Borst JG, Frotscher M, Sakmann B, Lubke JH (2002) Three-dimensional reconstruction of a calyx of Held and its postsynaptic principal neuron in the medial nucleus of the trapezoid body. J Neurosci 22:10567-10579.

Scheuss V, Schneggenburger R, Neher E (2002) Separation of presynaptic and postsynaptic contributions to depression by covariance analysis of successive EPSCs at the calyx of held synapse. J Neurosci 22:728-739.

Schneggenburger $\mathrm{R}$ (2004) Ca2+ uncaging in nerve terminals. In: Imaging in Neuroscience and Development: A Laboratory Manual (Yuste R, Konnerth A, eds), p 700: Cold Spring Harbor Laboratory Press.

Schneggenburger R, Neher E (2000) Intracellular calcium dependence of transmitter release rates at a fast central synapse. Nature 406:889-893.

Schneggenburger R, Meyer AC, Neher E (1999) Released fraction and total size of a pool of immediately available transmitter quanta at a calyx synapse. Neuron 23:399409.

Schneggenburger R, Sakaba T, Neher E (2002) Vesicle pools and short-term synaptic depression: lessons from a large synapse. Trends Neurosci 25:206-212.

Shimazaki Y, Nishiki T, Omori A, Sekiguchi M, Kamata Y, Kozaki S, Takahashi M (1996) Phosphorylation of $25-\mathrm{kDa}$ synaptosome-associated protein. Possible involvement in protein kinase $\mathrm{C}$-mediated regulation of neurotransmitter release. $\mathrm{J}$ Biol Chem 271:14548-14553.

Smith PH, Joris PX, Carney LH, Yin TC (1991) Projections of physiologically characterized globular bushy cell axons from the cochlear nucleus of the cat. $\mathrm{J}$ Comp Neurol 304:387-407.

Spirou GA, Brownell WE, Zidanic M (1990) Recordings from cat trapezoid body and HRP labeling of globular bushy cell axons. J Neurophysiol 63:1169-1190.

Stevens CF, Sullivan JM (1998) Regulation of the readily releasable vesicle pool by protein kinase C. Neuron 21:885-893.

Stevens CF, Wesseling JF (1999) Augmentation is a potentiation of the exocytotic process. Neuron 22:139-146. 
Stevens CF, Tonegawa S, Wang Y (1994) The role of calcium-calmodulin kinase II in three forms of synaptic plasticity. Curr Biol 4:687-693.

Sun JY, Wu LG (2001) Fast kinetics of exocytosis revealed by simultaneous measurements of presynaptic capacitance and postsynaptic currents at a central synapse. Neuron 30:171-182.

Takahashi T (2005) Postsynaptic receptor mechanisms underlying developmental speeding of synaptic transmission. Neurosci Res 53:229-240.

Takahashi T, Forsythe ID, Tsujimoto T, Barnes-Davies M, Onodera K (1996) Presynaptic calcium current modulation by a metabotropic glutamate receptor. Science 274:594-597.

Taschenberger H, von Gersdorff H (2000) Fine-tuning an auditory synapse for speed and fidelity: developmental changes in presynaptic waveform, EPSC kinetics, and synaptic plasticity. J Neurosci 20:9162-9173.

Trussell LO (1999) Synaptic mechanisms for coding timing in auditory neurons. Annu Rev Physiol 61:477-496.

Tsien RW, Malinow R (1990) Long-term potentiation: presynaptic enhancement following postsynaptic activation of $\mathrm{Ca}(++)$-dependent protein kinases. Cold Spring Harb Symp Quant Biol 55:147-159.

Vaughan PF, Walker JH, Peers C (1998) The regulation of neurotransmitter secretion by protein kinase C. Mol Neurobiol 18:125-155.

Verhage M, Maia AS, Plomp JJ, Brussaard AB, Heeroma JH, Vermeer H, Toonen RF, Hammer RE, van den Berg TK, Missler M, Geuze HJ, Sudhof TC (2000) Synaptic assembly of the brain in the absence of neurotransmitter secretion. Science 287:864-869.

von Gersdorff H, Borst JG (2002) Short-term plasticity at the calyx of held. Nat Rev Neurosci 3:53-64.

von Gersdorff H, Schneggenburger R, Weis S, Neher E (1997) Presynaptic depression at a calyx synapse: the small contribution of metabotropic glutamate receptors. $\mathrm{J}$ Neurosci 17:8137-8146.

Voronin LL, Cherubini E (2003) "Presynaptic silence" may be golden. Neuropharmacology 45:439-449.

Warchol ME, Dallos P (1990) Neural coding in the chick cochlear nucleus. J Comp Physiol [A] 166:721-734.

Weis S, Schneggenburger R, Neher E (1999) Properties of a model of $\mathrm{Ca}(++)$-dependent vesicle pool dynamics and short term synaptic depression. Biophys J 77:24182429.

Wu G, Malinow R, Cline HT (1996) Maturation of a central glutamatergic synapse. Science 274:972-976.

Wu LG, Borst JG (1999) The reduced release probability of releasable vesicles during recovery from short-term synaptic depression. Neuron 23:821-832.

Wu XS, Wu LG (2001) Protein kinase c increases the apparent affinity of the release machinery to $\mathrm{Ca} 2+$ by enhancing the release machinery downstream of the $\mathrm{Ca} 2+$ sensor. J Neurosci 21:7928-7936. 
$\mathrm{Xu} \mathrm{J,} \mathrm{Wu} \mathrm{LG} \mathrm{(2005)} \mathrm{The} \mathrm{decrease} \mathrm{in} \mathrm{the} \mathrm{presynaptic} \mathrm{calcium} \mathrm{current} \mathrm{is} \mathrm{a} \mathrm{major} \mathrm{cause} \mathrm{of}$ short-term depression at a calyx-type synapse. Neuron 46:633-645.

Yawo H (1999) Protein kinase C potentiates transmitter release from the chick ciliary presynaptic terminal by increasing the exocytotic fusion probability. J Physiol 515 ( Pt 1):169-180.

Zhang LI, Poo MM (2001) Electrical activity and development of neural circuits. Nat Neurosci 4 Suppl:1207-1214.

Zhong N, Beaumont V, Zucker RS (2001) Roles for mitochondrial and reverse mode $\mathrm{Na}+\mathrm{Ca} 2+$ exchange and the plasmalemma $\mathrm{Ca} 2+$ ATPase in post-tetanic potentiation at crayfish neuromuscular junctions. J Neurosci 21:9598-9607.

Zucker (1999) Calcium- and activity-dependent synaptic plasticity. Current Opinion in Neurobiology 9:305-313.

Zucker RS, Regehr WG (2002) Short-term synaptic plasticity. Annu Rev Physiol 64:355405. 


\section{Curriculum Vitae}

$\underline{\text { Personal data: }}$

Full name: Natalya Sergiivna Korogod

Born: 08.08.1979 in Dniepropetrovsk, Ukraine

Parents: Natalya Petrivna and Sergiy Mikhailovich Korogod

Citizenship: Ukraine

Martial status: married, no children. Husband, Kochubey Olexiy Olexandrovich

September 1986 - July 1993

September 1993 - July 1996

September 1996 - July 2001

July 2001

October 2001 - August 2002

August 2002

Since October 2002
Elementary and secondary school N174, Dniepropetrovsk, Ukraine

Studying at the Lyceum of Informational Technologies, Dniepropetrovsk, Ukraine Studying at the Physical Faculty, Department of Experimental Physics, Dniepropetrovsk National University, Ukraine. B.Sc. degree in July 2000.

Thesis defence for M.Sc. degree in "Biomedical and technical apparatus and systems"

Master's course in the International $\mathrm{MSc} / \mathrm{PhD}$ Study Program "Neurosciences", Georg-AugustUniversity, Göttingen, Germany

Master's examination in "Neurosciences" Program, admission to the $\mathrm{PhD}$ part of the Program

$\mathrm{PhD}$ project within the "Neurosciences" Program, in the group of Synaptic Dynamics and Modulation (Prof. Dr. Ralf Schneggenburger), Department of Membrane Biophysics (Prof. Dr. Neher), Max-Planck Institute for biophysical Chemistry, Gottingen, Germany.

Thesis advisor - Prof. Ralf Schneggenburger 



\section{Publication list}

Kim MH, Korogod N, Schneggenburger R, Ho WK, Lee SH. Interplay between $\mathrm{Na}^{+} / \mathrm{Ca}^{2+}$ exchangers and mitochondria in $\mathrm{Ca}^{2+}$ clearance at the calyx of Held. J Neurosci. 2005, 25(26):6057-65.

Korogod N, Lou X, Schneggenburger R. Presynaptic $\mathrm{Ca}^{2+}$ requirements and developmental regulation of posttetanic potentiation at the calyx of Held. $J$ Neurosci. 2005, 25(21):5127-37.

\section{Major congress contributions}

Korogod N and Schneggenburger R. "Post-tetanic potentiation and its presynaptic Ca2+ dependence at the calyx of Held". Abstract was published in " 4 th FENS Forum abstracts" book: A048.17, p.122, 2004.

N. Korogod and R. Schneggenburger."Post-tetanic potentiation and its presynaptic Ca2+ dependence at the calyx of Held". 6 th Meeting of the German Neuroscience Society / $30^{\text {th }}$ Göttingen Neurobiology Conference, 2005. 